NOTICE

This report was prepared as an account of work sponsored by the United States Government. Neither the United States nor the United States Energy Research and Development Administration, nor any of their employees, nor any of their contractors, subcontractors, or their employees, makes any warranty, express or implied, or assumes any legal liability or responsibility for the accuracy, completeness or usefulness of any information, apparatus, product or process disclosed, or represents that its use would not infringe privately owned rights.

\title{
A Compendium Of Computer Codes For The Safety Analysis Of LMFBR'S
}

\author{
Safety Analysis Branch \\ Division Of Reactor Research \& \\ Development
}

MASTER 


\section{DISCLAIMER}

This report was prepared as an account of work sponsored by an agency of the United States Government. Neither the United States Government nor any agency Thereof, nor any of their employees, makes any warranty, express or implied, or assumes any legal liability or responsibility for the accuracy, completeness, or usefulness of any information, apparatus, product, or process disclosed, or represents that its use would not infringe privately owned rights. Reference herein to any specific commercial product, process, or service by trade name, trademark, manufacturer, or otherwise does not necessarily constitute or imply its endorsement, recommendation, or favoring by the United States Government or any agency thereof. The views and opinions of authors expressed herein do not necessarily state or reflect those of the United States Government or any agency thereof. 


\section{DISCLAIMER}

Portions of this document may be illegible in electronic image products. Images are produced from the best available original document. 
FOREWORD

A high level of mathematical sophistication is required in the safety analysis of LMFBR's to adequately meet the demands for realism and confidence in all areas of accident consequence evaluation. The numerical solution procedures associated with these analyses are generally so complex and time consuming as to necessitate their programing into computer codes. These computer codes have become extremely powerful tools for safety analysis, combining unique advantages in accuracy, speed and cost.

The number, diversity and complexity of LMFBR safety codes in the U.S. has grown rapidly in recent years. It is estimated that over 100 such codes exist in various stages of development throughout the country. It is inevitable that such a large assortment of codes will require rigorous cataloguing and abstracting to aid individuals in identifying what is available. It is the purpose of this compendium to provide such a service through the compilation of code summaries which describe and clarify the status of domestic LMFBR safety codes.

This compendium is designed to address the following frequently asked questions from individuals in LMFBR licensing, research and development activities :

1. What does the code do?

2. To what safety problems has it been applied?

3. What are the code's limitations?

4. What is being done to remove these limitations?

5. What reference documents are available?

In order that this compendium provide the most complete, accurate and current information, a continuous process of review and updating will be required. It is anticipated that a revised compendium will be made available on an annual basis. In addition to the code summaries contained in this document, future compendium revisions will contain the following:

1. Code validation: Information relating to experimental validation and to validation by comparisons with other code predictions.

2. Code operation characteristics: Information relating to problem running time, machine requirements, programming language, program package contents and other programming or operating information.

In order that this compendium properly reflect the needs of the LMFBR safety community for general computer code information, comments and suggestions on the contents or on ways to improve the existing format are welcomed and encouraged. All correspondence should be addressed to:

Chief, Safety Analysis Branch

Division of Reactor Research \& Development

U.S. Energy Research and Development Administration

Washington, D.C. 20545 
TABLE OF CONTENTS

\begin{tabular}{|c|c|}
\hline Acronyms & 5 \\
\hline Origin of Code Names & 7 \\
\hline Code Summary Outline & 10 \\
\hline Code Summaries: & \\
\hline BEHAVE & 12 \\
\hline CACECO & 19 \\
\hline CLAZAS & 22 \\
\hline COBRA & 27 \\
\hline COMRADEX & 31 \\
\hline DEFORM & 34 \\
\hline DEMO & 39 \\
\hline FRAS & 42 \\
\hline FREADM & 45 \\
\hline GRASS & 47 \\
\hline HAA & 52 \\
\hline HAMOC & 55 \\
\hline HOPE & 57 \\
\hline HORSE & 61 \\
\hline HOTPIM & 63 \\
\hline IANUS & 65 \\
\hline ICECO & 68 \\
\hline ICEPEL & 71 \\
\hline ISOSHLD & 73 \\
\hline LIFE & 76 \\
\hline MARGE/SLUMP & 84 \\
\hline
\end{tabular}




\begin{tabular}{|c|c|}
\hline MELT & 86 \\
\hline MOTION & 90 \\
\hline NAHAMMER & 92 \\
\hline NALAP & 95 \\
\hline NATRAN & 97 \\
\hline NATRANS IENT & 100 \\
\hline ORRIBLE & 104 \\
\hline PAD & 106 \\
\hline PECS & 109 \\
\hline PIFITE & 113 \\
\hline PLUTO & 115 \\
\hline POPS & 118 \\
\hline PORPLUG & 120 \\
\hline REXCAT & 122 \\
\hline REXCO & 124 \\
\hline REZONE & 131 \\
\hline RIBD & 133 \\
\hline SADCAT & 135 \\
\hline SAS & 137 \\
\hline SIEX & 145 \\
\hline SIMMER & 148 \\
\hline S IMPLE & 150 \\
\hline SLUMPY & 152 \\
\hline SODIPROP & 158 \\
\hline SOFIRE & 160 \\
\hline SOMIX & 164 \\
\hline
\end{tabular}


Page

SPRAY

166

STRAW

168

THT

171

TOFF

175

TRANSWRAP

178

TRAPP

181

TUBE

183

VENUS

185 


\section{Acronyms}

\begin{tabular}{|c|c|}
\hline AI & A tomics Internationa 1 \\
\hline ANC & Aerojet Nuclear Gorporation \\
\hline ANL & Arrgonne National Laboratory \\
\hline ANL/AP & ANL/Applied Physics Division \\
\hline $\mathrm{ANL} / \mathrm{CT}$ & ANL/Components Technology Division \\
\hline $\mathrm{ANL} / \mathrm{MS}$ & ANL/Material Sciences Division \\
\hline ANL / RAS & ANL/Reactor Analysis and Safety Division \\
\hline BNL & Brookhaven National Laboratory \\
\hline BNWL & Battelle NorthWest Laboratory \\
\hline CRBR & Clinch River Breeder Reactor Plant \\
\hline DHX & Dump Heat Exchanger \\
\hline EBR-II & Experimental Breeder Reactor - II \\
\hline ENDF & Evaluated Nuclear Data File \\
\hline FCI & Fue1-Coolant thermal Interaction \\
\hline FFM & Failed Fuel Mockup Facility \\
\hline FFTF & Fast Flux Test Facility \\
\hline FSAR & $\underline{F}$ inal Safety Analysis Report \\
\hline FTR & Fast $\underline{\text { Test }}$ Reactor in FFTF \\
\hline EOS & Equation $\underline{\text { ff }}$ State \\
\hline GE-BRD & General Electric - Breeder Reactor Division \\
\hline $\mathrm{HCDA}$ & Hypothetical Core Disruptive Accident \\
\hline HEDL & Hanford Engineering Development Laboratory \\
\hline HNL & Holifield National Laboratory \\
\hline IHX & Intermediate Heat Exchanger \\
\hline LASL & Los Alamos Scientific Laboratory \\
\hline
\end{tabular}




\begin{tabular}{|c|c|}
\hline LBL & Lawrence Berkeley Laboratory \\
\hline LMFBR & Liquid Metal Fast Breeder Reactor \\
\hline LOF & Loss $\underline{\text { of }}$ Flow accident with simultaneous failure to scram \\
\hline PAHR & Post Accident Heat Removal \\
\hline PNL & Pacific Northwest Laboratory \\
\hline PPS & $\underline{\text { Plant }}$ Protection System \\
\hline PSAR & 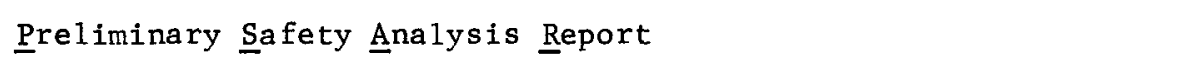 \\
\hline RAS & Reactor Analysis and Safety Division of ANL \\
\hline SAR & Safety Analysis Report \\
\hline SNR & Sodium-cooled Nuclear Reactor \\
\hline TOP & 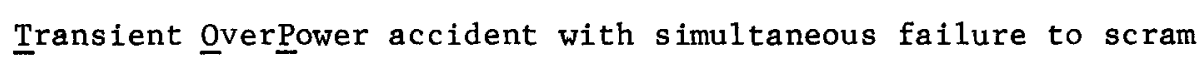 \\
\hline TREAT & Transient REActor Test Facility \\
\hline UCLA & University of California at Los Angeles \\
\hline W-ARD & Westinghouse - Advanced Reactor Division \\
\hline $1-D$ & One-Dimensiona 1 \\
\hline $2-D$ & Two-Dimensiona1 \\
\hline $3-D$ & Three-Dimensiona 1 \\
\hline
\end{tabular}


ORIGIN OF CODE NAMES

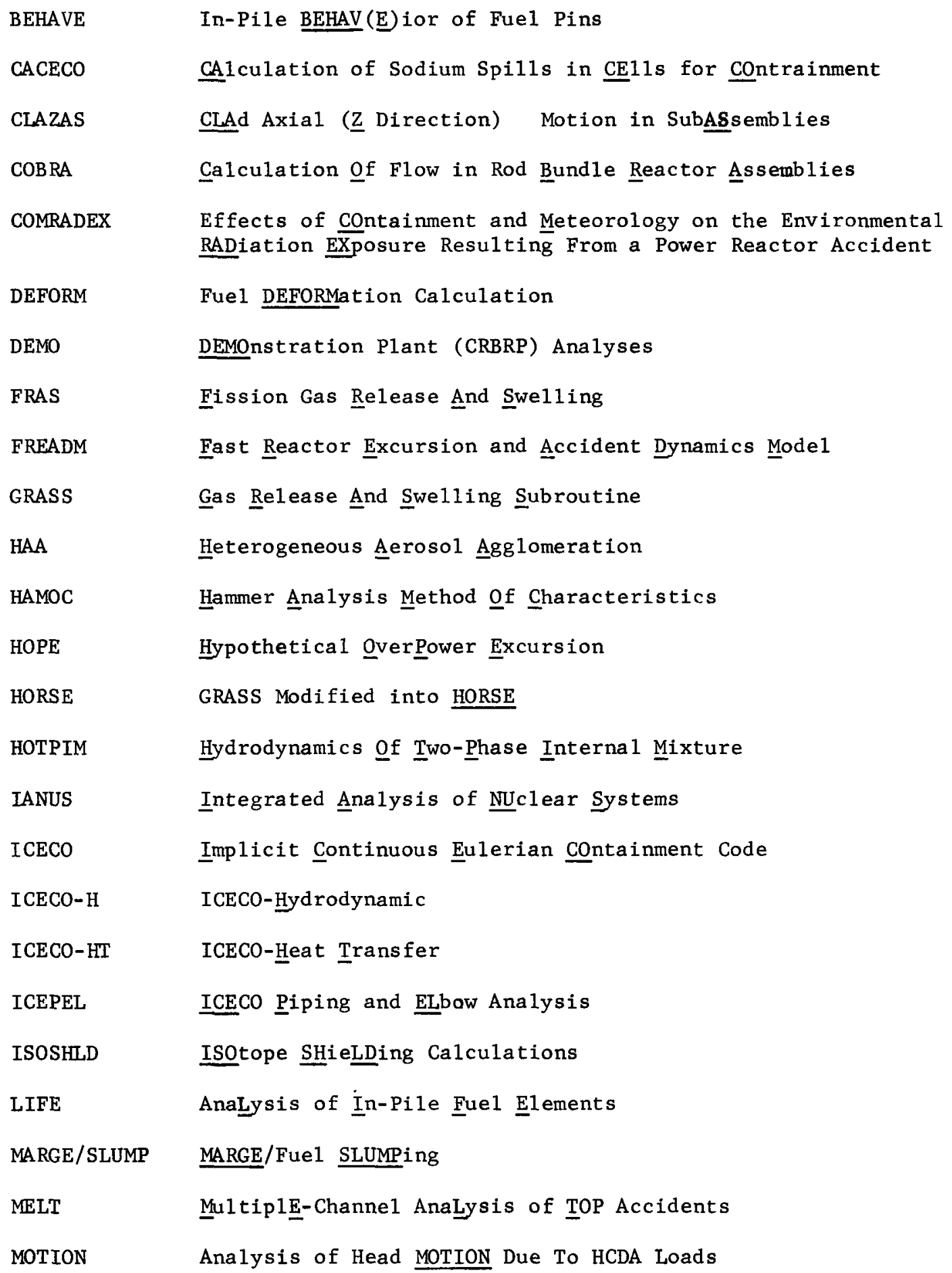




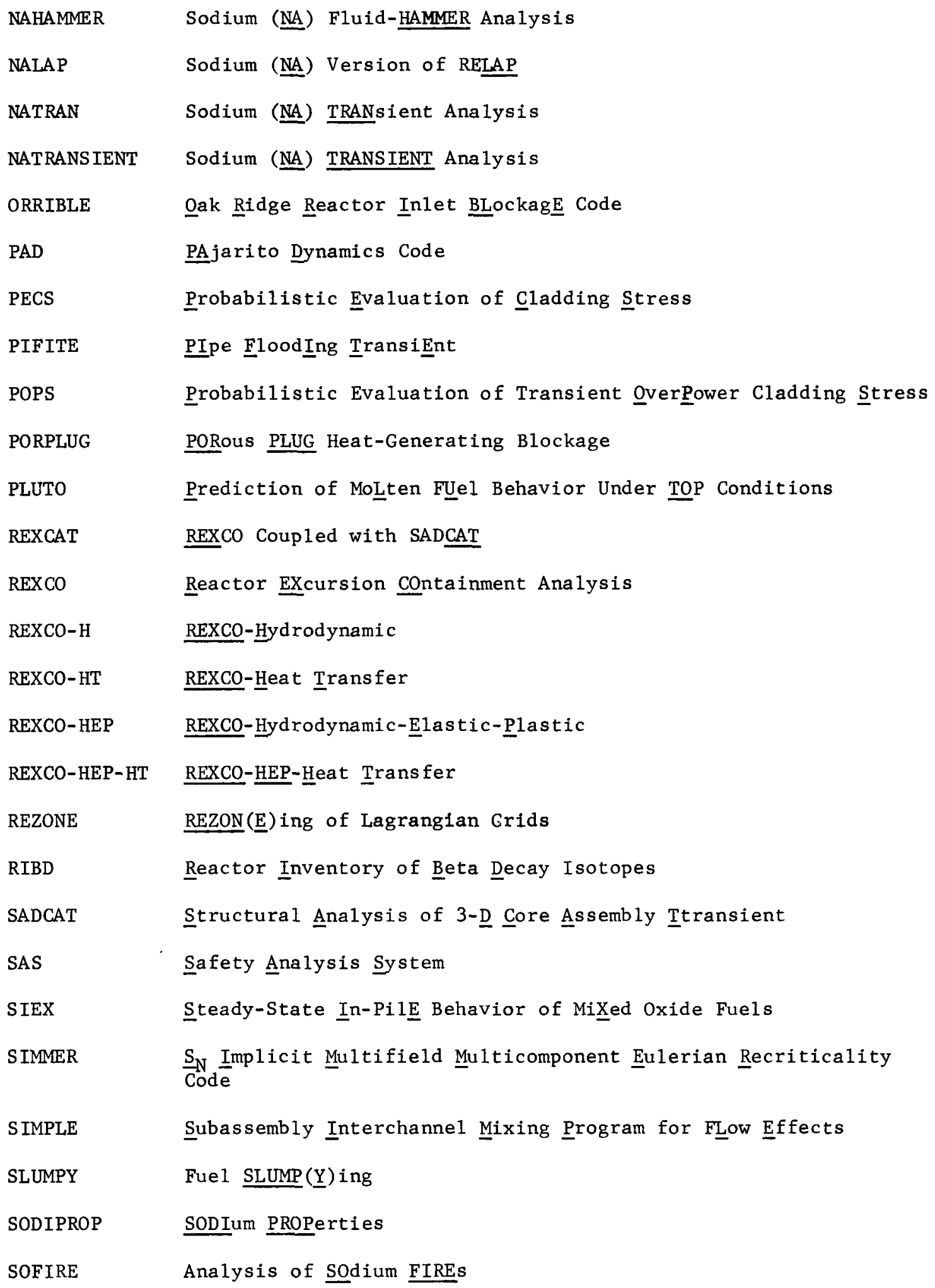


SOMIX SOdium MIXing with Oxygen

SPRAY Sodium SPRAY Fires

STRAW STRuctural Analysis of Subassembly Wrappers

THT Transient Heat Transfer

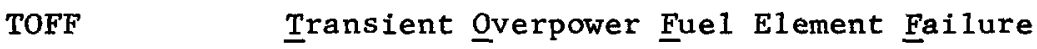

TRANSWRAP TRANsient Sodium Water Reaction Analysis Program

RAP $\quad$ Transient Response to Applied Pressure Pulses

TUBE Pressure Pulses in TUBEs

VENUS VENUS Superseded the MARS Code for Disassembly Analysis

9 
CODE SUMMARY OUTLINE

\section{Purpose}

A brief statement concerning the nature of the physical problem solved and/or the code objective.

\section{Status}

A. Development: Name of development organization and name of current developmental version.

B. Availability: Names of various versions of the code and their documentation or availability status, computers upon which the code has been made operational and the locations or organizations which have run the code. The availability status of a code is classified as one or more of the following:

Developmental: Code is still in its early development or in the process of debugging and has not been made to run successfully on a computer outside of development facility, but may be partially operational at the development site.

Operational: Code is being run successfully on a computer at or outside of the development facility. This implies the code is debugged and ready for use by people other than developer. An operational code is generally accompanied by a user's manual and some documentation.

Released: A released code implies a fully documented code available through the ANL Code Center.

Proprietary: Code is not available for use outside of development facility, except through contractual arrangements with the developer.

C. Utilization: Current use of code and specific safety problems for which it has been or is being applied.

Problems Solved

A listing of the various phenomena or physical problems solved. To identify the scope of problems for which the code is applicable.

\section{Model Description}

A verbal description of the mathematical models, basic physics approximations and numerical solution methodology contained in the code. 


\section{Limitations}

A listing of the restrictions on the range of applicability of the code or on the complexity of the phenomena or physical problems solved and of the restrictions implied by computer storage allocation (e.g., maximum number of mesh points) or inherent code approximations.

\section{Future Effort}

Efforts in progress or planned to reduce limitations.

\section{Interface/Overlap}

Other codes with which the described code interfaces to provide or receive datal similar or equivalent codes.

\section{$\underline{\text { References }}$}

A listing of references for documentation of or information relating to various versions of the code. 
BEHAVE

Purpose

Analysis of therma1-mechanical performance of fuel pins under steadystate and TOP conditions up to the point of clad failure.

\section{Status}

A. Development: Developed and under improvement at GE-BRD. Current development version is BEHAVE-3.

B. Availability: A1l versions of BEHAVE were designed by GE-BRD for the GE- 635 computer.

BEHAVE-1: Released in 1972; runs on the Honeywe11-6000 computer

BEHAVE-2: Released in 1973 (abstract distributed in Dec. 1973; GE-635 version submitted to ACC in Oct. 1972); runs on Honeywe11-6000

BEHAVE-3: Operationa1 at GE-BRD on GE-635; documentation and user's manual is in preparation

C. Utilization: 1. BEHAVE-2, the steady-state portion of BEHAVE-3, has been used by GE-BRD for analysis of EBR-II experimental fuel rods. Based on these non-transient calculations, a fuel swelling rate was chosen to calibrate the code for normal operating conditions.

2. BEHAVE-3 is currently being used by GE-BRD for analysis of seven TOP experiments which were conducted in TREAT; the results will provide base technology support for the FFTF FSAR.

Problems Solved

BEHAVE-2 calculates:

1. Position of clad, fuel and central void in a steady-state operating oxide fuel pin with unfailed clad, assuming axial symmetry throughout the calculation.

2. 2-D, steady-state stress, strain and temperature fields, with the inclusion of fuel cracking, dilation of fuel and clad due to irradiation effects and thermal expansion, fuel densification by both stress- and diffusion-controlled processes, axial slippage or locking at the fuel-clad interface and axial flow of fuel. 
BEHAVE-3: A transient version of BEHAVE-2.

\section{Models}

1. Geometry

Single fuel rod modeled in two dimensions (circumferential variations neglected). Rod may be divided into five axial sections. Clad is represented by a maximum of 10 radial rings. Fuel is divided into structural (outer), transport (inner), and non-transport (middle) radial zones; each zone may contain a maximum of 10 rings radially. Dished fuel pellets are described by user specification of a radially distributed gas volume at the top and bottom of each axial fuel section. The gas plenum is represented simply as a volume available for fission gas, and fuel rod hardware in the plenum region is modeled by imposing a boundary condition limiting the amount axial fuel expansion. Cladding thickness changes caused by corrosion are neglected. The fuel-clad gap is optional input for thermal calculations under the assumption that cracked fuel will be pushed against the clad and reach coherent contact to an unknown extent. As a second option, the fuel-clad gap size is determined by an empirical correlation derived from EBR-II experimental data. Radial and transverse fuel cracks are represented by boundary conditions on stress and strain. The crack distribution is developed within the code based on the stress distribution in the fuel.

2. Stress and Strain Model

Elastic-viscous-plastic analysis of cladding is performed. Model includes viscous plastic and hot-pressing analyses of fuel. Stress and strain solutions are obtained in two dimensions (radial and axial) by finiteelement analysis. Compressible molten fuel is simulated by a constant pressure boundary condition applied at the central void surface of the fuel. Incompressible molten fuel is assumed when the central void is entirely filled with fuel and the porosity of this fuel is $1 \%$. Under the latter conditions, displacement of fuel in the central region is transmitted to surrounding fuel and cladding. Axial shear forces are transmitted between fuel and cladding according to the relative fuelclad velocity. A rigid restraint can be imposed on axial fuel motion after a user specified amount of fuel movement; rigid axial restraint also occurs when high fuel-clad contact forces are present.

Cladding analysis includes thermal and irradiation-induced creep as well as plastic behavior. Local stress effects are neglected, and cladding failure predictions are not included within the program.

3. Fission Gas Release

Al1 of the fission gas contained in the columnar and equiaxed fuel grain regions is assumed to be released from the fuel in the nontransient analysis. 
The equiaxed grain region is defined as that region which is hotter than an empirically determined temperature. Thus, all fuel hotter than the temperature given by the correlation experiences $100 \%$ gas release in a short period of time.

Unrestructured fuel retains a portion of its fission gas, and the fraction retained is represented by an empirical equation which is a function of burnup and linear power.

An option is available in BEHAVE-3 (the "gas bottle" option) which allows one to assume that the gas released in the inviscid region is isolated from the gas plenum pressure. This creates high gas pressure in the inviscid region, which can cause a high displacement rate or a high pressure boundary condition to be applied to the structural fuel region.

\section{Fuel Swelling}

The fuel matrix material, which is the portion of fuel volume exclusive of crack volume and the volume of large pores, swells at an inexorable rate with burnup. The value of this swelling rate is a constant which was used for code validation. However, the fuel as a whole contains compressible crack and porosity volume, so net contraction of fuel in some time intervals is calculated. Fuel swelling due to expansion of trapped fission gas is not modeled. The swelling of the matrix material is assumed to be the same everywhere in the fuel.

5. Fuel Structure and Thermal Model

Fuel structure is determined by a combination of swelling, sintering, cracking, elastic and plastic creep, hot pressing, and melting.

The thermal and mechanical models are coupled through the fuel structure. Fuel is divided into structural, transport, and inviscid radial zones by definition of time-dependent structural transition temperatures. Porosity in the transport and inviscid zones is calculated by the code; porosity is reduced by diffusion processes in the transport region and by hot pressing in the inviscid, non-transport region. Further thermalmechanical coupling is introduced by the calculated crack distribution in the structural fuel zone. Cracks are assumed not to transfer heat in the thermal portion of the mode1. Cracking of fuel and consequent release of fission gas also affects the thermal model through the fuelclad gap conductance, which is dependent on the composition of gas in the fuel-clad gap.

The thermal model employs a phenomenological fuel-clad gap conductance model and an empirical relationship for fuel thermal conductivity. Thermal conductivity is a function of temperature and fuel density (i.e., porosity). BEHAVE does not calculate fuel-clad gap size; the gap is assumed to be closed for structural analysis and is modeled by an empirical correlation for thermal analysis. Gap size may also be specified by the user for thermal analysis. Plutonium and oxygen 
redistribution within the fuel is neglected. Axial fuel motion is neglected in the thermal analysis. The temperature solution is obtained using the axial and radial fuel distributions that exist at the beginning of each time step.

6. Fuel Motion (Non-Transient Operation)

After molten fuel volume is sufficient to fill the central void of an axial section and removal of porosity by hot-pressing has occurred, excess fuel is moved to the nearest axial section with available space. BEHAVE- 3 assumes that the top of the fuel column remains solid so that fuel cannot move beyond this point. A fuel-motion option may be specified, however, allowing fuel to flow into the axial blanket and gas plenum regions. This motion is restrained by plenum gas pressure, but not by fuel-clad friction or the weight of blanket pellets.

7. Fuel Thermal Expansion

Fuel thermal expansion is described by an empirical correlation which is a function of fuel stoichiometry and fuel plutonium fraction. Oxygen buildup with burnup is included in the code, but radial oxygen and plutonium redistribution is not.

\section{BEHAVE-3 :}

The models used by BEHAVE- 3 for transient calculations are those as described in BEHAVE-2, with the following exceptions:

1. Stress and Strain Mode1

Diffusion of porosity in the fuel does not occur during transients and hot pressing is essentially eliminated since these processes require more time than is available during a transient. In terms of fuel structure, elimination of the transport and low-temperature (i.e., below melting) inviscid non-transport regions is implied by elimination of these processes. Thus, all of the non-molten fuel acts as rigid pie-shaped elements during a transient. Molten fuel is free to move axially provided the top of the fuel column is not solid and the pressure causing motion is greater than the plenum pressure.

2. Fission Gas Release

Complete gas release is assumed as fuel reaches the solidus temperature.

3. Thermal Mode1

Transient thermal conditions are obtained, in typical applications from detailed three-dimensional temperature calculations performed by the THT codes. These results are supplied to BEHAVE on tape, and include detailed fuel temperature and molten fuel distributions. The internal BEHAVE thermal model is also available as a user option. None of the options involve internal iteration between fuel location and thermal conditions (normal usage involves THT updates by the user). 


\section{Limitations}

1. No treatment of multiple-rod (incoherence) effects.

2. Neither BEHAVE nor THT thermal models iterate to find a thermal solution which is consistent with the fuel structure caused by fuel motion.

3. Fue1 region boundary temperatures are a function of the time-step size used in structural and thermal finite-element calculations.

4. Most models only partially validated by experimental data.

5. No fuel swelling caused by growth of entrapped fission gas during transient or steady-state conditions.

6. Finite-element mesh limited to maximum of 5 axial nodes, 10 radial cladding nodes, 30 radial fuel nodes (20 for transient analysis), and neglects circumferential effects.

7. No radial or axial oxygen redistribution model (important in thermal expansion).

8. No radial or axial plutonium redistribution model (important in thermal expansion and temperature profiles).

9. Preferential fuel flow through cracks is neglected.

10. Matrix fuel swelling is assumed to be independent of position.

11. No model of events after clad failure.

12. No cladding wastage analysis.

13. Equation of motion for axial fuel movement neglects gravitational and frictional effects.

14. No cladding failure prediction (although strains can be compared with strain limits by the user).

15. Effects of adsorbed gas in fuel neglected.

\section{Future Effort}

Future development activities on BEHAVE- 3 will be selected from the following list, depending upon available funding. Present work involves refinement and validation of existing models rather than major new development.

1. Coupling BEHAVE-3 to whole-core, multiple-rod analysis package for analysis of incoherence effects.

2. Development of fast-running model based on BEHAVE-3 results for coupling to whole-core, multiple-rod analysis package. 
3. Experimental validation of models.

4. Extension to more than 5 axial nodes.

5. Develop iterative thermal model in BEHAVE that will assure consistency between fuel structure and thermal analysis.

6. Establish coupling between existing transient undercooling codes and BEHAVE and evaluate adequacy of BEHAVE for transient undercooling structural analysis.

7. Develop better models for fission gas distribution and release from fuel.

8. Review BEHAVE for compliance with coding standards. Refine code to improve running time. Make code operational on systems other than Honeywe11-6000.

9. Remove dependence of fuel boundary temperatures on time step size.

10. Add plutonium and oxygen redistribution in fuel.

11. Add cladding wastage models.

12. Add general equations of motion for molten fuel and provide for adjustable forcing function. Add inertial and frictional restraining forces.

13. Add cladding failure criteria (e.g., life fraction damage, strain damage fraction, etc.).

14. Compare BEHAVE steady-state predictions with LIFE and SIEX predictions and resolve differences.

15. Model adsorbed gas in fuel in computing fission gas pressure.

16. Model fuel swelling during transient conditions caused by expansion of trapped fission gas.

Interface/Overlap

Interface:

THT thermal-hydraulic programs. Interface with MELT and SAS codes has not been implemented.

Overlap:

SIEX, PECT, DEFORM, LIFE, TOFF; SIEX, PECT, LIFE and TOFF models can be considered as special cases of BEHAVE- 3 model

\section{References}

1. GEAP-13741 "Performance Predictions and Description of the Oxide Fuel Element Modeling Code BEHAVE-1," F. E. Gelhaus and J. D. Stephen (July 1972). 
2. GEAP-13788. "BEHAVE-2, Oxide Fuel Performance Code in Two Spatial Dimension and Time," S. Oldberg (February 1972).

3. "Steady-State and Transient Fuel Mechanics: The BEHAVE-3 Code," S. Oldberg, Jr., and R. G. Stuart (to be published). 


\section{Purpose}

Analyses of pressure and temperature histories in connected containment spaces which are involved in a loss-of-sodium accident.

$\underline{\text { Status }}$

A. Development: Developed and under improvement at HEDL. CACECO was developed for LMFBR's from the CONTEMPT (Ref. 1) code for LWR's, which was released in 1968.

B. Availability: Operational at HEDL and GE-BRD on UNIVAC 1108. To be released during 1975 .

C. Utilization: Has been used by HEDL for FFTF FSAR analysis and by GE for CRBR PSAR analysis.

\section{Problems Solved}

Predicts the pressure and temperature as a function of time for $1,2,3$ or 4 interconnected containment spaces (cells), at least one of which is involved in a loss-of-sodium accident. These cells represent the reactor cavity, pipeways, equipment cells, the reactor building, etc. Each cell contains a unique atmosphere and may contain sodium as a spray or as a pool. The atmosphere consists of nitrogen, oxygen, water vapor, hydrogen, sodium vapor and decay heat fission products. The water vapor forms from water released by heating of concrete and the hydrogen results from a sodium-water reaction. The roof, walls, floor and equipment of each cell are represented by one or more heat-conducting structures. The histories of (a) sodium vapor injection into any atmosphere, (b) sodium 1 iquid spray into any atmosphere, (c) nitrogen-oxygen mixture injection into any atmosphere and (d) sodium liquid spill into any cell pool are assumed available from previous calculation and are input. CACECO calculates:

1. The energy addition due to decay heating in any atmosphere or sodium pool

2. Energy reduction due to space coolers in any cell

3. Atmosphere vent and leakage flows between any of the cells or to outside sinks

4. Sodium vapor-oxygen reaction in any atmosphere

5. Sodium liquid spray-oxygen reaction or spray evaporation and heating of any a tmosphere

6. Sodium condensation out of any atmosphere

7. Sodium-oxygen reaction or sodium evaporation at the surface of any pool

8. Boil-off of any sodium pool into the atmosphere of the cell 
CACECO outputs include:

1. Atmosphere temperature and weight in each cell

2. Vent and leakage flow rates and the integrated flow rates between cells and to outside sinks

3. Heat transfer rates and integrated heat transfers at the surfaces of al1 heat-conducting structures

4. Temperature distribution through all heat-conducting structures

Models

1. Geometry

The system is modeled as up to four volumes (cells) which are connected to each other and to outside leak paths. All equations to describe phenomena within the cells are $1-D$.

2. Cel1 Composition

Each cell contains an atmosphere and some heat conducting structures (representing the cell roof, walls, floor, or equipment) and may also contain a sodium pool.

a. Atmosphere

The atmosphere is assumed to be well-mixed and characterized by a uniform temperature and homogeneous composition of nitrogen, oxygen, sodium vapor, water vapor, hydrogen, anddecay heat fission products.

b. Sodium Poo1

The pool, if it exists within a certain cell, is well-mixed and characterized by a uniform temperature which is usually different from the atmosphere temperature.

c. Heat-Conducting Structures

These are described by the 1-D, multi-layer, transient heat conduction equations. Heat inputs and outputs to the structures are by convection and radiation. A heat structure is limited to 20 different materials (layers) of constant thermal conductivity and heat capacity.

3. Heat Transfer

Heat transfer coefficients may depend on time, average film temperature or temperature difference, but are usually taken as natural convection coefficients which may be enhanced by the local condensation of sodium vapor. Radiation heat transfer is based on the assumption of grey surfaces having constant values of area, geometrical view factor, and emissitivity. The atmosphere may range from opaque to transparent for thermal radiation. 
4. Outside Flows

Atmosphere vent and leakage flow rates are based upon pressure differences and will not account for natural convection flows between vertical cells in which the lower cell has a higher temperature than the upper cell. Vent flow rates between cells and to the outside are calculated using the standard nozzle equation for compressible gas flow for both subsonic and sonic flow rates.

5. Chemical Reactions

a. In any atmosphere, sodium vapor reacts with oxygen and water vapor. The reaction with water produces hydrogen. Water originates from the release of adsorbed and bound water in concrete due to heating.

b. For any sodium pool, sodium reacts at the pool surface with oxygen to simulate a pool fire. Also, the sodium reacts with water vapor released from the concrete floor to produce hydrogen.

\section{Limitations}

1. Atmosphere and pool temperatures should be in the range of $50^{\circ} \mathrm{F}$ to $2500^{\circ} \mathrm{F}$ due to limits of accurate thermodynamic properties for sodium at high temperatures.

2. Atmospheres and pools are considered homogeneous and characterized by a single average temperature.

\section{Future Efforts}

Complete documentation with user's manual.

Interface/Overlap

$$
\text { /SOFIRE, SPRAY }
$$

\section{$\underline{\text { References }}$}

1. L. C. Richardson, et al, "CONTEMPT, A Computer Program for Predicting the Containment Pressure-Temperature Response to a Loss-of-Coolant Accident," IDO-17220, Phillips Petroleum Co., June 1967. 


\section{Purpose}

To analyze axial fuel pin clad motion resulting from a postulated LOF HCDA.

\section{Status}

A. Development: Developed and under improvement at ANL/RAS.

B. Availability: Available as a module of SAS 3A; primary documentation is informal (ANL/RAS report).

C. Utilization: Used in analysis of FFTF LOF HCDA consequences for FFTF FSAR support. Current application is for CRBR PSAR support. CLAZAS predictions have been tested against Land R-series experiments in TREAT and with various out-ofpile, simulant material experiments.

\section{Problems Solved}

CLAZAS, when integrated with the SAS $3 \mathrm{~A}$ coolant dynamics and other interfacing modules, provides an assessment of the consequences of axial clad motion within a subassembly resulting from coolant voiding and subsequent clad melting following a LOF HCDA. Phenomena which may be studied with CLAZAS include:

1. Heat sink effects of molten clad.

2. Clad relocation reactivity effects.

3. Influence of clad plug or blockage formation on voiding dynamics, sodium re-entry and fuel motion.

The current CLAZAS model is intended primarily as an evaluation of clad motion effects in the FTR core, which, as a high pressure drop system, results in high (hundreds of feet per second) transient sodium vapor velocities following boiling. These high vapor velocities may result in initial upward acceleration of molten clad, with subsequent freezing and plugging in the above core pin structures. The "plugging" effect results in reduction of sodium and subsequent downward draining of the remaining core molten clad.

\section{Models}

1. Geometry

Initial unperturbed geometry is same as multiple-channel concept of SAS $3 \mathrm{~A}$ (see SAS summary). The basic calculational model is the SAS "channel," which consists of a single fuel pin surrounded by its associated coolant and structure in cylindrical, axisymmetric geometry. 
2. Clad Motion Model

The clad motion model is based on the film motion hypothesis that, due to the high pressure drop in an LMFBR core, sodium voiding results in sufficiently high vapor velocities to satisfy "flooding" criteria (i.e., waves are formed on the clad surface and the interfacial shear force or drag between the sodium vapor and molten steel increases by at least an order of magnitude) which leads to initial upward acceleration of molten clad with resulting freezing and plugging in the cooler, above-core fuel pin structure. Subsequently, sodium vapor flow is cut-off in the subassembly, resulting in downward flow of the remaining core molten clad.

In general, molten clad is assumed to move under the influence of gravity, the channel sodium vapor pressure gradient, streaming sodium vapor friction forces, friction at the clad-fuel interface, and any fuel pressures from the SLUMPY compressible region (see SLUMPY summary). The clad motion is modeled by discrete clad segments which move axially and may combine or pile-up into blockages when more than one clad segment occupies the same space. Clad in a SAS channel is initially represented by three radial nodes and up to 20 axial nodes in the core and blanket.

The main computational problem on CLAZAS is the clad velocities for the various segments. The two basic cases considered are:

a. Norma1 Motion

The force balance equation on an individual clad segment gives an expression for the clad acceleration. The equation includes terms for gravitational acceleration, interfacial shear force or drag resulting from sodium vapor streaming against molten clad, viscous drag from molten clad moving against solid fuel, clad or wire wrap and the sodium vapor pressure gradient.

\section{b. Restricted Motion}

CLAZAS has built in various restrictions to the motion of an individual clad segment, e.g., temporary termination upon approaching a liquid sodium interface. Due to the lack of an explicit continuity equation in CLAZAS, these restrictions must be added until a more unified model is constructed.

In both the normal and restricted motion cases, it is possible to combine moving clad segments. The criteria for this combination is somewhat arbitrary, but the basic structure of CLAZAS and SAS has led to a set of criteria specified in CLAZAS.

\section{Clad Motion Initiation Criteria}

The various options available for initiation of axial clad motion at a given axial node are:

a. The middle radial node (comprising $70 \%$ of the segment) has gone completely through the melting transition. This represents the nominal LOF case of melting from the inside out. 
b. The outer radial node (comprising $5 \%$ of the segment) has gone completely through the melting transition. This represents melting from the outside in.

A non-axial type clad motion may be initiated by initiation of fuel motion (Via SLUMPY) at a given axial node, if clad motion is already occurring somewhat in the channel before any fuel motion criteria is satisfied. In this case, axial clad motion is suppressed and the clad is mixed with the fuel if fuel motion is initiated before the first clad motion time step in a voided channel, while fuel motion is suppressed from any node where a clad blockage temporarily exists.

\section{Clad Motion Termination Criteria}

In general, a clad segment is assumed to stop motion according to the following criteria:

a. Temporarily, if an unvoided region is reached and sodium contact is made.

b. Temporarily, when a clad segment temperature is more than $100^{\circ} \mathrm{C}$ below the freezing point (i.e., the clad may be able to move after technically freezing, but at $100^{\circ} \mathrm{C}$ below this freezing point, motion is very unlikely), which is determined by calculating a variable viscosity for moving clad as a function of a segment internal energy.

c. Permanently, if the end of the SAS blanket is reached.

To simulate the effects of radial incoherence and by-pass flow, user input can be used to stop upward clad motion at any axial position before the upper end of the blanket is reached.

\section{Heat Transfer}

The heat transfer relationships are based on the assumption of good thermal contact between moving $c$ lad and the underlying material. Each clad segment is assigned an initial internal energy based on the clad temperature and heat of fusion, and heat transfer is then based on the fraction of each axial node occupied by a clad segment with two separate heat transfer coefficients corresponding to underlying surfaces consisting of oxide fuel and/or solid clad. Heat transfer from stationary oxide fuel to moving clad is based on standard gap conductance arguments, while heat transfer from stationary clad to moving clad is based on convective liquid metal heat transfer.

6. Reactivity Treatment

Reactivity due to molten clad motion is computed by summing over a clad worth table, as previously determined by perturbation theory, with a special treatment for clad segments in core regions of high worth gradients. 


\section{Limitations}

The major modeling limitations of CLAZAS are:

1. The 1-D (axia1) nature of the model, with a single channel representing the behavior of one or more subassemblies, does not allow calculation of the radial incoherency of clad motion within a single subassembly.

2. Clad is treated as discrete segments instead of as a continium.

3. Reactivity treatment is based on perturbation theory.

4. The coupling (i.e., the interfacial shear force or drag, which is greatly enhanced by flooding) between the sodium vapor and molten clad is overstrong, generally predicting greater upward clad motion than experimentally observed.

5. Crude treatment of differential clad and fuel motion when both clad and fuel move simultaneously.

\section{Future Efforts}

1. Short-term (FY 75) Modifications

A1though the CLAZAS model currently suffers from a general lack of sophistication, there are no satisfactory short-term fixes possible due to the complexity of the next generation of mechanistic clad motion models, which would involve coupling all the sodium voiding incoherence within rigorously defensible multi-phase, multi-component clad and fuel motion models. The only short-term effort in the clad motion modeling area involves an investigation of the results of moving clad as postulated by the SAS user (e.g., with a user-specified acceleration function).

2. Long-term (FY 76 and Beyond) Modifications

CLAZAS will be reformulated as a parametric model, with the following characteristics :

a. Geometry will initially be that of a single pin (as in the current SAS channel) with application to multiple pins geometries possible later.

b. User-specified coupling between molten clad and sodium vapor.

c. Eulerian hydrodynamics, with resolution on a SAS mesh basis.

d. Arbitrary modes for clad freezing.

e. Consistent integration with SLUMPY.

\section{Interface/Overlap}

SAS / 


\section{References:}

W. R. Bohl and T. J. Heames, CIAZAS: The SAS 3A Clad Motion Mode1, ANL/RAS 74-15 (August 1974). 
COBRA

\section{Purpose}

A general program for steady-state and transient thermal-hydraulic subchannel analysis of rod bundle nuclear fuel elements.

\section{$\underline{\text { Status }}$}

A. Development: Development and under improvement at BNWL. COBRA IV is current development version.

B. Availability: COBRA I: Released in 1967

COBRA II: Released in 1970

COBRA III: Released in 1971

COBRA III C: Released in 1973; versions available for UNIVAC 1108, IBM 370 , and CDC 6600. Operational at BNWL (1108 and 6600) and ANC (370)

CObRA III M: Operational at ANL on IBM 360 ; documented in RAS i2-34 (1972)

COBRA IV: In process of documentation

.. Utilization: Utilized extensively in LWR and more recently in LMFBR thermal-hydraulic analysis. ANL has used COBRA for analysis of steady-state and transient single phase sodium flow for wire-wrap pin assemblies.

\section{Problems Solved}

1. Computes the steady-state and transient coolant flow, enthalpy and pressure drop in the subchannel of rod bundles during both boiling and non-boiling conditions with inclusion of the effects of cross-flow mixing. The solution is performed as a boundary value problem using as boundary conditions the inlet enthalpy, inlet flow, inlet crossflow and uniform exit pressure. Handles two-phase water flow and sodium fluid flow at present by using a psudeo-homogeneous slip flow model. More advanced two-phase flow models are required to handle two-phase sodium flow, and are under development at PNL.

2. Design and analysis of transient in-pile experiments, gives detailed fuel and coolant temperatures to predict fuel melting, local boiling, fuel/clad differential expansion.

3. Can be used for a wide variety of rod bundle fuel element configurations. Handles distorted bundles, and arbitrary axial, radial and circumferential heat flux distributions. Modifications have been made under COBRA IV to handle a 217-pin wire-wrap bundle.

4. Has been successful in calculating steady-state sodium boiling in a 7-pin (12 channel) bundle with uniform and non-uniform radial power. 


\section{Models}

\section{General COBRA-III}

Solution Methodology: A lumped parameter treatment of a rod bundle where the flow cross section is divided into subchannels and then the subchannels are divided axially into control volumes. Equations of mass, energy and momentum are written as integral equations for the control volumes. These integral equations are space averaged and reduced to a finite difference form. This integral treatment necessitates providing semi-empirical data at control volume boundaries -- friction factors, mixing coefficients, etc. The entire set of control volume equations is generalized using matrix operators to allow an arbitrary layout of subchannels and thus allow a truly three dimensional representation of the bundle.

COBRA-III C: PNL version of COBRA-III with following capabilities:

1. Fuel heat transfer model - considers radial conduction in fuel and clad.

2. Mixing models - considers effects of turbulent and thermal conduction mixing throughout the bundle by using empirically determined mixing coefficients. Includes convective transport of enthalpy by diversion crossflow mixing, transverse resistance to crossflow, temporal and spatial acceleration of diversion crossflow, and momentum transport from turbulent and diversion crossflow.

3. Each.subchannel is assumed to contain two-phase separated slip-flow during boiling.

4. Two-phase flow structure is assumed to be fine enough to define the void fraction as a function of enthalpy, flow rate, heat flux, pressure, position and time.

5. Transients are limited to times that are greater than time for sonic wave to pass through channel.

6. Numerical solution has no stability limitation on space or time steps for flow in the positive axial direction.

7. Forced flow mixing due to diverter vanes or wire wraps is included.

8. Can analyze bundles with partial flow blockages.

9. Numerical scheme performs boundary value solution with semi-explicit finite difference scheme.

10. Turbulent mixing is analogous to eddy diffusion and is defined through empirical correlations.

11. Considers non-uniform hydraulic behavior. 
COBRA-III M: ANL modified version of COBRA III, used for design and analysis of experiments, with following capabilities:

1. Uses orthogonal collocation, a weighed residuals method, for calculation of fuel rod temperatures. This greatly reduces computer storage requirements while maintaining sufficient computational accuracy. COBRA-IV provides a higher accuracy alternate to the finite difference methods of COBRA-III.

2. Allows for flow reversal and the use of a pressure boundary condition.

\section{Limitations}

There are several areas of analytical work that require considerably more attention and experimental evaluation:

1. General two-phase flow modeling is a major problem area and work is needed both analytically and experimentally. Presently available models such as homogeneous, separated slip flow, and void drift have a limited range of applicability and are inadequate for transient sodium boiling under LMFBR accident conditions. Separated slip flow modeling is valid provided that separated phases have uniform properties on mass flux in regions they occupy in the subchannels. This model breaks down for gross departures from psuedohomogeneous flow, such as annular flow where liquid at the walls has a lower velocity than entrained droplets. More complete models are needed to allow a more general treatment of transients, turbulent mixing, thermal nonequilibrium and possibly countercurrent liquid vapor flow under low mass flux conditions. Some of these phenomena are especially important for boiling liquid metals. COBRA-IV development has removed many computational limitations of COBRA-III, which is now becoming mathematical model limited. Improved models need to be developed and proper experiments need to be performed for verification.

2. The general areas of transient code verification are very weak. There are presently no data for even single phase transient flow distribution in rod bundles. Some thermal transient data exist, but the flow behavior must be inferred from analysis. Steady-state correlations for friction factors, subcooled void fraction, bulk void fraction and two-phase friction multiplier must be used for transient calculations when no others are available. Experiments are needed to verify the subchannel methods for both single and two-phase flow transients.

3. More general implicit numerical schemes need to be developed for use in subchannel analysis so that time step restrictions can be removed. An implicit scheme is used in COBRA-III $\mathrm{C}$, but it is limited to the positive flow direction. For flow reversal transients, explicit methods are used but are limited to time steps less than the transient time through a mode.

\section{Future Efforts}

1. Improve physical two-phase flow modeling. Improve numerical capabilities to handle pressure boundary conditions, flow reversal, coolant expulsion, decreased running time and large bundle analysis. 
2. Studies of flow distribution in wire wrapped bundles with water and LWR bundles containing flow blockages.

3. Continued attention to determination of input parameters (friction factors, eddy mixing coefficients, forced flow diversion factors, etc.) to reduce uncertainty of choice for design calculations.

This will be accomplished through extensive comparison with experimental data.

4. Continue effort for transient multichannel sodium boiling.

5. Investigate application of finite element methods to the subchannel problem. The basic problem to be overcome is the application of the finite element approach to a convection dominated set of flow equations. Present finite element approaches remove convection by assumption and limit the analysis to diffusion dominated equations.

Interface/Overlap

-/THT, SIMPLE, ORRIBLE

References

COBRA-I: $\quad$ D. S. Rowe, Crossflow Mixing Between Parallel Flow Channels During Boiling, Part I. COBRA--Computer Program for Coolant Boiling in Rod Arrays, BNWL-371, Pt. 1. Pacific Northwest Laboratory, Richland, Washington (March 1967).

COBRA-II: D. S. Rowe, COBRA-II: A Digital Computer Program for Thermal Hydraulic Subchannel Analys is of Rod Bundle Nuclear Fuel Elements, BNWL-1229. Pacific Northwest Laboratory, Richland, Washington (February 1970).

COBRA-III: D. S. Rowe, Interim Report. COBRA-III: A Digital Computer Program for Steady-State and Transient Therma1-Hydraulic Analysis of Rod Bundle Nuclear Fuel Elements, BNWL-B-82, Pacific Northwest Laboratory, Richland, Washington (1971).

COBRA-III C: D. S. Rowe, COBRA-III C: A Digital Computer Program for Steady State and Transient Thermal-Hydraulic Analysis of Rod Bundle Nuclear Fuel Elements, BNWL-1695, PNL, Richland, Washington (March 1973).

COBRA-III M: W. W. Marr, COBRA-III M: An IBM 360 Computer Code for Analyzing the Thermal-Hydraulics of Pin Bundles, ANL/RAS 72-34, Argonne National Laboratory, Argonne, III. (December 1972). A1so ANL-8131 
COMRADEX

\section{$\underline{\text { Purpose }}$}

Analysis of the effects of reactor containment and meteorology on the environmental radiation exposure resulting from reactor accidents.

\section{$\underline{\text { Status }}$}

A. Development: Developed and under improvement at AI. COMRADEX II is current development version.

B. Availability: COMRADEX I was documented in 1967 (Ref. 1). COMRADEX II was released in February 1975. It is operational at AI and GE; runs on the IBM 370/168, IBM 360, UNIVAC 1108

C. Utilization: Has been used for FFTF FSAR and CRBR PSAR safety analysis.

\section{Problems Solved}

COMRADEX calculates the attenuation effect of containment barriers and meteorological dispersion on radiation doses due to release of a radioactive inventory from a postulated reactor accident. The code calculates:

1. The "shine" dose resulting from the direct gamma radiation from the containment building.

2. The internal dose resulting from the inhalation of gases and aerosols in the released cloud following meteorological diffusion.

3. The external gamma and beta dose from immersion in the released cloud.

\section{Models}

1. Inventory

The initial radioactive inventory available at the time of the accident must be input. Release fractions (i.e., gases, solids, fission products, etc.) are input or may be calculated for sodium, fuel and/or other element groups.

\section{Containment}

The code evaluates the activity released to the atmosphere from the containment barriers, accounting for leakage from and cleanup (attenuation) processes within up to four barriers of containment. These barriers are modeled as concentric shells (up to four). The leakage and filtration from one shell to an adjacent she11 and from the outside she11 to the atmosphere are input as variable leak rates with time. Cleanup processes within each shel1 may also be input to account for fallout, plateout and forced (filtration) cleaning. Cleanup rates are input as variable cleanup factors in time COMRADEX II will accept leak rate and fallout data as provided from HAA-3 (see HAA summary). 
3. Atmospheric Dispersion

Dispersion in the atmosphere of the radioactive plume released from containment is calculated from the model of Pasquill (Ref. 2-3).

4. Direct Building Dose

The radiation dose resulting from direct gamma dose potential in the containment building based on a spherical source with uniform distribution of radionuclides.

5. Cloud Dose

The external gamma dose resulting from immersion in the cloud is calculated from a uniform spherical cloud, with no credit for air attenuation of gammas. COMRADEX II includes a beta dose mode1.

6. Interna1 Dose

The internal dose resulting from inhalation of activity in the cloud is calculated from using the model in Ref. 4 for up to 10 organs. A lung dose calculation in COMRADEX II can be performed with the standard ICRP method (Ref. 5) or the new lung model (Ref. 6).

\section{Limitations}

1. COMRADEX is not equipped to evaluate depletion of the cloud by fallout, rainout, or washout or to calculate the doses which would result from the deposited activity.

2. The shielding afforded by air between the building and the downwind interest is calculated by assuming attenuation and buildup factors appropriate to $3 \mathrm{MeV}$ photons.

3. Perfect reflection of the cloud at the ground surface is assumed.

4. Aerosols are assumed to behave like gases for leakage through containment barriers.

\section{Future Efforts}

1. Incorporate improved lung model.

2. Modify external dose calculation to include sector averaging.

3. Eliminate limitation $\#_{1}$.

Interface/Overlap

CURIE, HAA, SOFIRE/ -

\section{References}

1. G. W. Spangler, M. Boling, W. A. Rhoades, and C. A. Willis, "Description of the COMRADEX Code," AI-67-TDR No. 108, August 1, 1967. 
2. F. Pasquill, Atmospheric Dispersion, D. Van Nostrand Co., Ltd., 1962.

3. W. F. Hilsmeier and F. A. Gifford, Jr., "Graphs for Estimating Atmospheric Disperson," ORD-545, Ju1y 1962.

4. G. P. Kenfield, et al, "CURIE-DOSE-THUNDERHEAD, A Digital Computer Program for External and Internal Radiation Dose Calculations," NAA-SR-8884 (1965).

5. Internal Commission on Radiological Protection, Report of Committee II on Permissible Dose for Internal Radiation, ICRP Pub. 2, Pergamon Press, N.Y., 1959.

6. Task Group on Lung Dynamics, "Deposition and Retention Models for Internal Dosimetry of the Human Respiratory Tract," Health Physics, Vol. 12, pp. 173-207, February 1966. 
DEFORM

Purpose

A fuel pin mechanics module of SAS for prediction of the deformation and the ultimate failure of a fuel pin under an overpower or loss of flow transient.

$\underline{\text { Status }}$

A. Development: DEFORM I and II were developed at ANL/RAS. DEFORM III is current development version.

B. Availability: Versions of DEFORM are available as modules of SAS, which is operational on the IBM 360. DEFORM I is available as a module in SAS 1A, 2A, 2D and 3A. Code description is available through documentation of SAS 1A (Ref. 1).

DEFORM II is available as the module of special twochannel version of SAS 2A. Model descriptions have been documented (Ref. 2).

C. Utilization: Has been used exclusively as a module of the SAS code to provide fuel pin deformation information. Experiments in TREAT have been analyzed.

\section{$\underline{\text { Problems Solved }}$}

DEFORM calculates transient stresses and deformation in the fuel and clad of a fuel pin during a power-to-flow mismatch. Calculated are the thermoelastic deformation of the fuel and the elastic-plastic deformation of the clad, using fuel pin temperature profiles as provided by the heat transfer module of SAS. DEFORM I analysis is based on a stress-free steady-state operating condition without any consideration to pre-irradiation effects. DEFORM II is designed specifically to predict the transient behavior of preirradiated fuel, and can also be used to investigate fuel-clad behavior of a fresh fuel element undergoing transient irradiation. DEFORM II includes the following irradiation effects not found in DEFORM I:

1. Distinct metallurgica1 (up to three) regions in the fuel.

2. Fission gases in the central fuel cavity and fuel matrix.

3. Elastic-plastic behavior of both fuel and clad, including workhardening effects.

4. Non-zero residual stresses prior to transient initiation. 
Mode1s

DEFORM I

1. Geometry

As in the heat transfer module of SAS, the fuel pin is divided into coupled axial segments. Each axial segment may contain a central cavity with some molten fuel, solid fuel, a gap and clad. All materials are assumed isotropic and zonewise homogeneous. Local effects, as due to finite size of fuel pellets, are neglected. Since the radial temperature variations for a reactor fuel rod are much more severe than the axial, equations with appropriate boundary conditions are solved in closed form for radial variations, but only approximately by iteration with respect to axial variations of stress and deformation. Depending on the conditions of the fuel and clad, anyone of nine cases may pertain to each of the axial segments representing a broad range of potential conditions for solid fuel with a central hole containing molten fuel. These nine cases represent three options for each axial segment: (1) the existence of a radial gap,

(2) the elastic deformation of the clad due to closing of the gap and

(3) the plastic deformation of the clad due to excessive loading.

2. Fuel Deformation

The following assumptions are made:

a. Fuel behaves as a perfectly elastic material.

b. A quasi-static deformation analysis is applicable which implies that there is no explosive loading on the fuel elements to produce shock waves.

c. The time scale of the loading is short enough that long-term effects as radiation growth and viscoelastic creep can be neglected.

d. Fuel is initially assumed to be stress-free at normal operating conditions. This assumption is justified if the stresses produced by the change from room temperatures to operating conditions are annealed out.

e. Thermal expansion coefficient of fuel is average or constant value.

The elastic deformation description of the fuel includes two models:

a. Elastic deformation with no melting: the thermoelastic field equations of equilibrium in cylindrical, axisymmetric coordinates with zero shearing stresses are used with appropriate boundary conditions to determine radial displacements, axial elongations and circumferential stresses. 
b. Elastic deformation with partial fuel melting: the assumptions made to determine structural response of a cell in which partial melting has occurred are (1) the material in the cell behaves mechanically as a liquid with density and bulk modulus between those for solid and liquid states, (2) all cells where melting has occurred in any axial segment are acted on by the same fluid pressure, which can vary axially, (3) fuel does not cross cell boundaries and (4) axial expansion of an axial segment does not vary radially. Assumption (3) and (4) imply that migration of liquid fuel through a central hole is not permitted.

3. Fue1-C1ad Gap

The gap is assumed to be occupied by a bonding material or inert gas which is squeezed out as fuel expands.

4. Clad Deformation

The following assumptions are made:

a. The clad tube can be treated as if it were an elastic-plastic membrane (thin she11) made of an elastic, perfectly plastic material. The circumferential stress is constant across the tube wall thickness and plastic yielding occurs when the clicumferential stress reaches a critical stress. Plastic yielding is limited due to the resultant reduction in pressure from the thermally expanding fuel.

b. Clad material is incompressible, i.e., during plastic deformation wall thickness decreases as clad expands, causing eventual rupture.

c. Clad thins uniformly around the crrcumference during expansion.

The elastic deformation of the clad is treated by the same equations as for the solid fuel.

\section{DEFORM II}

1. Geometry and Configuration

Same axially coupled axisymmetric, cylindrical axial segment structure as DEFORM I. Allowance is made for dividing fuel into three distinct zones to represent irradiation-induced restructuring. Also, there may be fission gases in the central cavity and bubbles in the fuel matrix. Otherwise, has same assumption of material isotrophy, and zonewise homogeneity as in DEFORM I.

2. Fuel and Clad Deformation

The stresses and strains in the solid fuel and clad material are determined from a rheological model of a cylindrical body that involves elastic, viscous, or plastic behavior. The plane-strain approximation with cylindrical axisymmetry is used for treating both the solid fuel 
and clad. Thus, the thin shell approximation for the clad in DEFORM I is replaced with a multinode representation in DEFORM II which enables a much more detailed clad mechanical analysis.

3. Fuel-Clad Interaction

When solid fuel and clad are not in contact, they may be treated independently since coupling via the gap gas is weak. For fuel and clad in contact, the plane-strain approximation used in the code does not allow a rigorous treatment of the shear force (friction) resulting from relative motion between fuel and clad in contact. Two optional approximate solutions to this friction problem are used:

a. Complete slip model: no friction in fuel-clad sliding.

b. Frictional slip model: attempts to approximate shear effect.

4. Fission-Gas Swelling Effects

This effect is taken into account arbitrarily by increasing the thermal expansion coefficient of the fuel from columnar to the equiaxed region and from the equiaxed to the unrestructured region.

\section{Limitations}

DEFORM II has the following improvements over DEFORM $I$ :

1. The geometry may be that of an irradiated fuel pin.

2. Fission product gases in the central cavity as well as bubbles in the fuel matrix may be accommodated.

3. General plastic behavior with an arbitrary yield surface may be prescribed for both fuel and clad (fuel plasticity is ignored in DEFORM I), including work-hardening effects.

4. The thin shell approximation for the clad in DEFORM I is replaced by a multinode representation, enabling more detailed analysis of clad stresses and strains.

5. The pressure of molten fuel is no longer axially dependent.

6. Non-zero residuals stress are allowed before transient initiation.

7. Explicit temperature dependence of thermal expansion coefficient is considered.

DEFORM II limitations are based on the following properties of the code:

1. Mechanical equations are quasi-static (i.e., entire system is in mechanical equilibrium at all time). 
2. Plane-strain approximation is used, with shear stress neglected except for approximate treatment of friction between fuel and clad.

3. All materials are isotropic and zonewise homogeneous.

4. Local effects, as due to finite fuel pellet size, are neglected.

5. No hot-pressing (porosity compression) model.

6. No microscopic model for fission-gas swelling of fuel; swelling is approximated by adjusting the fuel thermal expansion coefficient.

7. No bulk motion of molten fuel in central cavity.

8. No fuel cracking model.

\section{Future Efforts}

The DEFORM III code, which is in the early development stage at ANL/RAS, will eliminate many of the current DEFORM II limitations.

\section{Interface/Overlap}

SAS/PECT, TOFF, BEHAVE

\section{References}

1. DEFORM I :

J. C. Carter, et a1., SAS 1A, A Computer Code for the Analysis of Fast-Reactor Power and Flow Transients, ANL-7607 (October 1970)

\section{DEFORM II:}

A. Watanabe, The DEFORM II: Mathematical Analysis of Elastic, Viscous, and Plastic Deformations of a Reactor Fuel Pin, ANL-8041 (August 1973) 
DEMO

\section{Purpose}

Simulation of transient neutronic-thermal-hydraulic behavior of a commercialtype LMFBR.

\section{$\underline{\text { Status }}$}

A. Development: Developed and under improvement at WARD.

B. Availability: Model description report appeared in 1974; to be released with user's manual in FY 1975.

C. Utilization: Used exclusively by WARD in support of CRBRP PSAR and to produce design thermal transients for CRBRP component equipment specifications.

\section{Problems Solved}

DEMO is currently used to generate preliminary thermal-hydraulic transients for the CRBRP and serves (1) to provide traceability of plant transients, (2) as a means for interested component engineers to verify the simulation of their components, and (3) to form the basis for check by an independent analysis, if desired. A wide range of plant transients, including pipe rupture, can be performed.

\section{Models}

Many of the models and equations used in DEMO are taken directly from IANUS, al though the numerics in DEMO are much less refined. All major heat transfer coefficients are based on experimental correlations.

\section{A. Reactor}

1. Core - active core model similar to IANUS, but does not provide the flexibility in selecting nodes as IANUS does, DEMO having a fixed number of nodes.

2. Internals - includes lower plenum, upper and lower axial blankets, radial blanket, bypass channel and upper plenum. Heat transfer to internal structures is accounted for by homogenizing and using an effective heat capacity. Assumes constant flow fractions of total flow for all flow regimes.

3. Bypass channel - modeled as being unheated, with heat capacity of associated structure and transport time neglected. Exit temperature of coolant leaving bypass is identical to mixed mean temperature of lower plenum. 
4. Plena

Lower plenum - represented by perfect mixing model with single mixing node and effective heat capacity.

Upper plenum - model includes coolant level, which considers thermal expansion of sodium and makeup-overflow from sodium purification system, and the cover gas. Two mixing node options are available: (1) single node mixing with effective heat capacity (perfect mixing), or (2) stratified flow model, which is used when jet height of sodium leaving core is less than 20 feet.

B. Heat transport loops - Three loops are simulated by a two loop model in which one loop represents two of the plant loops and a second represents a single plant loop. Heat capacity of the pipe walls and mixing in pipes is generally neglected, with pipe mass being accounted for during events where it is needed to be conservative.

1. Primary heat transport loops - each includes piping, valves, pump tank with free surface and cover gas, and the shell side of the IHX. Hydraulic effects include vessel upper plenum level, pump tank level, pressure drops in the core, IHX and valves, pump characteristics, gravity heat, fluid inertia, and transport time effects in piping.

2. Intermediate heat transport loops - each has tube side of IHX, piping, shell side of superheater and evaporator, and pump. Hydraulic effects include pressure drops in pipes, IHX, superheater and evaporator.

3. Water/steam system - each has feedwater pump, feedwater control valves, piping, recirculation pumps, tube side of evaporator and superheater, and a steam drum. Steam leaving superheaters enters a common steam header, flows through piping to the turbine throttle valve and then to a steam dump valve.

Steam generator - each has a steam drum, recirculating pump, a number of isolation and check valves, one equivalent superheater, and one equivalent evaporator. Two optional steam generator modules give a choice of detailed water/steam pressure and flow or a simplified calculation.

\section{Limitations}

1. Core is modeled with a single "average" channel with factors for hot and peak dynamic channels.

2. Sodium boiling is not allowed.

3. Homogenized reactor internals and constant flow fractions may inaccurately calculate low flows.

4. Numerics are less refined than in IANUS and thus DEMO requires longer run times for equivalent problems. 
5. Upper plenum mixing model is crude for low flows and requires experimental validation.

6. Bypass channel model does not include heat transfer.

\section{Future Efforts}

1. DEMO is still in developmental stage for CRBRP analysis and will be updated with CRBRP design modifications and requirements as needed.

2. Improve upper plenum mixing model with data from experimental programs in scale models.

Interface/Overlap

- / IANUS

\section{$\underline{\text { References }}$}

"C1inch River Breeder Reactor Plant Nuclear Island," WARD-D-0005, Rev. 2, August 1974. 
FRAS

\section{Purpose}

Analysis of transient fission gas release and swelling in oxide fuel.

\section{$\underline{\text { Status }}$}

A. Development: Developed and under improvement at ANL/RAS.

B. Availability: Operational at ANL on IBM 370. A code description is available $(\operatorname{Ref.1})$.

C. Utilization: Has been used by ANL to test different models of fission gas behavior and to perform parametric studies for accident analysis (Ref. 1).

\section{Problems Solved}

FRAS was developed to serve as a simplified version of GRASS (see GRASS summary) which would allow easy modification for testing new fission gas behavior models and could be used for parametric studies of value to safety analysis. FRAS is oriented toward the rapid temperature transient behavior of fission gas and therefore does not consider phenomena modeled in GRASS, such as resolution, which are unimportant for short-time, high-temperature power transients. Although the code is much more simplified than GRASS, it retains as much accuracy and detail as possible for computation of the evolution of the bubble-size distribution in the fuel.

FRAS computes, as in GRASS, the bubble-size distribution of all types of bubbles (i.e., bubbles pinned to structural defects and those that are unpinned), which is then used to determine the fuel swelling and fission gas release. In FRAS, however, fission gas "release" is restricted to the migration to and pinning at grain boundaries of fission gas bubbles (i.e., intragranular precipitation of bubbles on grain boundaries) during transient heating of irradiated fuel. FRAS is especially useful in predicting the fission gas distribution in the fuel up to fuel melting or disruption in a LOF or TOP accident, since it will determine how much fission gas is available at the grain boundaries and within the fuel matrix for fuel dispersal and pressurization. FRAS applicability is primarily for unrestructured fuel, where the bulk of the fission gas is retained in the fuel during steady state operation.

\section{Models}

The basic model of PRAS is the same as GRASS: fission gas atoms nucleate to form bubbbles that move both by random (Brownian) motion and under the driving force of a temperature or stress gradient. The bubbles may collide and coalesce to form larger bubbles. Bubbles are also attracted to fuel structural defects, as grain boundaries, where they are pinned but may continue to grow by coalescence until they are pulled off by the thermal gradient driving force. 


\section{Geometry}

The fuel is considered to be uniform in properties (i.e., only one fuel node is modeled). The only consideration of structure is in the calculation of fission gas migration to the grain boundaries. The single fuel node represents the unrestructured fuel, where the bulk of the fission gas is retained during steady state operation.

2. Bubble motion and coalescence

Bubbles move by random (Brownian) motion and under the driving force of a temperature or stress gradient. The only migration mechanism considered is that of surface diffusion of maxtrix atoms around the interface between gas and fuel (Ref. 2), which usually dominates in rapid TOP conditions. The contribution of other mechanisms (especially vapor diffusion of evaporated fuel across the bubble) can be added if surface diffusion is no longer the dominant mechanism due to the growth by coalescence of large bubbles.

Bubble coalescence probability is computed, as in GRASS, by the method of Gruber (Ref. 3).

3. Bubble size distribution

The bubble size distribution is computed as in GRASS (see GRASS summary), except the gas is assumed to obey the van der Waals EOS.

\section{Limitations}

In the attempt to make FRAS simple and fast-running, but still accurate for rapid transient situations, many phenomenological models that are incorporated in GRASS, but which are not important to the rapid temperature transient situations, are not available in FRAS. However, for the sake of comparison, FRAS has the following model limitations when compared to GRASS or HORSE.

1. Resolution effects are not treated

2. One bubble transport mechanism (surface diffusion) is treated

3. Fuel is considered uniform (i.e., no breakdown into columnar, equiaxed and unrestructed fuel)

4. The only fission gas "release" mechanism is that of precipitation on grain boundaries

Future Efforts

Continue parametric and semi-empirical model development for incorporation into F'RAS.

\section{Interface/Overlap}

SAS/GRASS, HORSE 


\section{References}

1. E. E. Gruber, "Transient Gas Release from Oxide Fuels: Parametric Representation of FRAS Results," ANL/RAS 75-7 (March 1975).

2. E. E. Gruber, "Migration and Coalescence of Fission Gas Bubbles in Oxide Fuels by Surface Diffusion," Int. Conf. on Phys. Met. of Rea. Fuel Elements, September 2-7, 1973, Berkeley, U.K.

3. E. E. Gruber, "On the Theory of Migration and Coalescence of Bubbles in Solids," ANL-7079 (November 1965). 


\section{FREADM}

\section{$\underline{\text { Purpose }}$}

A LMFBR multi-channel accident analysis program for simulation of a reactor transient from initiation to the point of core disassembly.

\section{Status}

A. Development: Developed at GE-BRD; FREADM-1 is only existing version, with no improvements currently in progress.

B. Availability: FREADM-1 released in 1972 for use on GE-635.

C. Utilization: Not directly used in FFTF accident analysis, but in conjunction with safety development programs involving fuel failure phenomena of applicability to FFTF.

\section{Problems Solved}

Integrated analysis for the initiating phase of a TOP and LOF HCDA. A broad range of assumed accident initiating and propagating activities may be simulated using triggering logic included in the code.

\section{Mode1s}

Major code modules include:

1. Coupled reactor kinetics (point kinetics) and multichannel heat transfer with space dependent reactivity feedback.

2. Primary loop hydraulics with slug ejection in coolant voiding accidents. This module may be run independently or in a coupled mode with the kinetics and heat transfer module.

3. A disassembly module, as VENUS, may be run in the coupled mode or as an independent code package.

4. May be coupled to TOFF.

5. Subroutine BUBL predicts residual sodium film thickness and sodium bubble pressure.

6. Subroutine STRES determines clad stresses and strains due to fuel melting and release of fission gas.

\section{$\underline{\text { Limitations }}$}

1. Point kinetics formulation is probably non-conservative.

2. No coolant re-entry model. 
3. Natural source of pin failure incoherency, due to statistical fluctuations and differing power ratings in subassemblies, is ignored.

\section{Future Efforts}

None planned.

Interface/Overlaps

VENUS/MELT, SAS

\section{$\underline{\text { References }}$}

D. D. Freeman, et a1., "The FREADM-1 Code--A Fast Reactor Excursion and Accident Dynamics Model," June 1970 (GEAP-13608).

D. D. Freeman, "FREADM Code Development: A Status Report," May 1973 (GEAP-13936). 
GRASS

\section{Purpose}

Analysis of transient fission gas release and swelling in oxide fuel.

Status

A. Development: Developed and under improvement at ANL/MSD.

B. Availability: Operationa1 at ANL on IBM 370. Models have been documented (Ref. 1).

C. Utilization: The code was developed to serve as a subroutine of LIFE (see LIFE summary), but may operate independently of LIFE if the initial fuel operating conditions are provided. The code has been used by ANL (Ref. 2) for sensitivity studies of the various parameters affecting fission gas swelling and release during TOP conditions.

\section{Problems Solved}

The code calculates the detailed transient behavior and effects of fission gases in oxide fuel pins. The code is oriented toward steady-state burnup analysis, but has been applied to TOP situations (Ref. 2). GRASS has been extended to more accurately calculate TOP situations by modifying it into the HORSE code (see HORSE summary).

GRASS predicts the fission gas release (i.e., movement of fission gases to and from grain boundaries and/or to the fuel central void) and fuel swelling (i.e., fuel volumetric expansion due to fission gas accumulation and subsequent fuel displacement) as a function of time and operating conditions. The predictions are based on models of microscopic fission gas behavior which include the following:

a. Bubble migration (motion) by all competing mechanisms

b. Bubble coalescence and growth

c. Bubble radiation-induced resolution

d. Bubble interaction with structural defects (i.e., grain boundaries and dislocations)

These models are used to compute the evolution of the bubble-size distribution of all types of bubbles (i.e., those pin to structural defects and those that are unpinned) in the fuel, which is then used to compute total fuel swelling and gas release. GRASS requires the following as input from LIFE: fuel temperature, temperature gradient, fission rate and hydrostatic stress rate. 
Mode1s

The basic model of GRASS (Ref. 1) assumes that fission gas atoms nucleate to form bubbles that move both by random (Brownian) motion and under the driving force of a temperature gradient which drives the gas bubbles toward the fuel centerline. The bubbles may collide and coalesce to form larger bubbles, with the bubble gas pressure balanced by capillary and hydrostatic stress in the fuel. Bubbles are attracted to and pinned by structural defects, especially dislocations and grain boundaries, where they may continue to grow by coalescence until they are pulled off by the temperature graident force. The bubbles then migrate to the central void. Included in the calculation of growth is a negative term describing radiation-induced resolution.

1. Geometry

The full fuel radial cross section is treated by dividing it into three regions representing columnar grain, equiaxed grain and unrestructured fuel. A11 equations are 1-D (radia1), the calculations representing an axisymmetric segment of a fuel pin with uniform axial properties.

2. Bubble motion and coalescence

Bubble mobility and velocity are computed through the bubble diffusion coefficient on the basis of three separate migration mechanisms for bubble motion, all of which occur whether or not there is a driving force present.

a. Surface diffusion of fuel matrix atoms around the interface between gas and fuel

b. Volume self-diffusion of fuel constituents

c. Evaporation-condensation or vapor phase diffusion of evaporated fuel molecules across the bubble

The functional form of the bubble diffusion coefficient is derived from several sets of diffusion data and theoretical considerations as a function of bubble radius (Ref. 2). For a given bubble size range, one of the three migration mechanisms is assumed to dominate, and the bubble diffusion coefficient is determined accordingly.

Based on the size of the bubble and the fuel region under consideration, the migration mechanism is used which gives the largest mobility and/or highest velocity. The bubble coalescence probability is computed following Gruber (Ref. 3), with the migration mechanism giving the greatest probability used. Where two or more mechanisms dominate, the calculation of the coalescence probability is based on the sum of the probabilities calculated separately for the various mechanisms.

When bubbles coalesce, they are assumed to reach equilibrium volume instantly. Bubble transport from one fuel region to another is allowed. 
3. Bubble-size distribution

The bubble size distribution is determined as a function of time in each of the three fuel regions for the following three types of bubbles:

a. Bubbles not pinned to structural defects

b. Bubbles pinned to dislocations

c. Bubbles pinned to grain boundaries

The bubbles are divided into equal size groups on a $\log$ scale and properties are averaged over each group.

Bubble sizes are defined according to the number of gas atoms contained, with the gas assumed to obey the extrapolated EOS of Harrison (Ref. 5), which is essentially the van der Waals EOS with the constants being temperature and pressure dependent.

4. Bubble interaction with structural defects

The dislocations and grain boundary (i.e., the microscopic fuel structural defects) are assumed to be randomly dispersed within the fuel. Bubbles are attracted to these defects due to the stress gradients surrounding them. Bubbles impinging on these defects are assumed "pinned" (i.e., they are attached but may still migrate along the defect and coalesce) if they are smaller than some critical size derived by Weeks et al (Ref. 4). They are pulled away from the defect by the thermal gradient driving force when they reach the critical size.

5. Bubble resolution

Gas bubbles may be reduced in size by irradiation-induced gas atom resolution in which the rate of gas atoms lost is assumed to be proportional to the fission rate and a resolution constant (Ref. 6).

6. Bubble release

The rate at which gas leaves the columnar fuel region and is released to the central void is calculated explicitly, but does not include bubbles pinned to dislocations.

7. Method of solution for fuel swelling

From the models on the behavior of individual gas bubbles and atoms, differential equations are written to describe the rate of change of the number of bubbles in each size range. The diffusion coefficients and bubble radii are calculated for the input fuel temperature and stress at the beginning of each time step. The code then integrates through time the rates of bubble coalescence, pinning and subsequent release. The total bubble volume or fuel swelling is calculated from a summation over the contribution from each of the three bubble types and all size groups, with swelling calculated separately for the three fuel regions. 
8. TOP calculations

GRASS performs TOP calculations in a quasi-static manner; i.e., the entire transient histories of fuel temperature, power and hydrostatic stress (as computed by a transient code as SAS) must be input to GRASS by dividing the histories into small time steps and assuming values to be constant over the time step.

\section{Limitations}

1. The fact that, when two bubbles coalesce, some time is required for the resultant bubble to reach equilibrium volume makes the assumption of instantaneous equilibrium of volume doubtful for short-term transients.

2. The numerical integration assumes constant temperature, which requires taking small time steps for the coalescence during a temperature ramp. A more rigorous product would be to include the temperature variation in the integration loop of the coalescence equations, as is done in HORSE (see HORSE summary).

\section{Future Efforts}

Models will be upgraded and correlated with experiments. Application of GRASS to rapid transients has been terminated in lieu of HORSE (see HORSE summary).

Interface/Overlap

SAS, LIFE/HORSE, FRAS

\section{References}

GRASS model description:

1. R. B. Peoppe1, "An Advanced Gas Release and Swelling Subroutine," Proc. Conf. on Fast Reactor Finel Element Tech,, Am. Nuc. Soc., Hinsdale, Ill, , pp. 311-326 (1971).

Sensitivity studies with GRASS:

2. J. W. Dias and R. B. Poeppe1, "Transient Swelling Studies with the GRASS Code," ANL-7992 (March 1973).

Bubble coalescence:

3. E. E. Gruber, Calculated Size Distributions for Gas Bubble Migration and Coalescence in Solids, J. of Applied Phys., 38, 243 (January 1967).

Structural defects:

4. R. W. Weeks, et al, Migration Velocities of Bubble-Defect Configurations in Nuclear Fuels, J. of Nucl. Mater., 36 (2), 223-229 (1970). 
Gas EOS :

5. J. W. Harrison, An Extrapolated Equation of State for Xenon for Use in Fuel Swelling Calculations, J. Nuc1. Mater. 31, 99 (1969).

Resolution:

6. R. B. Poeppel and S. R. Pati, Resolution Effects on Fission Gas Bubble Distribution in Oxide Fuels, Trans. Am. Nuc1. Soc., 15 (1), 213-214 (June 1972) 


\section{$\underline{\text { Purpose }}$}

Predicts aerosol behavior and transport following various LMFBR HCDA's, and establishes the capability of containment related design features of LMFBR structures to limit aerosol contributions to the site dose.

\section{$\underline{\text { Status }}$}
A. Development: Developed and under improvement at AI.
B. Availability: HAA-3 released in 1970 for use on IBM 360 .
C. Utilization: LMFBR containment design evaluation and radiological consequence assessment for FFTF and CRBR .

\section{Problems Solved}

Predicts aerosol behavior and transport following various LMFBR HCDA's. The code computes the following:

1. Plated, settled, suspended, and leaked masses.

2. Time-dependent geometric mean deviation, number concentration, and geometric mean radius for the log-normal distribution of the suspended material.

3. Time-dependent $50 \%$ radius for the suspended materia1.

4. Time-dependent number and volume distributions (functions of radius) for the settled, plated, and leaked material.

5. Time-dependent effective radii for the suspended, settled, and plated material.

6. Time-dependent aerodynamic equivalent radii for the suspended material.

\section{Models}

The Smoluchowski (Ref. 1) integro-differential equation for spherical particle aerosol behavior is solved in the moments method approximation during the high concentration phase. This method assumes the time-dependent particle density distribution to be log-normal. The physical model includes:

1. Particle generation: Source assumed to be log-normal with constant or variable rate of production

2. Brownian and gravitational agglomeration

3. Settling, plating and leakage removal mechanisms 
HAA-3A and -3B include a stirred settling model for calculating aerosol remova1 when the agglomeration rate equals the settling rate (multipled by a userselected constant). In this case, the log-normal distribution assumption is relaxed and settling and leakage become the only removal mechanisms, with agglomeration being neglected. HAA-3B also allows the user to select correction factors for non-spherical particle shapes and orientation to account for changes in viscous drag, target area and collision rate due to particles bending their trajectories by aerodynamic forces.

\section{Limitations}

1. Drop coalescent model (aerosol particles are assumed to be spherical) requires correction for particle density and shape factor.

2. Time-dependent particles number distribution is assumed to be always lognormal until Stirred Settling Model is called.

3. The Cunningham gas viscosity correction exponential term is neglected which introduces small error; otherwise, inclusion complicates computer solution of equations.

4. Diffusion is assumed to account for wall plating (i.e., no thermophoresis term - no temperature gradient driving force close to containment wall).

5. Turbulent agglomeration omitted.

6. Aerosols assumed to leak as if they were gases.

7. Resuspension neglected.

8. Charge effects neglected.

\section{Future Efforts}

1. Develop more realistic aerosol leakage model.

2. Compare to large scale experiments.

3. Examine charge effects.

4. Add turbulent agglomeration term.

5. Compare to other codes.

6. Add thermophoretic term.

7. Add realistic gas mixing (stratification) for outer containment.

Interface/Overlap

COMRADEX/ - 


\section{References}

1. M. Smoluchowski, Physik. Z., 17, 557, 1916)

2. AI-AEC-MEMO-12880, Hubner, R. S., "An Approximate Solution to the Genera1 Equation for the Coagulation of Heterogeneous Aerosols," September 26, 1969.

3. AI-AEC-13038, Hubner, R. S., et a1, "HAA-3 User Report," March 30, 1973.

4. AI-AEC-12977, Koontz, R. L., et a1, "Aerosol Modeling of Hypothetical LMFBR Accidents," August 31, 1970.

5. TI-707-130-014, Hubner, R. S., "Program HAA-3B: A Modification of the Computer Code HAA-3A for Two-Compartment Modeling," February 24, 1971.

6. TI-707-130-003, Hubner, R. S., "Program HAA-3A: A Modification of the Compuler Code HAA-3," April 28, 1970. 
HAMOC

\section{$\underline{\text { Purpose }}$}

Analysis of pressure transients in sodium piping networks.

\section{Status}

A. Development: Developed at HEDL.

B. Availability: No documentation is currently available (Ref. 1). It is operational at HEDL on CDC-6600, GE-BRD and W-ARD.

C. Utilization: Has been used by HEDL and W-ARD for HCDA response analysis of FFTF auxiliary and closed loop systems and to check HCDA response of the primary piping system as predicted by other codes. GE- BRD has used it for analysis of HCDA pressures in the primary piping system of CRBR.

\section{Problems Solved}

Calculates pressure transients in liquid sodium piping systems resulting from pressure disturbances introduced at one or two points in the system.

\section{Models}

1. Fluid Flow and Numerical Method

The governing partial differential equations are the $1-D$, compressible, time-dependent conservation equations of continuity and momentum. These equations are reduced to the fluid-hammer (slightly compressible) equations and solved by the method of characteristics.

2. EOS

The code contains liquid sodium properties only, but could easily be expanded or changed to include any fluid properties.

3. Piping System

Forms pipe networks from individual straight pipe sections joined together at junctions. Junctions options are as follows:
a. Diameter discontinuity: an expansion or contraction
b. E1bow
c. Pump 
d. Pressurizer

e. Tee or other 3-way connection

f. Dead end or full blockage

g. Orifice-1ike restriction

One or two piping system boundary conditions are allowed.

4. Pressure Source

Arbitrary pressure-time histories may be input at one or two positions in the piping system.

5. Cavitation

A column separation method is used (Ref. 2).

6. Pipe Dilation

The speed of sound calculation is corrected to account for elastic behavior of pipe walls.

\section{Limitations}

1. Number of nodal points in the system model is limited only by the availability of computer memory. Problems have been run for models containing up to 300 pipe sections, each with a maximum of 20 nodal points.

2. The simplified cavitation logic used when pressures fall to saturation values has not been completely verified by comparisons to experimental data. However, favorable comparisons have been made to more elaborate codes which include the energy equation along with the momentum and continuity equations.

3. Does not allow pipe wall plastic deformation.

\section{Future Efforts}

No definite work has been identified.

Interface/Overlap

REXCO, TUBE /NAHAMMER, NATRANSIENT, TRANSWRAP

\section{$\underline{\text { References }}$}

1. "HCDA Requirement and Loading for FFTF Design Evaluation," HEDL-FS-257, (to be published).

2. Streeter and Wylie, Hydraulic Transients, McGraw-Hil1, N.Y., 1967.

3. H. J. Johnson, "HAMOC, A Computer Program for Fluid Hammer Analysis," October 1972 . 
HOPE

\section{Purpose}

An integrated program for studying the predisassembly behavior of a whole LMFBR core or a single fuel pin involved in a TOP accident.

\section{$\underline{\text { Status }}$}

A. Development: Developed and under improvement at UCLA.

B. Availability: Operational at UCLA.

C. Utilization: Used at UCLA for TOP HCDA sensitivity studies of the SNR-300 core for prediction of clad failure, fuel movement and related phenomena as a function of reactivity ramp rate, burnup, power and clad failure location. Similar in many aspects to other integrated codes, as SAS and MELT, but has new time-dependent fragmentation model for FCI.

\section{Problems Solved}

The phenomena treated by HOPE for studying TOP fuel movement include:

1. Reactor kinetics.

2. Steady-state fuel behavior.

3. Steady-state and transient fuel, clad and single phase coolant heat transfer.

4. Fuel melting and formation of a molten fuel-fission gas cavity.

5. Clad deformation and failure.

6. Fuel and fission gas ejection.

7. Fuel fragmentation and FCI.

8. Fuel movement and reactivity feedbacks.

HOPE is applicable to all burnup and operating power conditions of either LMFBR whole cores or single pins in which sodium boiling does not occur prior to clad failure.

\section{Models}

\section{Geometry}

Fundamental unit is a fuel pin with its associated coolant. A subassembly model includes a single representative fuel pin, coolant channel and associated hexcan structure, with all fuel pins in one subassembly assumed 
to act coherently. Interactions between channels in whole core analysis are not modeled since hexcans are assumed to maintain their integrity, with core transient thermal and hydraulic boundary conditions being fixed.

2. Steady-state

Initial state of reactor is user-specified. Fuel restructuring and central void formation models are available. Several models for fission gas release from fuel pins are available. Center void pressure is determined by assuming pressure equilibrium with the gas plenum, due to long periods of steady-state operation and temporary fuel cracks formed during shutdown.

3. Pre-clad failure transient

a. Heat transfer: heat conduction equation solved in a manner of SAS $1 \mathrm{~A}$.

b. Neutronics: point kinetics includes Doppler, sodium voiding and fuel movement reactivity feedbacks.

c. Coolant dynamics: single phase conservation equations are used to determine coolant conditions.

d. Fuel mechanics: a simplified fuel-clad thermal expansion model is used where clad is considered to behave as a thin shell and solid fuel is allowed to transmit stress to the clad assuming no slip between them. Plastic deformation of the clad is described using a high strain rate, irradiated, temperature dependent yield surface. Pressure in the fuel pin cavity is transmitted through the solid fuel to the clad, with the fuel considered strengthless. When the cavity-induced stress exceeds that caused by differential fuel-clad thermal expansion, the clad stress is assumed to be caused entirely by cavity pressure. Clad failure time and location is predicted by setting a clad permanent deformation or stress failure criteria can be selected. Clad failure flow area is user-specified.

e. Fuel pin cavity model: cavity is assumed to be homogeneous and impermeable, with size and state determined by combination of central void fission gas. The cavity pressure is determined from the Berthelot EOS for a gas.

4. Fuel/fission gas ejection

Similar to SAS/FCI model: the time-dependent Bernoulli equations with additional flow choking considerations is used to model the assumed homogeneous, compressible removal of fuel/fission gas mixture.

5. Fuel fragmentation

A time-dependent fragmentation model in which ejected fuel fragments only when liquid-liquid contact with sodium occurs. This can cause delayed fragmentation events when vapor bubbles collapse from heat losses to cooler steel regions high in the core. Fission heating of ejected fuel 
particles is accounted for, delaying their solidification. The fragmentation model slows the rate of energy transfer to the coolant and thus slows fuel sweeping.

Assumes that molten fuel will be highly disturbed and fragmentation will not occur if the bulk sodium temperature is less than a few degrees subcooled or the fuel is not molten. Also, fragmentation can be stopped at a prespecified void fraction considering homogeneous distribution of fission gas and sodium vapor in the interaction zone. When fragmentation is permitted, the mass of fuel particles is divided exponentially during a specified time interval (obtained from experiments) into more particles of smaller volume. This determines the heat transfer area available.

6. FCI

Similar to SAS/FCI model: a single zone interaction model, in which the length of the zone is initially specified as the clad failure length. Fuel is uniformly distributed in the zone. Sodium above and below the interaction zone is incompressible. An energy equation, in which the heat is transferred between clad, upper and lower zone interfaces and fuel particles, is coupled with an inertial constraint equation and an EOS, and all three are solved by Gauss elimination to find the average coolant properties in the interaction zone. Heat transfer between the fuel particles and sodium takes into account the fuels thermal conductivity and convective heat transfer is based on a Nusselt number correlation. Implicit in the FCI model is the assumption that the fragmentation process itself is not energetic.

7. Fuel movement in coolant channel

Al1 particles are bounded in cells with cell boundary motion describing axial fuel movement. Within each cell, the fuel mass is represented by a uniform dispersion of particles, a11 with the same time-dependent radius. The movement of the particles is determined by calculating the drag, gravity, and buoyance forces on the particles. A correlation is used for the situation where particles become closely packed.

\section{Limitations}

1. No allowance for multiple clad failures or a time-dependent failure area.

2. The fuel motion/fuel-coolant interaction modeling is similar to the SAS/FCI model and thus it has all the limitation of that model.

Future Efforts

None specified

Interface/Overlap

- /SAS, MELT 


\section{References}

1. E. T. Rumb1e, "A Hypothetica1 Overpower Excursion Model for Liquid Meta1Cooled Fast Breeder Reactors," Ph.D. Dissertation in Engineering, UCLA (June 1974).

2. E. T. Rumble, et al., "Fuel Movement Investigations During LMFBR Overpower Excursions Using a New Model," Proc. Conf. Fast Reactor Safety, Beverly Hills, California (April 1974).

3. E. T. Rumble, et al., "Sensitivity Analysis of an LMFBR to Whole-Core Overpower Excursions," Trans. American Nuclear Society, 1974 Winter Meeting, Volume 19. 
HORSE

Purpose

Analysis of rapid transient fission gas release and swelling in oxide fuel.

$\underline{\text { Status }}$

A. Development: Developed and under improvement at ANL/MSD. HORSE is an extension of GRASS (see GRASS summary) to rapid temperature transient situations.

B. Availability: Operational at ANL on IBM 370. No formal documentation is available for HORSE, but GRASS model documentation is applicable (see GRASS references). A code listing is available via an ANL interlab memo.

C. Utilization: Has been coupled with SAS/DEFORM to provide an integrated fuel stress - fission gas swelling analysis for prediction of clad loading and failure during a TOP situation.

\section{Problems Solved}

HORSE is a modified version of GRASS (see GRASS summary) for analysis of fission gas behavior and effects during short-term TOP accidents. As in GRASS, the evolution in time of the fission gas bubble size distribution in the fuel is calculated in order to determine the total fuel swelling. This capability allows HORSE to be coupled with SAS/DEFORM (see SAS and DEFORM summaries) to study the contribution that gas swelling makes to total fuel deformation and clad loading during a TOP accident. SAS/DEFORM supp1ies HORSE with the fuel temperature and hydrostatic stress, while HORSE supplies SAS/DEFORM with changes in the bubble size distribution and resultant swelling.

\section{Mode1s}

GRASS and HORSE are essentially the same as with the following modifications made in GRASS to obtain HORSE:

1. Temperature, bubble radii and diffusion coefficient calculations are put inside the numerical integration loop (i.e., bubble sizes and coalescence rates are calculated for temperature at the current time) instead of calculating the diffusion coefficients and bubble radii for the input temperatures and stresses in the fuel at the beginning of each time step.

2. Instead of assuming the bubbles are instantaneously pulled away from dislocations and grain boundaries once they have reached a critical size, in which the thermal gradient driving force is greater than the pinning force, a finite release rate is given. 


\section{Limitations}

The code does not include all variables in the numerical integration loop, e.g., hydrostatic pressure, temperature gradient, and reactor power.

\section{Future Efforts}

Remove above limitation.

Interface/Overlap

DEFORM /GRASS, FRAS

$\underline{\text { References }}$

See GRASS summary references. 
HOTPIM

\section{Purpose}

A 1-D, two-phase compressible hydrodynamics model for the behavior of the molten fuel/fission gas mixture inside a fuel pin which has been subjected to a ToP accident.

Status

A. Development: Developed at HEDL for implementation into MELT.

B. Availability: Operational at HEDL. In process of being incorporated into MELT-III, but presently is available only as a stand-alone version.

C. Utilization: Used by HEDL to do sensitivity analysis of molten fuel dynamics to FFTF TOP fuel pins. Advanced model of its type, since no other available codes consider two-phase flow.

\section{Problems Solved}

HOTPIM can be used to study the following major concerns regarding molten fuel dynamics inside a TOP fuel pin:

1. Spatially non-uniform pressure and density.

2. Clad rupture size.

3. Composition of the molten fuel/fission gas mixture, which escapes through the clad rupture into the coolant channel.

\section{Mode1s}

HOTPIM uses Hartree's form of the method of characteristics (D. R. Hartree, Numerical Analysis, Second Edition, Oxford U. Press, 1958), which is modified to consider three characteristics in order to allow anfsotropy in 1-D, twophase flow. The conservation equations of mass, momentum and energy are reduced to characteristic form, with the characteristic equation being solved simultaneously on a constant Eulerian grid by using an iterative scheme.

Relative motion between the molten fuel and gas is treated as a perturbation to homogeneous flow, modeled as the drift of independent bubbles in 1-D vertical flow in a static liquid. A volumetric drift flux is determined from a set of correlations, and a new void fraction is computed at each time step.

The major assumptions used in HOTPIM are as follows:

1. The flow is strictly one-dimensional.

2. The flowing medium is a two-phase, two-component fluid, with no mass transfer between the components. 
3. The gas is ideal and does not condense, and the liquid is non-volatile.

4. The flow remains in the bubbly flow regime.

5. Flow through the cladding rupture is strictly transverse, with no velocity component parallel to the cladding wall.

6. The bubbles attain their terminal drift velocity instantaneously.

7. The correlations for steady-state drift in a hydrostatic pressure gradient apply for transient drift of fission/fill gas bubbles in molten fuel in a hydrodynamic pressure gradient.

8. The effects of dissipative forces, such as viscosity and wall friction, are insignificant.

9. There is no relative motion between pure liquid and the solid fuel grains existing when the bulk temperature of the fuel is between the solidus and the 1iquidus.

10. Pressure immediately outside the rupture is assumed to remain constant throughout the transient.

The following must be input:

1. Internal pin conditions at time of clad rupture (i.e., dimensions of molten region, initial void fraction and heating rate).

2. Location and size of rupture.

3. Failure criteria (internal fuel pin pressure).

4. Pressure outside rupture.

Limitations

HOTPIM limitations can be evaluated from the list of assumptions under Models.

Future Efforts

Incorporate HOTPIM into MELT III.

Interface/Overlap

MELT/PLUTO

$\underline{\text { References }}$

H. J. Willenberg, et al., "Dynamics of Molten Fuel Motion During a Fast-Reactor Overpower Transient," Proc. of Fast Reactor Safety Meeting, Beverly Hills, California (April 1974). 
IANUS

\section{$\underline{\text { Purpose }}$}

Simulation of transient neutronic - thermal-hydraulic behavior for a 1oop-type liquid metal cooled reactor plant, with detailed application to FFTF-type systems.

\section{$\underline{\text { Status }}$}

A. Development: Developed by WARD. Currently under review and updating for FFTE FSAR support.

B. Availability: Proprietary code, available only through lease or purchase arrangements; operational at WARD.

C. Utilization: Used by WARD and HEDL for FFTF thermal transient design, pipe rupture and natural circulation analysis, and PPS and control system design.

Problems Solved

Analysis of:

1. Loss-of-electrical power transient.

2. Single or multiple pump seizure or coastdown.

3. Pipe rupture.

4. Natural circulation.

5. Control system malfunctions.

6. Tornado events (loss of secondary loops).

7. Control rod transients.

8. Tertiary (DHX) system failures.

\section{$\underline{\text { Models }}$}

Reactor is modeled as follows:

1. Core - modeled by single "average" fuel pin and coolant channel with neutron point kinetics, reactivity feedbacks, fission product decay heat kinetics, and hot and peak channel factors.

2. Internals - radial reflectors, radial shielding and vessel shielding are homogenized, with heat generation, heat capacity and coolant transport effects included. 
3. Plena - mixing models for inlet and outlet plena are chosen by input with heat transfer to structure included.

4. Any number of heat transport loops, but only one of which may be behaving differently from others, are modeled with each containing the following:

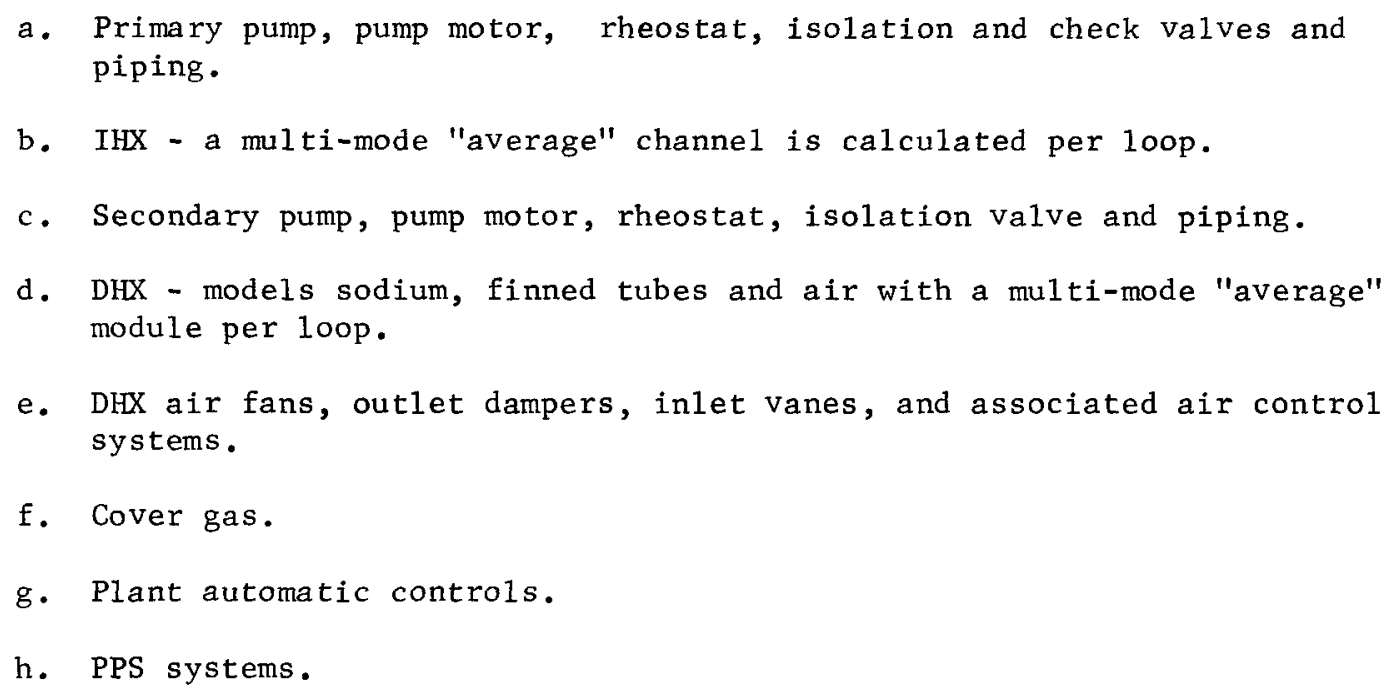

\section{Limitations}

1. Core model has single dynamic average channel and uses hot and peak channel factors.

2. Code handles only single phase coolant flow, with SAS used for excursions beyond boiling.

3. Bypass flow structure is homogenized.

4. Reactivity inserted must be less than $+\$ 1.00$, due to point kinetics formulation.

5. Fuel restructuring and melting not allowed in code.

6. Transient, hydraulics treats only non-acoustical phenomena due to incompressible flow assumption.

7. Fluid and metal temperature expansion effects on vessel and pump tank fluid levels are not calculated.

\section{Future Efforts}

Test verification of pipe rupture hydraulics 
Interface/Overlap

SAS/DEMO

References

F. M. Heck, "IANUS Outline Description," WARD Report FPC-939. 


\section{Purpose}

Analysis of primary containment hydrodynamic-structural response to pressure loadings resulting from HCDA's.

\section{Status}

A. Development: Developed and under improvement at ANL/RAS. ICECO-H is current development version.

B. Availability: ICECO-H and ICECO-HT are operational at ANL on IBM 360 . ICECO documentation will be published during 1975 (REF. 1).

C. Utilization: Has been used exclusively by ANL due to its developmental status until 1975.

\section{Problems Solved}

The ICECO codes were developed to extend analytical capabilities of REXCO-type analysis for primary system hydrodynamic-structural response to pressure loads resulting from nuclear excursions. REXCO analysis, which is based on an explicit time-differencing scheme and a Lagrangian coordinate system, is not applicable to problems involving large fluid motions (see REXCO summary). ICECO, which is based on an implicit time-differencing scheme and an Eulerian coordinate system, is particularly suited for problems involving long time duration events and large fluid motions and thus can continue the hydrodynamic-structural analysis after REXCO becomes inadequate. Thus, a coupling of the two codes allows a complete response analysis for the full range of postulated nuclear excursion energies up to the point of system pressure equilibrium.

ICECO has been applied to the following HCDA analysis problems:

1. Studies of low-energy excursions

2. Effect of coolant compressibility on pressure wave propagation

3. Dynamics of HCDA-induced core vapor bubble motion within the reactor vessel

4. Sodium spillage through head-vessel opening as a consequence of slug impact on the head

\section{$\underline{\text { Mode1s }}$}

ICECO-H :

\section{Geometry}

All formulations are for 2-D, cylindrical axisymmetric geometry. 
2. Hydrodynamics

The governing equations for fluids are the full, compressible, transient, non-linear differential equations for conservation of mass, momentum and energy. The momentum conservation equations include non-1inear convective and viscous diffusion terms. The full viscous stress tensor is incorporated instead of a simple artificial viscosity for elimination of shock discontinuities, and an optional mass diffusion term can be employed to enhance numerical accuracy for certain problems. The conservation equations are solved along with an arbitrary EOS to yield the desired field variables.

3. Method of solution for hydrodynamics

Solution of the conservation and EOS equations is based on the ICE (Implicit, Continuous-Fluid, Eulerian) technique (Ref. 2). All equations are expressed in Eulerian coordinate form and then set into numerical form by finite-difference equations which use an implicit time differencing scheme. Substitution of advanced-time densities and velocities into the difference form of the mass and momentum equations leads to a set of Poisson equations for the advanced-time pressures which are solved iteratively at each time step for the new velocities, pressures, densities and internal energies. The implicit treatment of the density variation provides a solution capability for problems involving the full range of flow regimes from the incompressible limit to hypersonic. A generalized time-centering capability is available for elimination of undesirable loworder truncation errors. The ICECO solution methodology possesses the advantages of: (a) the inviscid boundary condition between the fluidsolid interfaces are easy to handle, (b) suitable for both plane and cylindrical symmetric geometries, (c) large time steps can be chosen without compromising numerical stability and (d) the fluids may distort without limit.

\section{Reactor Structures}

All reactor internal structures and head are rigid and openings within internal structures are at least the size of an Eulerian cell. An option allows the code to be coupled with a subroutine which allows treatment of a flexible reactor vessel and core barrel as elastic-plastic, cylindrical, thin shells. Another option treats axial motion of the rigid head, with the holddown bolts modeled as a restraining force on the head. Plug jump (i.e., sudden head motion due to slug impact) can be accommodated with numerical stability and an irregular cell treatment eliminates the restriction that sodium spillage area be at least the size of a fixed Eulerian cell.

ICECO-HT :

This version consists of ICECO-H with FCI and condensation models incorporated.

1. FCI models

Same as for REXCO-HT

2. Condensation mode1 
As the FCI zones expand and uncover steel, heat is transferred from the sodium vapor to the cold steel, thereby condensing sodium and reducing the FCI zone pressure. Different values of the area and mass of exposed steel can be prescribed for each Eulerian cell.

\section{Limitations}

1. All material within a single Eulerian cell is homogeneous.

2. Restricted to single-field calculations (single-field restriction implies that ICECO cannot handle the interpenetration of two different homogeneous materials across an interface).

3. All obstacles to flow within the reactor are rigid.

4. Turbulent flow capabilities have not been incorporated.

\section{Future Efforts}

1. Multi-field capabilities.

2. Turbulent flow capabilities.

Interface/Overlap

VENUS / REXCO

\section{References}

ICECO documentation:

1. Chung-Yi Wang, An Implicit Eulerian Method for Calculating Fluid Transients in Fast Reactor Containment, ANL/RAS 75-9, March 1975.

ICE technique:

2. F. H. Harlow and A. A. Amsden, "A Numerical Fluid Dynamics Calculation Method for A11 Flow Speeds," J. Computational Physics, 8 (1971), 197. 
ICEPEL

\section{Purpose}

Analyses of primary piping system hydrodynamic-structural response to pressure loads resulting from $\mathrm{HCDA}^{\prime} \mathrm{s}$.

\section{Status}
A. Development: Under development at ANL/RAS.
B. Availability: Operational at ANL on IBM 360. Documentation will be published during 1975.
C. Utilization: Currently undergoing testing for eventual utilization as CRBR safety analysis support.

\section{$\underline{\text { Problems Solved }}$}

ICEPEL couples 2-D compressible hydrodynamics with a structural response analysis to compute the following for pressure loadings in any range:

1. The mechanical response of a straight fluid-filled elastic-plastic pipe to a pressure pulse injected at one end of the pipe and the propagation of the pulse within the pipe. The straight pipe may contain an axisymmetric enlarged section (i.e., a sudden expansion) which may simulate the effect of a valve.

2. The propagation of pressure pulse within a fluid-filled non-deformable pipe elbow of any angle.

3. Propagation of pressure pulses within the fluid of an open-ended piping network consisting of any combination of straight pipes, elbows and valves, and the mechanical response of the straight pipe and valve sections to the pressures. Different pressure pulses may be input at the open ends.

\section{Mode1s}

1. Geometry

The straight pipe and valve sections are modeled as 2-D axisymmetric. The elbow is 2-D and considers flow in the radial (i.e., radially outward from the center of curvature) and the tangential directions, with secondary motion ignored.

2. Hydrodynamics

The hydrodynamics formulation is identical to ICECO (see ICECO summary).

3. Method of Solution

The method of solution is identical to that of ICECO (see ICECO summary). 
4. Piping Loop Mechanical Response

The walls of the straight pipes and the valves can be treated as rigid or deformable. In the deformable analysis, the wall boundary is modeled as thin cylindrical shells of revolution undergoing large deflections. The wall material is elastic-plastic and strain-hardening. The elbows are considered to have rigid walls.

\section{E1bow Model}

The 2-D model approximates the transient flow in an elbow of arbitrary angle. The analysis accounts for the effect of centrifugal force, but neglects the secondary flow in the elbow region.

6. Valve Model

A valve model consists of a cylindrical section of the straight pipe having an enlarged diameter. The valve and straight pipe are connected by straight adapters of arbitrary angle.

\section{Limitations}

1. Modeling of piping loop components is restricted to simple valves.

2. Elbow walls are non-deformable.

\section{Future Efforts}

1. Modeling of pumps and heat exchangers.

2. Deformable elbow walls.

3. Coupling with ICECO to provide integrated analysis of primary containment system.

Interface/Overlap

REXCO/ICECO

\section{References}

1. C. Y. Wang, et a1., "An Implicit Finite Difference Method for Fluid Dynamics Calculation in the Primary Coolant Systems," ANS Topical Meeting on Mathematical Computation Methods, April 1975, Charleston, S.C.

2. M. T. A. Moneim, "ICEPEL, A Two-Dimensional Computer Program for the Transient Analysis of a Pipe-Elbow Loop," ANL/RAS 75-10, March 1975. 
ISOSHLD

\section{Purpose}

Calculation of gamma ray attenuation for various source and shield configurations.

Status

A. Development: Developed at HEDL; ISOSHLD-III is latest version.

B. Availability: Available through Oak Ridge Radiation Shielding Information Center; ISOSHLD I, II and III have been documented (see references).

C. Utilization: In use at a number of sites.

Problems Solved

ISOSHLD performs gamma ray shielding attenuation calculations for isotope sources in a wide variety of source and shield configurations. All necessary data libraries for use of the code are included. For most problems, ISOSHLD requires as input only the geometry and material composition of the source and shields. ISOSHLD will perform a calculation for a source consisting of a fission product inventory if linked to RIBD (see RIBD summary). The source may be distributed uniformly or exponentially.

\section{Models}

1. Attenuation calculations

Gamma ray attenuation is calculated by a point kernel technique, for most geometries by a Simpson's Rule numerical integration.

Buildup factors are calculated based on the number of mean free paths of material between the source and the detector points, the effective atomic number of a particular shield region, and the point isotropic buildup data avallable as Taylor coefficients in the effective atomic number range of 4 to 82 .

\section{Source selection}

Source strength in uniform or exponential distribution may be calculated by the linked fission product inventory code RIBD or by other options as desired. The isotopes contained in the source can be selected in any one of three ways: by selection of specific isotope or isotopes and the number of curies of each, by defining any arbitrary source in terms of photon energy and production rate, or by use of the subroutine RIBD to calculate the fission product inventory associated with fuel. If the RIBD option is employed, the user can arbitrarily select fractional quantities of specific groups of isotopes (noble gases, halogens, volatile solids, other fission products, or all isotopes) for use in the source. 
3. Geometry options

Ten different general geometry options are included to simplify input and use of the code. These include:

a. point source, slab shields

b. line source, slab shields

c. spherical source, spherical shields

d. spherical source, slab shields

e. truncated cone source, slab shields

f. disk source, slab shields (detectors on centerline)

g. cylindrical source, cylindrical shields (side)

h. cylindrical source, slab shields (side)

i. cylindrical source, slab shields (end)

j. rectangular solid source, slab shields (detector on centerline of face)

4. Data libraries available

a. Shield materials

Mass attenuation coefficients for eighteen shield materials are contained in the included data library. Materials include: water, tissue, air, hydrogen, lithium, carbon, aluminum titanium, iron, nickel, zirconium, tin, tungsten, lead, uranium, ordinary concrete, magnetite concrete, ferrophosphorus concrete. Additional materials can be added by the user.

b. Photon probability library

The photon decay energy and the probability of photon emission for each of 450 isotopes or isomeric states are included in the library. As many different photon energies and probabilities are included for each isotope or isomeric state as have been identified.

c. Buildup factors

Buildup factors for the exponential form are included in the library for six different materials: water, aluminum, iron, tin, tungsten, and lead. Interpolation of the coefficients is done in the code to provide buildup factors for any shield material based on its effective atomic number. 


\section{Limitations}

1. Geometry choices are limited to those ten described, but more complex source arrangements can be treated by appropriate combinations of those available.

2. Gamma dose rates cannot be calculated at points internal to the source.

3. Isotopes that are pure beta emitters and those that yield neutrons by various interactions are not treated.

Future Efforts

None planned.

Interface/Overlap

RIBD/GRACE, QAD

\section{$\underline{\text { References }}$}

1. ISOSHLD-I :

R. L. Engle, J. Greenborg, M. M. Hendrickson, "ISOSHLD-A Computer Code for General Purpose Isotope Shielding Analysis," BNWL-236 (June 1966).

2. ISOSHLD-II:

G. I. Simmons, J. J. Regimbal, J. Greenborg, E. L. Kelly, Jr., H. H. VanTuyl, "ISOSHLD-II: Code Revision to Include Calculation of Dose Rate from Shielded Bremsstrahlung Sources," BNWL-236 Sup-1 (Narch 1967).

3. ISOSHLD-III:

C. A. Mansius, "A Revised Photon Probability Library for Use With ISOSHLD-III," BNWL-236 Sup-2 (April 1969). 


\section{Purpose}

Analysis of in-pile thermal, mechanical and nuclear performance of cylindrical, fast-reactor fuel pins as a function of reactor operating history.

\section{Status}

A. Development: LIFE-1 and -2 were developed at ANL/MSD. LIFE-3 development is the result of a working group composed of $A I, A N L, G E-B R D$, HEDL and W-ARD.

B. Availability: LIFE-1 was released in 1970 (Ref. 1-3). LIFE-2 (Ref. 4) will not be released in lieu of the release and documentation of LIFE-3 during 1975. LIFE-3 is operational on the IBM 370/195 at ANL and the CDC 7600 at LBL and W-ARD.

C. Utilization: The LIFE codes have been used extensively to provide initial fuel pin characteristics for whole-core and single fuel pin accident analysis codes, sensitivity analysis for fuel pin materials and performance, correlation with other similar codes and for design and interpretation of in-pile experiments. LIFE-3 is the national fuel pin performance code and as such is considered the standard or reference tool for prediction of LMFBR fuel pin steady-state performance characteristics.

\section{Problems Solved}

The LIFE codes are designed to compute the detailed thermal and mechanical behavior of a fuel pin over the long times during any specified history of fast flux irradiation in a normal reactor power cycle. The codes have been primarily applied to stainless steel clad oxide fuel, but any other material systems can be treated. LIFE-1 calculations include the following as a

function of time and axial position:

1. Temperature distributions in fuel and clad

2. Fuel restructing rates and dimensions

3. Hot-pressing or densification of fuel

4. Fission product generation and distribution in the fuel

5. Clad swelling due to void nucleation and growth

6. Fuel swelling due to accumulation of fission products

7. Migration of fuel constituents (as plutonium)

8. Fission gas release from fuel and resulting fission gas plenum pressure 
9. Interface pressure between fuel and clad

10. Stress and strain distributions from thermoelastic, creep (thermal and irradiation induced), and swelling deformations in fuel and clad

11. Dimensions of the clad, each fuel zone and the central void, including fuel and clad length changes

LIFE-1 can also treat encapsulated fuel pins as an option.

LIFE-2 is an extension of LIFE-1 to include the following:

1. Fuel cracking and crack healing

2. Cumulative damage failure criteria for the clad

3. Improved fuel-clad contact thermal conductance

4. Capsule, as well as clad swelling, for encapsulated fuel pins

5. Reduction of power in a fuel pin in relation to total reactor operating power as burnup increases

LIFE-3 contains improvements over LIFE-2 with capabilities for:

1. Clad corrosion

2. Primary thermal creep

Mode1s

LIFE-1

1. Geometry

The cylindrical fuel pin is divided into axial sections to account for axial variations in power, fuel pin geometry, coolant pressure and coolant temperature. The plenum always forms a single axial section regardless of length, whereas the fueled part of the pin is divided in up to ten axial sections of equal length. In each axial section, the assumptions of axial $s_{j}$ mmetry and generalized plane strain reduce all equations to $1-D$. An initial gap between the fuel and clad is allowed and the gap may open or close any number of times, depending on the reactor operating conditions. The central void, which develops during fuel operation, is assumed to be open to the gas plenum so that the gas plenum pressure loads the fuel interna1ly.

2. Heat transfer

The radial quasi-static temperature distribution in the fuel and clad is obtained by a 1-D, steady-state calculation at each time step, and is based on the average power level and inlet coolant temperature expected during the time step, the fuel zone dimensions, the fuel-clad gap size, the clad dimensions and the fuel density. Two thermal conductivity options are 
available for the fuel. The fuel and clad are divided into an arbitrary number of radial, equal mass sections for the thermal calculation. The effective fuel-clad gap thermal conductivity is taken to be a linear function of the temperature evaluated at the average gap temperature. The pressure dependence of the gap heat transfer coefficient is neglected. The temperature calculations in the fuel are used to determine temperature gradients which affect plutonium and volatile fission-product migration rates.

3. Fuel restructuring

The fuel is divided radially in each axial segment into a central void and three solid regions corresponding to a columnar grain structure, an equiaxed grain structure and an unrestructured fuel. The fuel density in each region is assumed independent of initial fuel density. The rate of restructuring is derived from the theory of columnar grain formation (Ref. 6) and is a sensitive function of temperature and temperature gradient at the boundaries of the regions.

4. Plutonium migration

The computation of radial migration of plutonium in the fuel by thermal and chemical diffusion is based on a subroutine by Poeppel (Ref. 7 ). The analysis neglects possible effects due to oxygen redistribution, bubble migration and fuel melting and resolidification.

5. Fission product production and gas release

The amount of solid and gaseous fission products generated during each time interval is calculated, along with the amount of fission gas released to the plenum. The amount of gas released from each fuel region is a function of both amount of gas in and density of the region.

6. P1enum pressure

The plenum pressure is determined by the perfect gas law from the amount of fission gas released to the plenum and the volume average of the plenum and central void gas.

7. Stress-strain analysis

The three fuel regions and the clad are as treated concentric cylinders with average thermal and mechanical properties for each region determined by integration. The mechanical analysis is limited to four regions because the resulting equations may be readily solved algebraically. The field equations assume axial symmetry and a state of generalized plane strain existing in the cylinders. The stress analysis of the fuel and clad includes the effects of fuel swelling caused by accumulation of fission products, hot pressing of fuel, (i.e., compaction by decreasing of fuel porosity), thermoelastic and creep deformations of both fuel and clad (including thermal and irradiation enhanced creep) stress relaxation and several options for clad swelling due to void formation and growth. Almost any creep law is allowed. 
The coolant pressure exerts an external load on the clad and an additional axial force may be user-specified. When the fuel-clad gap is open, the plenum pressure is assumed to be exerted between the fuel and clad. The plenum pressure is also assumed to load the fuel internally via the control void. When the gap is closed, a "stick" boundary condition is assumed where the changes in axial strain of the fuel and clad are set equal. If the computed frictional force is larger than can be justified by the contact pressure and the specified fuel-clad friction factor, a "slip" condition occurs where the fuel and clad axial strains may change at different rates.

8. Fuel hot pressing

Hot pressing decreases the porosity initially present in the fuel, and is based on a diffusion process (Ref. 9).

9. Fuel Swelling Due to Fission Products

Swelling due to solid fission products is treated by specifying the net solid volume created per fission and multiplying by the number of fissions occurring in each fuel region. Gaseous fission-product swelling for the restructured regions is determined by a simple gas-law approach, while in the unrestructed region, the gas bubbles are so small that they are assumed incompressible and thus contribute to swelling in a manner similar to solid fission products.

\section{LIFE-2}

LIFE-2 (Ref. 4) is an extension of LIFE-1 to include fuel cracking during power transients and subsequent crack healing, and cumulative damage failure criteria for the clad. The other models and correlations of LIFE-2 are basically the same as for LIFE-1, with several minor changes including a more realistic fuelclad contact thermal conductance, a capability for capsule as well as clad swelling for encapsulated fuel pins, and a capability to gradually reduce the power of a fuel pin in relation to the reactor operating power as burnup increases.

1. Geometry

Same as for LIFE-1.

2. Heat Transfer

The radial, quasi-static temperature distribution is calculated by the same method as for LIFE-1, with following improvements having been made over LIFE-1:

a. A third option (Ref. 8) was added for the fuel thermal conductivity

b. Pressure and temperature-dependent gap conductance is included as an option 
3. Fuel restructuring

Same as LIFE-1, but with each restructured fuel region density made a function of initial fuel density.

4. Plutonium migration

Same as LIFE-1.

5. Fission product production and gas release

Same as LIFE-1, but with temperature-dependent fission gas release rates for each fuel region.

6. Plenum pressure

Same as LIFE-1.

7. Stress-strain analysis

Same as for LIFE-1, except during power transients when local thermal stresses are required for fuel cracking analysis.

8. Hot pressing

Same as LIFE-1, but includes decrease of fuel porosity generated due to fuel cracking.

9. Fuel swelling due to fission products

Same as for LIFE-1.

10. Fuel cracking and healing

At the end of each time step, the code computes whether fuel cracking would occur in any of the three principal directions. If the power has changed, the local thermal stresses are computed and superimposed for each fuel region and cracking is predicted from a fracture strength correlation for the ultimate tensile strength (Ref. 10). The stress component perpendicular to the crack vanishes in the fuel region and the elastic strain existing prior to cracking is then redistributed. The mechanical properties of the cracked fuel are than modified to represent the cracked fuel as an isotropic material. Cracked fuel is allowed to creep faster than uncracked fuel by modification of the creep rate, which is assumed to be related to the shear modulus.

When a fuel pin operates without a change in power during a time step, crack healing is allowed whenever:

a. The stresses in a fuel region become compressive

b. The temperature exceeds $1400^{\circ} \mathrm{C}$ or

c. The time at steady state exceeds one hour. 
When the cracks heal, the mechanical properties of the fuel are again restored to their usual values.

11. Clad Failure Criteria

The failure criterion is a linear cumulative damage law relating clad hoop stress and time-to-rupture. The time-to-rupture is based on a correlation for unirradiated $20 \%$ cold-worked SS-316 (Ref. 11 ).

LIFE-3

This improved version of LIFE- 2 contains models for primary thermal creep, and clad corrosion due to flowing sodium. A new hot pressing model has been incorporated.

\section{Limitations}

\section{LIFE-1 :}

1. The thermal and generalized plane strain analysis neglect possible circumferential variations and ignore the finite length of the fuel pellets and/or the initial particle behavior of vibratorily compacted fuel.

2. No fuel cracking mode1, which causes overprediction of ratchetting effect in full irradiation histories.

3. When the fuel contacts, but does not stick to the clad, compatibility between axial sections is not required by the code (this may be avoided by using only one axial fuel section and one plenum section).

4. Steady-state thermal calculations are used at each time step.

5. No clad or fuel melting is allowed.

6. Clad degradation due to fuel-clad chemical reaction or coolant corrosion (wastage) is not treated.

7. Effects of stoichiometric changes during burnup are ignored.

8. The fuel-clad gap thermal conductivity is not temperature and pressure dependent.

9. Plutonium migration model neglects effects of oxygen redistribution, bubble migration, and fuel melting and resolidification.

10. Does not contain nonlinear time dependence of creep deformation due to primary creep and/or stress relaxation.

11. Fuel swelling and gas release model does not include nucleation, migration and coalescence of bubble distributions and their interaction with structural defects.

12. No clad failure criteria are incorporated; failure is inferred from the computed stress-strain state of the fuel pin. 
13. Fission gas release rate for each fuel region is temperature independent.

LIFE- 2 :

The following LIFE-1 limitations apply to LIFE 2:

$\# 1,3,4,5,6,7,9,10$, and 11 .

LIFE-3:

The following LIFE-1 1imitations apply to LIFE-3:

非 $1,3,4,5,7,9,11$.

\section{Future Efforts}

The following are scheduled for short-term improvements in LIFE-3:

1. Overall material property correlation and mechanistic model upgrading and improvement.

2. Improved clad corrosion and failure criteria.

3. Time-dependent plastic flow of fuel and clad.

4. Oxygen redistribution.

5. Solid fission product migration, precipitation and release.

6. Fuel-clad chemical reaction.

7. Improved fuel swelling, cracking and healing models.

Long-term efforts will be directed to development of a LIFE-4 version of the code. This version will improve the models and methodology of LIFE- 3 and will possibly include:

1. 2-D analysis.

2. Transient (overpower, loss-of-coolant) response.

3. Mechanically integrated axial analysis.

Interface/Overlap

SAS, MELT, GRASS/SIEX, BEHAVE

\section{$\underline{\text { References }}$}

LIFE-1 :

1. V. Z. Jankus and R. W. Weeks, LIFE-1, A FORTRAN IV Computer Code for the Prediction of Fast-Reactor Fue1-Element Behavior, ANL-7736 (November 1970 ). 
2. V. Z. Jankus and R. W. Weeks, "LIFE I, A History-Dependent Analysis of Fast Reactor Fue1 Element Behavior," ANS Trans. 13, 2 (November 1970) 830.

3. R. W. Weeks, V. Z. Jankus, M. Katsuragawa and J. D. B. Lambert, "Analysis of Mixed-Oxide Fuel Element Irradiations Using the LIFE-1 Computer Code," Proc. ANS Topical Meeting on Fast Reactor Fuel Element Technology, New Orleans, April 1971.

LIFE-2:

4. V. Z. Jankus and R. W. Weeks, "LIFE-II A Computer Analysis of Fast Reactor Fuel-Element Behavior as a Function of Reactor Operating History," Nuclear Engineering Design, 18 (1), 86 (1972).

5. R. F. Hilbert, et al, "Evaluation of Material Property Correlations Used in LIFE-II," GEAP-13967, June 1973.

Fue1 Restructuring:

6. Nichols, F. A., Behavior of Gaseous Fission Products in Oxide Fuel Elements, WAPD-TM 570 (October 1966).

Plutonium Migration:

7. Poeppel, R. B., Swelling Mechanisms and Models for Oxide Fuel ANL-7577 (Apri1-May 1969).

Fuel Therma1 Conductivity:

8. A. Biancheria, et al, Westinghouse Report WARD-4135-1 (September 1969). Hot Pressing:

9. R. C. Rossi and R. M. Fulrath, Final Stage Densification in Vacuum HotPressing of Alumina, J. of Am. Ceram. Soc., 48 (1965) 558.

Fuel Cracking:

10. R. F. Canon, J. T. A. Roberts and R. J. Beals, Deformation of UO 2 at High Temperatures, J. Am. Ceram Soc., 54 (1971) 105.

Time-to-Rupture Correlation

11. C. Y. Cheng and R. W. Weeks, RDP Progress Report (ANL), July 1971. 
MARGE/SLUMP

\section{Purpose}

Predicts molten fuel inventory in overpower LMFBR fuel pins due to overenrichment and/or loading errors.

\section{Status}

A. Development: Developed at ANL from the MARGE code.

B. Availability: Documentation on MARGE/SLUMP is available only in ANL intra-lab memos. MARGE documentation appeared in 1971.

C. Utilization: Used by ANL to predict molten fuel inventory in overpower pins for fuel element failure propagation studies.

\section{Problems Solved}

MARGE/SLUMP is a modification of the MARGE code, which was developed to predict the melting fraction in LMFBR fuel pins. MARGE/SLUMP used a one-dimensional model to calculate amount of fuel relocation and size of molten pool in an overpower pin.

\section{Models}

MARGE: Carries out a series of l-D radial calculations at various axial levels along the fuel pin to determine the amount of fuel melting at each axial level. MARGE does not allow any axial relocation (slumping) of molten fuel.

IARGE/SLUMP: Allows axial relocation of molten fuel, which is expected in reality since molten fuel should slump downward along the central void created by high-temperature fuel restructuring. MARGE/SLUMP has two options for molten pool formation:

1. With bridge: Molten fuel does not slump all the way down to the bottom of the central void, but only to an axial level where the heat transfer is sufficient to solidify the molten fuel at the radial center; this forms a solid fuel bridge with molten fuel above and void below. The formation of a fuel bridge results in a larger molten fuel pool and, therefore, is a more conservative case.

2. Without bridge: Molten fuel is assumed to slump downward and fill up the central void in the lower portion of the fuel pin. This forms a molten pool.

\section{Limiations}

1. No axial heat conduction. 
2. Fuel relocation results must be processed manually.

\section{Future Efforts}

None in progress.

Interface/Overlap

- I -

$\underline{\text { References }}$

D. H. Thompson and W. W. Marr, "Prediction of Maximum Temperature or Melting Fraction in a LMFBR Fuel Element," Nuclear Engineering and Design, 17: 361-370 (1971). 
MELT

\section{Purpose}

A multi-channel neutronics, thermal-hydraulics acc' ent analysis code simulation of fast reactor behavior from accident inception to the start of core disassembly r to nuclear shutdown.

\section{$\underline{\text { Status }}$}

A. Development: MELT-I was developed at BNWL, MELT-II and MELT-III were developed at HEDL. MELT-III is current development version at HEDL.

B. Availability: MELT-I documented appeared in 1968; operational at HEDL. MELT-II documented appeared in 1972; operational at HEDL. MELT-III is operational at HEDL and documentation is under preparation for release.

MELT versions run on the CDC CYBER-74 and CDC 7600.

C. Utilization: Primary code used for TOP HCDA analysis in FFTF.

\section{$\underline{\text { Problems Solved }}$}

1. Simulation of unprotected TOP accident in an LMFBR.

2. Provides backup capability for unprotected LOF HCDA in form of scoping and support analysis.

\section{Mode1s}

MELT-II: MELT-II represents a complete revision of the earlier MELT-I program. The major improvements include a detailed heat transfer package, treatment of variable material properties, and the capability for treating coolant expulsion due to sodium voiding, fission gas release, or a molten fuel-coolant interaction. Further, to facilitate continuity in the analytical investigation of major fast reactor excursions, the MELT-II program was constructed to directly interface the VENUS two-dimensional core hydrodynamic disassembly program. If disassembly conditions are established, the fine structure temperature information is integrated to conform to the $R-Z$ spatial mesh structure used in VENUS and this input, along with the power distribution and all reactivity feedback components, is used directly as the starting point for the disassembly phase in VENUS. In addition, the core is scanned for liquid sodium content to determine the effective Doppler coefficient and to establish whether a sodium-in or sodium-out equation-of-state should be employed at each particular mesh point in the hydrodynamics calculation. 
MELT-III: Similar in structure to MELT-II, with some improved models.

1. Geometry

Multiple channels for core mockup (up to 20).

Multiple coolant loops (up to 3 ) coupled by neutronics model.

2. Neutronics

A lumped parameter kinetics routine with spatially weighted reactivity feedback models including Doppler broadenins, Euel redistribution and coolant density decrease and expulsion. The method used to solve the kinetics equations is stable for very substantial increases in the power per step. Accuracy is controlled by forcing a recalculation of the temperature, feedback terms, etc., at a reduced time step if the power computed using an extrapolated feedback in the first pass does not agree, within a specific criterion, with the power computed using the actual feedback. Further, time step size increases can be accomplished for the slow moving portions of the transient by utilization of a zero neutron lifetime approximation. Reactivity feedback due to density changes or motion of core constituents is computed by searching input worth tables.

3. Heat-transfer

Detailed heat-transfer calculations are made for selected fuel pins, each of which is normally assumed to be representative of all pins within any set of subassemblies. Heat transfer calculations are accomplished by an implicit scheme, removing any geometric constraint on the size of the time step.

4. Coolant voiding

a. One operational model for sodium voiding - molten fuel/fission gas release from failed fuel (FCI). FCI zone is a homogeneous mixture of fuel, fission gas, sodium vapor, and condensed sodium.

b. Fission gas release directly from fission gas plenum prior to FCI (to initiate a bubble) or after an FCI (to dilute bubble and retard fuel sweepout) were previously operational, but nave been removed from the principal HEDL version due to local HEDL machine limitations.

c. Boiling model currently under development.

5. Hydraulics

a. Pins within the fuel drive subassemblies are hydraulically coupled at the inlet and outlet plenums.

b. Flow path around primary loop is closed.

c. Two separate hydraulic flow paths can be used to simulate a size break on independent closed loops. 
d. Modeling emphasis on inlet plenum to pool level detail (not yet operational) - a multi-media hydraulic formulation allows explicit pressure gradients to be calculated across each material type.

6. Steady-state fuel in characteristics: Provided by direct machine coupling to SIEX II, which calculates restructuring patterns.

7. Fission gas release - models for gas release from plenum and from fuel matrix.

8. Fuel failure - provided by empirical failure criteria correlations.

9. Fuel motion - fuel motion is allowed to occur in three ways: Movement of fuel axially in pin, movement of molten fuel from ruptured pin into channel, movement of fuel within channel. After clad failure, fuel/gas mixture moves inside fuel pin through orifice in clad wall and into coolant stream. HOTPIM hydrodynamics model, for molten fuel flow inside cladding, is currently used.

10. FCI model with fragmentation and mixing.

\section{Limitations}

1. A point kinetics formulation is used which is probably non-conservative. It is suspected, however, that significantly larger uncertainties are inherent in the present model for molten fuel motion and coolant expulsion.

2. Detailed loading on the cladding cannot be done because only one fuel material type is treated and fuel expansion, due to density reduction or fission gas release, is not taken into account.

3. A natural source of pin failure incoherency, due to statistical fluctuations and differing power ratings within subassemblies and ring of subassemblies, is ignored, although the program can be modified to partially account for the latter effect.

4. Limited integral experimental verification - scale-up of TREAT experiments is difficult.

\section{Future Efforts}

1. More mechanistıc FCI, boiling, fuel sweepout and plating model: Continue development, checkout and improvement of boiling model (need exists to provide more definitive experimental data on flow regimes during boiling). Improve evaporation/condensation model in FCI bubble.

2. Additional experimental tiedown with TREAT and out-of-pile data.

Interface/Overlap

VENUS / SAS, HOPE 


\section{References}

Alan E. Walter, "MELT-I, A Simplified Meltdown Code for Fast Reactor Safety Analysis," BNWL-944, Battelle-Northwest, Richland, Washing ton (1968).

A. E. Walter, et a1., "MELT-II - A Two-Dimensional Neutronics-Heat Transfer Program for Fast Reactor Safety Analysis," HEDL-TME 72-43, April 1972.

A. E. Waltar, et al., "MELT-III - A Neutronics, Thermal-Hydraulics Computer Program for Fast Reactor Safety Analysis," HEDL-TME 74-47, Draft, October 15, 1974. 


\section{Purpose}

Analysis of the dynamic response of reactor head, vessel and support systems to HCDA pressure loads.

\section{$\underline{\text { Status }}$}

A. Development: Developed at HEDL.

B. Availability: No documentation is available. Operational at HEDL on CYBER-74.

C. Utilization: MOTION is the primary code used by HEDL for prediction of forces and movements of the FTR head, vessel and supports under HCDA loadings. It was also used in scale-up to full-sized FTR of results from scale-model experiments which simulated the mechanical response of FTR to HCDA pressure loads (Ref. 1).

\section{Problems Solved}

The code calculates the following as a function of time for HCDA pressure loads :

1. Displacements, velocities and accelerations of the reactor vessel, vessel support ring, vessel support structures and reactor head.

2. Stresses and strains in bolt systems which tie components together, including the head stretch bolt system.

\section{$\underline{\text { Models }}$}

1. Geometry

Al1 models are 1-D, allowing only vertical displacements.

2. Structure Mode1

The code models the large reactor structures with up to five lumped mass points with elastic-plastic springs and damping elements connecting the masses. The five masses are usually taken to be the reactor vessel, vessel support ring, vessel support structure, and the reactor head, with two masses used for the head to simulate head doming effects.

3. Bolting Systems

Bolting systems which tie components together are represented as springs with bi-linear force-deflection characteristics to provide for elastic and plastic strains. 
4. Reinforced Concrete Support Structures

Represented by force-deflection characteristics.

5. Input

Requirement code input includes a force-time history for any two masses, stress-strain properties of bolting systems at high strain rates, forcedeflection characteristics and damping coefficients.

\section{Limitations}

1. The code performs a simple 1-D, lumped mass and spring calculation and therefore cannot handle the details of continuum material dynamic response required to accurately predict mechanical failures.

2. The bolt model does not accurately simulate plastic strain effects for relaxing loads since bolts are treated as springs which provide the same force-deflection characteristics for decreasing strain following plastic strain as for initial force-deflection characteristics.

\section{Future Efforts}

None planned.

Interface/Overlap

$-1-$

\section{References}

1. G. L. Fox, D. Stepnewsli \& \& L. M. Polentz, "Scale-up of Test Results from Simulation Experiments of an HCDA in the FFTF," HEDL-TME-74-54. 
NAHAMMER

\section{Purpose}

Analysis of 1-D pressure pulse propagation in a fluid piping system.

Status

A. Development: Developed at ANL/CT.

B. Availability: Operational at ANL on IBM S/360-195. Documentation is available (Ref. 1$)$.

C. Utilization: Has been used by ANL for (a) prediction of pressure pulse transmission and flow development following an FCI in the SLSF operating in the ETR and (b) analysis of pressure pulse transmission resulting from a sodiumwater reaction in the secondary sodium network of EBR-II.

\section{Problems Solved}

NAHAMMER analyzes plane-wave pressure pulse transmission in a closed hydraulic network system consisting of connected series or parallel l-D pipe sections, pipe junctions and various components. The analysis is valid for pressure wave amplitudes in liquid sodium up to about 5800 psi. The code contains an FCI model to internally calculate a source pressure.

\section{Mode1s}

\section{Geometry}

The piping network is modeled by a subdivision of the system into a number of connected $1-D$ sections having uniform cross-sectional area, the sections being joined at junctions which are defined by mathematical conditions.

\section{Fluid Dynamics}

The code is based on a l-D linearized fluid-hammer analysis for isentropic, inviscid flow of a homogeneous, isotropic, perfectly elastic fluid. The l-D conservation equations of mass and momentum for unsteady isentropic, inviscid, compressible flow in a passage of constant cross-section are simplified by introducing an expression for the sonic speed which eliminates variations in density. The equations are then 1 inearized by assuming that the flow velocity is small compared to the sonic speed (less than a 1 to 100 ratio). For liquid sodium, this assumption limits the maximum pressure pulse amplitude which can be handled to about 5800 psi. Linearization of the fluid-hammer equations results in a description of the pressure wave which is similar to that of a longitudinal wave in a solid such that an acoustic plane-wave equation can be used to describe the pressure wave transmission in a fluid like that of sound wave transmission in solids. 
3. Method of Solution

The method for solution of the linearized fluid-hammer equations is based on the method of characteristics solution technique, but is unique in that it uses the analytical solutions of the $1-D$ wave equation in place of the compatability equation of the more conventional method of characteristics. The numerical solution is obtained by a simple superposition technique for tracing the waves traveling along each characteristic and extends the solution from one constant time line to the next. Using the predetermined constant characteristic net, the spatial interpolation is eliminated, thus maintaining the pressure wave in its full amplitude in the numerical procedure. This contrasts to the nonlinear fluid-hammer analysis in which the pressure peaks are always flattened in the interpolation procedure.

4. Pressure Source

The source region is a special region through which waves are not allowed to traverse. The user has two options for a pressure source:

a. Input pressure-time history

b. FCI generated pressure which is calculated by a subroutine based on the ANL rate-limited parametric model (Ref. 2). An acoustic constraint on expansion of the FCI interaction zone is assumed in calculating the pressure-temperature-time history

5. Junction Conditions

The junctions separating the 1-D pipe sections are described by one of the following conditions which, when appropriate, are given for both positive and negative flow directions:

a. Diameter discontinuity: an expansion or contraction is treated with a loss coefficient correlation (all loss coefficients are based on steady-state incompressible flow)

b. Elbow: uses elbow loss coefficient correlation

c. Partial blockage or orifice-like restriction: treated the same as an elbow, but with an orifice loss coefficient correlation

d. Tee: joins from 3 to 6 sections.

e. Acoustic-impedance discontinuity: for sudden changes in fluid temperature

f. Dummy junction: to provide a boundary condition for the pressure source or to accommodate exceptionally long pipe sections.

g. Dead end or full blockage

h. Free surface: the gas pressure above a gas liquid interface in a partially filled tank or plenum remains unchanged 
6. Cavitation

The cavitation effect is precluded by replacing any negative pressure by the saturation pressure of the fluid.

7. EOS

Thermodynamic properties of sodium are taken from Golden and Tokar (Ref. 3).

\section{Limitations}

1. Limited to homogeneous, isotropic, inviscid fluids.

2. Maximum pressure wave amplitude is restricted to pressure such that the wave velocity is at least a hundred times less than the sonic speed (about 5800 psi in liquid sodium).

3. No cavitation or shock waves are allowed.

4. The linear treatment of the fluid-hammer equations is not extendable to nonlinear effects which are required to treat such phenomena as a sodium-water reaction zone or sodium slug evacuation through a relief system.

Future Effort

None

Interface/Overlap

- /NATRANSIENT, TRANSWRAP, HAMOC

\section{$\underline{\text { References }}$}

1. W. L. Chen, D. H. Thompson, and Y. W. Shin, "NAHAMMER, A Computer Program for Analysis of One-Dimensional Pressure-Pulse Propagation in a Closed F1uid System," ANL-8059, May 1974.

FCI Mode1

2. D. H. Cho, R. O. Ivins, and R. W. Wright, "A Rate-Limited Model of Molten Fuel/Coolant Interactions: Model Development and Preliminary Calculations," ANL-7919, March 1972.

EOS

3. G. H. Golden and J. V. Tokar, "Thermodynamic Properties of Sodium," ANL-7323, August 1967. 


\section{Purpose}

A transient thermal-hydraulic analysis code for description of a sodium-cooled reactor behavior subject to postulated transients such as resulting from a pipe rupture accident.

\section{$\underline{\text { Status }}$}

A. Development: Under development by BNL. Effort centered on a modification of the RELAP-4 code, used for water-cooled reactor analysis, to include sodium coolant properties.

B. Availability: Based on RELAP-4, which has been documented (December 1973) by ANC. NALAP is in early development stage for use on CDC 7600 .

C. Utilization: Used by BNL to perform thermal-hydraulic analysis of FFTF subjected to a double-ended rupture of the vessel inlet pipe in one of the three primary loops.

Problems Solved

Describes the thermal-hydraulic behavior of a sodium-cooled nuclear reactor subjected to postulated transients as those resulting from loss of coolant, pump failure or power excursions. Calculates (1) fluid conditions such as flow, pressure and mass inventory, (2) thermal conditions such as surface temperatures, temperature profiles and energy distributions and (3) heat fluxes in power generating and dissipating elements.

$\underline{\text { Models }}$

User defines geometric features of the system to be analyzed. Code then solves an integral form of the fluid conservation and state equations applied to each user definea control volume. Currently, the number of these control volumes is limited to 20 ( 75 in RELAP-4) and the number of junctions (flow paths) between volumes is limited to les a than 10 . By increasing array size, these limits can be raised to the computer capacity limit.

\section{$\underline{\text { Limitations }}$}

1. Reactor core is currently modeled as a "point" core, i.e., the entire heated portion of the core is represented by a single control element.

2. No sodium voiding mode1.

\section{Future Efforts}

Continue development for application to FTR pipe rupture consequence analyses. 
Interface/Overlap

- /DEMO, IANUS

\section{References}

K. V. More and W. H. Rettig, "RELAP-4: A Computer Program for Transient Thermal-Hydraulic Analysis," Aerojet Nuclear Company, ANCR-1127, December 1973. 
NATRAN

\section{Purpose}

Analysis of 2-D flow transients in fluid-filled cylindrical pipes.

\section{$\underline{\text { Status }}$}
A. Developed: Developed at ANL/CT. Latest version is NATRAN-II.
B. Availability: Operational at ANL on the IBM 360/195. Complete documentation has been published (Ref. 1).
C. Utilization: Has been used exclusively by ANL.

\section{Problems Solved}

Provides analysis for 2-D hydraulic transients in an axisymmetric cylindrical domain connected to a system of 1-D domains, with the pressure source prescribed as an input pressure-time history located in (a) the 2-D domain or (b) a connected I-D network, where either an input pressure-time history or a sodium-water reaction can be specified. NATRAINSIENT is used as a subroutine to provide (b). The user has three problem solution options in using NATRAN-II:

1. Treating problems involving non-zero initial velocities by calculating initial steady-state flow conditions consistent with the 1-D NATRANSIENT description.

2. Solving a completely closed flow problem in a cylindrical container bounded by rigid walls on both ends (bypasses 1-D NATRANSIENT subroutine).

3. Purely 1-D calculations (bypasses 2-D calculation and uses NATRANSIENT).

\section{Mode1s}

1. Fluid flow

The governing partial differential equations are the 2-D (axisymmetric cylindrical), compressible, time-dependent conservation equations of continuity, momentum and energy. All viscous effects, body forces and heat transfer are neglected.

2. EOS

Same as NATRANSIENT.

3. Method of Solution

The original equations are reduced to a set of first order, non-linear, hyperbolic partial differential equations which provide a fluid-hammer (slightly compressible) description of sodium flow. These equations are 
converted by the method of characteristics, to a system of integral equations written along bicharacteristic curves. The solution is constructed in a step-by-step procedure by approximating the integral equations by the trapezoidal formula. With spatial derivatives of the dependent variables eliminated from the result difference relations, the solution at any point is obtained explicitly by a linear combination of the remaining difference relations.

4. Pressure Source Input

User has two options:
a. 2-D pressure-time input
b. 1-D pressure-time input (or sodium-water reaction) specified by NATRANSIENT.

\section{Limitations}

1. Dimension limitations are as follows:

a. Grid points in $\mathrm{r}-$ direction: up to 30

b. Grid points in z-direction: up to 60

c. 1-D branches: up to 50

d. Nodes in a 1-D branch: up to 120

e. Junctions: up to 50

f. Surge tanks: up to 10

g. Branches joined at any one tee junction: up to 6

2. Viscosity effects are neglected in 2-D analysis.

3. A sufficiently large length-to-diameter ratio has to be allowed for both extended regions upstream and downstream of the 2-D domain, since the matching of the boundary conditions at the interface neglects any 2-D effects close to the interface.

4. No treatment of shock waves.

5. No treatment of pipe elasticity; all boundaries are assumed rigid.

\section{Future Efforts}

None defined.

Interface/Overlap

NATRANSIENT/ - 
References

1. Code Documentation:

Y. W. Shin and R. A. Valentin, Two-Dimensional Fluid-Hammer Analys is

by the Method of Characteristics in a Closed Axisymmetric Cylindrical Domain, ANL-8090, August 1974. 
NATRANSIENT

\section{Purpose}

Analysis of 1-D flow transients in a sodium piping network subject to a sodiumwater reaction from a large leak accident in a steam generator.

\section{$\underline{\text { Status }}$}

A. Development: Developed at ANL/CT.

B. Availability: Operational at ANL on IBM 360/195. Complete documentation has been published (Ref. 1).

C. Utilization: Has been applied by ANL for calculation of pressure-pulse propagation in the EBR-II secondary piping network due to a water leak in the superheater. Currently used by ANL/CT Pressure Transient Analysis Program.

\section{Problems Solved}

Calculates flow transients resulting from a sodium-water reaction and the subsequent propagation of pressure pulses throughout a connected piping network for the entire accident duration from the rapid initial transient to the final blowdown. The hydraulic network consists of a series of pipes joined by various connectors at junctions.

\section{Mode1s}

\section{Sodium-Water Reaction Dynamics}

The 1-D Zaker-Salmon model (Ref. 2) is used to characterize the reaction zone pressure, assuming an instantaneous chemical reaction. Mass and energy balances taken for a control volume enclosing the reaction product growth zone leads to two ordinary differential equations in pressure and product zone volume. These equations, along with the initial conditions determine pressure and volume for a given water-into-sodium leak rate and velocity.

2. Fluid Flow and Numerical Method

The governing partial differential equations are the 1-D, compressible, time-dependent conservation equations of continuity, momentum, and energy. The momentum equation is the complete Navier-Stokes equation in which viscous effects are limited to the treatment of wall friction using the Darcy-Weisbach law to compute friction factors based on the local velocity and pipe roughness. The Colebrook-White correlation (Ref. 3) determines the friction coefficient. The four equations (three for conservation and one for EOS) are eliminated for terms involving enthalpy and density, and are reduced to two equations, unknowns being velocity and pressure, with the density and sonic speed approximated as constants. These first-order partial differential equations are nonlinear hyperbolic having real characteristics. They provide a fluid-hammer (slightly compressible) description of sodium 
flow. These equations are reduced by the method of characteristics to a set of ordinary differential (compatibility) equations, the solution of which is extended from the given initial curve along the characteristics curve. The characteristic and compatibility equations are finite differenced and solved together with various junction conditions for a fixed space-time grid by a stepwise (explicit) numerical integration scheme.

3. EOS

The sodium EOS determines enthalpy as a function of pressure and density. Thermophysical properties of sodium are extracted from Golden and Tokar (Ref. 4).

\section{Piping System}

Forms pipe networks on flow systems from individual numbered pipe branches joined together at appropriate numbered pipe junctions. The components and flow junctions which may be treated are:

a. Sudden expansion or contraction: equations for continuity, energy and compatibility are solved simultaneously using a loss coefficient factor.

b. Tee junction: from three to six branches may be considered, with pressure loss and kinetic energy change neglected in continuity, energy and compatibility equations.

c. Closed end: a zero-velocity condition at the junction and the compatibility relation along the characteristic directed toward the junction determine the flow conditions at the closed end.

d. Surge tank or reservoir: pressure is assumed constant in the tank or reservoix. This condition and the compatibility relation along the characteristic direction to the junction determine the flow condition.

e. Far end: this condition is used when a large and complicated system network is to be simplified, providing a means of discarding part of the network with no effects on the remaining part of the system. No reflected waves are admitted to the system from the far end.

f. Dummy junction: used when the network contains a pipe branch extremely long compared to other sections and it is desirable to treat it as two or more branches.

g. Acoustic impedance discontinuity: this discontinuity, resulting from sudden change in sonic speed, is treated at the same time as a dummy junction.

h. Rupture disk: a pressure relief device is assumed to act as a closed end until it is exposed to a user-selected critical pressure. At the instant the junction reaches critical pressure, it is assumed to behave as a reservoir. A time-dependent rupture model is also available in the code. 
Loss coefficients for the pressure drops at pipe expansions and contractions are computed using formulations developed for steady flow. Pressure drop at tee junctions are neglected.

5. Pipe Dilation

The elastic response of the pipe is handled by modifying the wave speed (Ref. 5) to account for pipe expansion due to fluid pressure.

\section{$\underline{\text { Limitations }}$}

1. Piping system limitations are as follows:

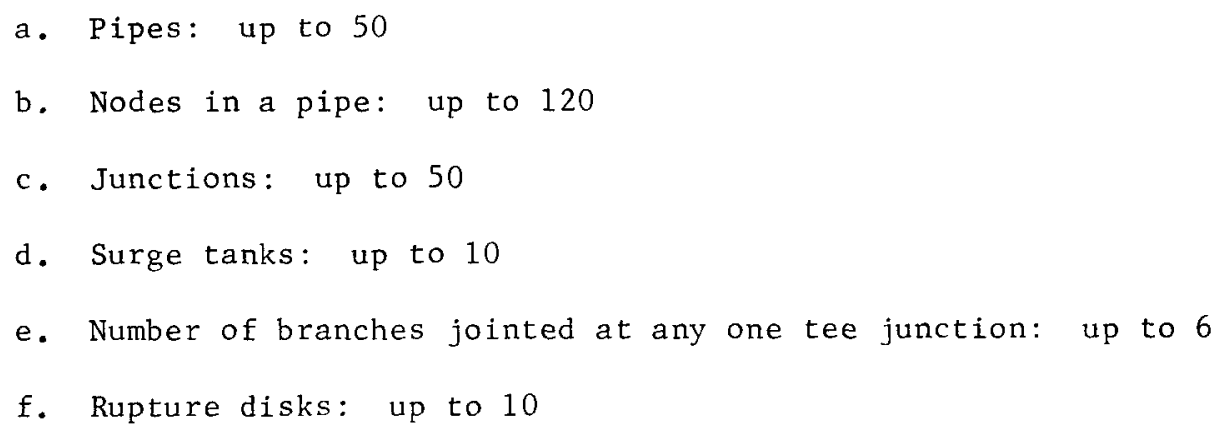

2. The 1-D nature of the code does not allow for multi-dimensional effects, such as component geometry.

3. Does not treat shock waves.

4. No treatment of gravity or cavitation.

5. Plastic pipe deformation is not accounted for.

6. Sodium-water reaction dynamics has limitations similar to TRANSWRAP I (see TRANSWRAP summary).

\section{Future Efforts}

Currently in use as base development code for ANL/CT Pressure Transient Analysis Program.

\section{Interface/Overlap}

NATRAN/NAHAMMER, TRANSWRAP

\section{$\underline{\text { References }}$}

1. Code Documentation:

Y. W. Shin, The Method of Characteristics for Analysis of Pressure Transients Resulting From Sodium-Water Reaction in Hydraulic Networks, ANL-8049

(December 1973) 
2. Sodium-Water Interaction:

T. A. Zaker and M. A. Salmon, Effects of Tube Rupture in Sodium Heated Steam Generator Units, ASME Pub., 69-WA/NE-18 (1969).

3. Friction Coefficient Correlation:

J. E. Plapp, Engineering Fluid Mechanics, Prentic-Hall, Englewood Cliffs, N.J. (1968).

4. Sodium Properties:

G. H. Golden and J. V. Tokar, Thermophysical Properties of Sodium, ANL-7323 (August 1967)

5. Pipe Dilation Effects:

V. L. Streeter and E. B. Wylie, Hydraulic Transients, McGraw-Hill, N.Y. (1967). 
ORRIBLE

\section{Purpose}

To perform thermal-hydraulic analysis of steady flow in wire-wrapped, heat generat ng rod bundles.

\section{Status}

A. Development: Developed and under improvement at HNL.

B. Availability: Currently, there are eleven optrational versions of ORRIBLE: 6 for 19 rod bundle configurations, and 5 for 37,91 and 217 rod bundles. All eleven have been documented (latest in 1974).

C. Utilization: ORNL developed code for analysis of the FFM facility, which is used for out-of-pile simulation of inlet flow blockages in LMFBR subassemblies.

\section{Problems Solved}

1. Predicts the flow and temperature distribution for steady-state single phase flow in wire-wrapped heat-generating rod bundles having any combination of flow subrhannels blocked at the inlet.

2. Due to its rapid execution, is useful in making parametric studies and in correlating data from tests of unblocked FFM bundles.

3. The eleven versions of ORRIBLE will calculate the following rod bundle configurations:
a. 19-, 37-, 91- and 217-rod bundles
b. Hexagonal ducts
c. Scalloped ducts
d. Left-handed pitch wire wrap

$\underline{\text { Models }}$

1. Transverse interactions between flow subchannels are due to turbulent interchange, pressure-induced diversion cross-flow, directed sweeping cross-flow due to wire-wrap, and transverse thermal conduction. Expressions for the transverse interactions are used in the equations of conservation of mass and energy to establish the thermal and hydrodynamic characteristics of the system.

2. Salient feature of ORRIBLE is the implicit use of the equation of conservation of axial momentum by obtaining an expression for pressure-diversion cross-flow in terms of the axial mass velocity 
in the two adjacent flow channels. By so doing, pressure is eliminated as a variable, and the solution is obtained without recourse to iterative techniques.

\section{Limitations}

Some of the basic assumptions of the codes are:

1. Pressure induced cross-flows are computed assuming that a two-channel model is applicable to a multi-connected system.

2. Sweep cross-flow is taken to be significant only while the spiral wire is within $120^{\circ}$ from the inter-channel gap, with the maximum value occurring when the wire wrap is in the gap between two adjacent rods.

Interface/Overlap

- / THT, SIMPLE, COBRA

\section{$\underline{\text { References }}$}

J. L. Wantland, "ORRIBLE - A Series of Computer Programs for Flow and Temperature Distribution in LMFBR Fuel Rod Bundles of Different Sizes and Configurations," ORNL-TM-4384, March, 1974.

J. L. Wantland, "ORRIBLE - A Computer Program for Flow \& Temperature Distribution in LMFBR Fuel Rod Bundles," ORNL-TM-3516, October, 1971. 


\section{Purpose}

Neutronic-hydrodynamic analysis of reactor behavior resulting from promptcritical reactivity insertion transients.

\section{Status}

A. Development: Developed and under improvement at LASL. PAD evolved from the RAC code (Ref. 1).

B. Availability: Operational at LASL on CDC 7600 and 6600 and at U. of Arizona on CDC 6400. To be released during 1975.

C. Utilization: Has been used extensively by LASL for analysis of destructive and non-destructive experiments involving prompt-critical reactivity insertions and has been applied to analysis of reactivity transients for various power reactor concepts (fast, intermediate, light water and solution reactors.

\section{$\underline{\text { Problems Solved }}$}

1. Calculation of non-destructive experimental prompt-critical transients for temperature rise and total fissions.

2. Calculation of destructive experimental prompt-critical transients for explosive energy release and prediction of threshold for an explosion.

3. Calculation of destructive and non-destructive regimes for postulated molten fuel recriticality accidents.

4. Calculation of kinetic energy imparted to the sodium slug (sodium hammer) for postulated reactor prompt-critical excursions.

5. Calculation of simple thermodynamic systems to compare conversion of internal energy to kinetic energy with thermodynamic theory for work done by adiabatically expanding systems.

6. Reactor prompt-critical transient parametric studies varying Doppler coefficient, FCI heat transfer rates, and reactivity insertion ramp rates to provide bounding estimates of explosive energy releases for various initial core conditions.

Models

The basic technique of PAD is similar to that used in the AX-1 code (Ref. 2). The EOS, however, is quite different. 
1. Geometry

PAD is 1-D, with options for symmetrical spherical, planar and cylindrical geometries. The calculated system is divided into a series of computational nodes or lumped mass points.

2. Neutronics

Based on the DTF code (Ref. 3), which uses 1-D $S_{n}$ transport theory. The neutronics serves to define the neutron flux and ${ }^{n}$ fission energy density assigned to each calculated mass point. Doppler reactivity feedback is included.

3. Hydrodynamics

Material motion is described by the 1-D fluid-hammer (i.e., slightly compressible) equations of hydrodynamics in Lagrangian coordinates.

4. Calculational Scheme

The fission energy raises temperatures and pressures and the cyclic calculation for each mass point proceeds through acceleration, velocity, geometric change, resulting reactivity change and then again to energy production, temperatures and pressure. The temperature calculation includes thermodynamic work as well as deposition of fission energy.

5. Heat Transfer

PAD allows two different materials at a mass point, with the fission energy deposited in one material allowed to be transferred to the other when preset conditions are reached. The rate of heat transfer between materials, as between fuel and sodium, may take several optional forms. The heat transfer rate may be constant, linear (a function of the temperature difference) or exponential.

6. EOS

The EOS consists of a set of functions and coded decisions which, with specific constants, describes a material in the condensed and the vapor state and provides an orderly transition between these states. Pressure is given as a function of temperature and density. Specific heat and latent heats are included in a broad definition. Allowance is made for a solid-liquid phase change by providing the option for a heat sink at a specific temperature. The functional form for the condensed state pressure is only adequate for small changes in density and pressure. The expression for the fuel vapor pressure is the ideal gas law, while the sodium pressure is given by a van der Waal's equation. PAD includes EOS data for uranium metal, uranium dioxide, graphite, sodium, zirconium hydride, uranium hexafluoride and water.

\section{Limitations}

1. Limited to 1-D calculations. 
2. Only two materials are allowed per mass point.

3. Heat transfer model does not include time-dependent processes.

4. EOS formulation not applicable to large changes in temperature or density.

Future Efforts

1. Upgrade to two dimensions.

2. Improve input data and models for heat transfer and EOS.

3. Analysis of integral experiments (Godiva series, Snaptran series, and Kiwi-TNT).

4. Applications to postulated LMFBR reactivity insertion accidents.

Interface/Overlap

- /VENUS

\section{$\underline{\text { References }}$}

1. C. G. Chezem and W. R. Stratton, "RAC, A Computer Program for Reactor Accident Calculations," LAMS-2920 (January 1963).

2. D. Okrent, R. Layarus, et a1, "AX-1, A Computing Program for Coupled Neutronics-hydrodynamics Calculations on the IBM 704," ANL-5977 (May 1959).

\section{Neutronics:}

3. Bengt G. Carlson and Kaye D. Lathrop, "Transport Theory, The Method of Discrete Ordinates," LA-3251-MS Revised (August 1965).

Model Description and Experimental Validation:

4. W. R. Stratton, et a1, "Reactor Power Excursion Studies," given at International Conference on Engineering of Fast Reactors of Fast Reactors for Safe and Reliable Operation, Karlsruhe, October 9-13, 1975. 


\section{Purpose}

Analysis of the probability of fuel pin cladding structural failure under steady-state and transient internal fission gas pressure loading.

\section{Status}

A. Development: Developed and under improvement at GE-BRD. PECS-III is current development version.

B. Availability: PECS-I is operational on the GE-635 and has been documented (Ref. 1). PECS-II is operational on Honeywe11-6000 at $G E$ and $C D C-7600$ at $L B L$, and has been documented (Ref. 2). PECS-III is developmental.

C. Utilization: Has been used to support the development of conventional fuel rod design criteria and to relate required design.

\section{Problems Solved}

The PECS codes calculate probability distributions for the time-to-failure of sealed plenum fuel pins operating under clad loading caused solely by fission gas pressure. These failure probability distributions are calculated for each of several representative fuel pins in the core and the mean number of failed pins is then estimated. The main advantage of this probabilistic approach is that it takes into account in a logical and systematic way the effects of uncertainties in environmental conditions (e.g., temperature and burnup), dimensions (e.g., fuel pin and pellet diameter), physical properties and laws (e.g., correlation of stress, temperature and time to failure). Thus, estimates of fuel pin failures need not be based on the unrealistic assumption that all fuel pins within a certain group fail and that failures occur simultaneously.

PEC-II calculates the probability of cladding failure at the axial position of maximum cladding temperature. Cladding hoop stress in a thin cylinder caused by fission gas pressure is calculated, and clad failure is assessed using Life Fraction Damage, Strain Fraction Damage, thermal creep strain, or stress criteria. Cladding wastage due to fuel-clad corrosion, sodium corrosion, fabrication defects, fretting and wear are considered. Cladding and gas temperatures vary with time and need not be continuous in time. Fifty fuel rods are analyzed simultaneously to represent a core loading, although the number is limited only by the computer memory available. Seventeen input parameters are specified as probability distributions. Output includes probability distributions describing the failure time of each rod, the value of strain, etc., at any specified time, and the number of failed rods in the core at any time. 
Models

PECS-I

The principal difference between PECS-I and II is that PECS-II is more optimized in computer running time due to an improved integration procedure and an added importance sampling. Other differences between PECS-I and II include the addition in PECS-II of stress, strain and strain damage failure criteria and the calculation of a probability distribution for the number of core-wide failures.

PECS-II

1. Geometry

A11 fuel pins in the core are included within a calculation by defining groups (typically about 50) of pins and assuming that all pins within a group are identical. The code analyzes one pin from each group. The cladding of each analyzed pin is modeled as a thin-walled, pressurized cylinder. One axial location on each pin is considered. The fuel pins are analyzed simultaneously to account for random and systematic uncertainties in a proper manner.

2. Fission gas production and release

The fission gas inventory of a fuel rod is composed of initial fill gas, adsorbed gas in fresh fuel, and fission gas. Adsorbed gas is proportional to the mass of fuel in the active core and axial blanket regions. Fission gas is assumed to be produced only in the active core region, and is proportional to burnup and fuel mass. The fraction of fission gas released from the fuel is described by an empirical correlation which is a function of burnup, average linear power, and fuel density.

3. Cladding stress and strain analysis

The hoop stress in the cladding is determined by the gas pressure multiplied by mean clad radius divided by the effective clad thickness. The effective clad thickness is found by subtracting the effective depth of intergranular corrosion due to fuel-clad chemical reaction from the initial, hot clad thickness. External corrosion caused by flowing sodium is also subtracted from the initial clad thickness. Time-independent reductions in clad thickness are also included to account for scratches, fretting, and wear. Gas pressure acting on the axial section of interest is assumed to equal the gas plenum pressure. Thermal creep strain in the clad is found by neglecting primary and tertiary thermal creep and using an empirical correlation for thermal creep rate. Irradiation-induced creep is neglected. Creep rate is evaluated at the mean clad temperature. Circumferential variations in temperature and the strain distribution through the cladding thickness are neglected. In calculating Life Fraction Damage, the time-to-rupture is found from a correlation which is a function of temperature, stress, fluence, and sodium exposure time. The strain limit used to calculate Strain Fraction Damage is also a function of temperature, fluence, and sodium exposure. 
4. Thermal mode1

$\mathrm{Clad}$ and gas plenum temperatures are specified as independent input variables which are functions of time. Each temperature is represented by a second-order polynomial within each of five separate time intervals. Temperature discontinuities are allowed between intervals to represent refueling, transients, etc. No fuel temperature calculation is performed.

5. Clad wastage

Fuel-clad corrosion is represented by an empirical correlation which is a function of cladding temperature and burnup. The fraction of this corrosion which is effective in reducing clad strength is represented by a correlation which is a function of fluence and clad temperature. cladding corrosion by flowing sodium is calculated as a function of clad temperature and the oxygen content of sodium. Sodium velocity effects are neglected. The effect of flowing sodium on clad composition and strength is represented by terms in the time-to-rupture and strain limit correlations. Wastage due to fretting and wear is represented by a constant reduction in thickness applied at beginning of life.

6. Probabilistic models

Monte Carlo simulation is the basic probabilistic technique used. Monte Carlo sampling is performed such that systematic uncertainties affect all pins in the core in the same way, while random uncertainties affect each pin differently. Care is taken to ensure that random sampling does not destroy the important relationships between variables. Importance sampling or biasing is used to reduce the cost of a typical problem, reducing the number of Monte Carlo samples required to obtain adequate statistics.

\section{Limitations}

1. Many of the models and correlations used in PECS-II have been validated in nonprototypic experiments. The overall model has not been validated.

2. Fission gas pressure is the only clad loading mechanism represented by the model. There is no fuel-clad mechanical interaction model.

3. The contribution to rod failure probability of lower-temperature axial sections than the one chosen is not represented.

4. Although the model can represent rapid gas pressure increases, the material property correlations are not valid for these conditions, particularly when significant fuel melting occurs.

5. Failure is assessed by one of four options. Failure should be assessed using selected combinations of these.

6. Neutron flux is not variable between fuel rods.

7. Clad and plenum temperatures are assumed to be statistically independent when, in fact, a significant dependence exists. 


\section{Future Efforts}

Improvements to the PECS-II code will be made as part of the development of PECS-III and POPS (see POPS summary). Present plans for development include the following:

1. Validation of PECS-II by comparison with experimental data from EBR-II.

2. Addition of fuel-clad mechanical interaction as a clad loading mechanism.

3. Addition of neutron flux as a parameter which can vary between fuel rods.

4. Introduction of a cladding temperature drop calculation to relate clad and gas plenum temperatures (plenum temperature is approximately equal to coolant temperature at the top of the fuel column).

5. Development of transient overpower clad loading mechanism and review of material properties for applicability during transient and fuel melting conditions (see POPS summary).

Interface/Overlap

- I -

\section{$\underline{\text { References }}$}

PECS-I

1. G. E. Orr and M. I. Temme, "PECS - A Computer Code for the Probabilistic Evaluation of cladding Stress Caused by Fission Gas Failure," GE- BRD, NEDE-13845, September 1972.

PECS-II

2. GEAP-13993, "PECS-II: A Computer Program for the Probabilistic Evaluation of Fuel Rod Failure Caused by Fission Gas Pressure," M. I. Temme and D. B. Atcheson, June 1974 . 
PIFITE

\section{Purpose}

Analysis of the thermal and pressure consequences in a gas pipe subjected to sodium flooding as the result of an HCDA.

\section{Status}

A. Development: Developed at HEDL.

B. Availability: No documentation is available. Operational at HEDL and W-ARD.

C. Utilization: Used by HEDL and W-ARD for HCDA analysis of cover gas and low level flux monitor piping penetrations in the reactor head.

\section{Problems Solved}

The code calculates flooding (transient fluid injection) in a gas pipe by liquid sodium driven under HCDA pressures, the forces on the pipe elbows due to transient momentum and pressure effects of flooding and the pipe wall temperatures as the sodium heats the pipe.

\section{Models}

1. Geometry

The gas pipe is a single continuous pipe composed of any number of straight pipe sections connected at elbows and is of uniform diameter along its entire length. The straight pipe sections may be of any length and elevation slope and the elbows may be of any turn angle. All equations are $1-D$.

2. Fluid Flow and Method of Solution

The 1-D fluid equations for the sodium flow are solved using the fourthorder Runge-Kutta-Gill method.

3. Heat Sources and Pipe Insulation

The pipe may have a heater (Calrod) and insulation along part or all of its length.

4. Heat Transfer

The 1-D heat transfer equations include the following:

a. Convection from sodium to the pipe wall (inside surface). 
b. Conduction through the pipe wall.

c. Convection from pipe wall (outside surface) to air trapped inside the insulation.

d. Convection from air trapped inside insulation to the heater and insulation.

e. Radiation from pipe wa1l (outside surface) to heater and insulation.

f. Conduction inside heater and through insulation.

g. Convection from insulation to surrounding gas atmosphere.

\section{Limitations}

1. The gas pipe has a constant diameter along its entire length.

2. The gas pipe cannot branch.

\section{Future Efforts}

No code refinements are planned.

Interface/Overlap

$-1-$

\section{References}

"HCDA Requirement and Loading for FFTF Design Evaluation," HEDL-FS-257 (to be published). 


\section{Purpose}

Analysis of molten fuel ejection from a TOP fuel pin into a flowing sodium coolant channel.

\section{Status}

A. Development: Initial development was at Northwestern University (Ref. 1). PLUTO-1 was developed at ANL/RAS. PLUTO-2 is current development version at ANL/RAS.

B. Availability: PLUTO-1 (Ref. 2) is operational at ANL on IBM 360, at LBL on CDC- 7600 and at BNL. PLUTO- 1 will not be released in lieu of release of SAS 3D, which will contain PLUTO-2.

C. Utilization: PLUTO-2 will be incorporated into SAS 3D to improve TOP FCI modeling capabilities. It may also be used to furnish an improved LOF fuel motion model.

\section{Problems Solved}

The PLUTO codes predict the phenomena associated with the movement of molten fuel out of a TOP fuel pin which has loaded the clad sufficiently to rupture it and provide a fuel ejection path to the sodium coolant. Specific phenomena calculated by PLUTO are:

1. Flow of fuel/fission gas mixture from the fuel pin central cavity through the ruptured clad and into flowing sodium coolant.

2. Motion of fuel particles (resulting from an FCI), fission gases, sodium vapor and liquid sodium in the coolant channel following fuel ejection from the ruptured fuel pin. Multiple interaction zones are treated where sodium vapor is generated by FCI heat transfer and sodium vapor is lost by condensation.

Models

PLUTO-1:

1. Motion in pin

Motion of molten fuel/fission gas within the pin cavity is treated as 1-D homogeneous, compressible flow with nonuniform flow cross-section; hydrodynamic equations are solved in Eulerian form. A model calculates fission gas release from the gas plenum. A simplified incompressible treatment of densely packed fuel is included. PLUTO-1 overcomes limitations of SAS/FCI, which allows fuel to move only radially into the coolant (no axial motion in pin) and considers only uniform removal of fuel/fission gas mixture during the ejection process. 


\section{Ejection into coolant}

Calculation of fuel and fission gas ejection is based on assumption that the fuel pin nodes and coolant nodes adjacent to the clad rupture are in pressure equilibrium. The amount of fuel/fission gas mixture ejected in a time step is set equal to the amount which is necessary to establish the pressure equilibrium. No backflow into the pin is allowed.

3. Motion in coolant channel

Treats the motion of materials in the coolant channel as 1-D (axial) two-component slip-flow. The liquid sodium, or mixture of liquid sodium, sodium vapor and fission gas, is regarded as one component and is modeled with compressible, 1-D hydrodynamics in Lagrangian form. The other component is fuel in the form of particles, the motion of which is ca1culated by solving the momentum equation for representative ("master") particles. The interactive force between the two phases is a particle drag law based on a fluidized-bed correlation.

The entire coolant channel is covered with a moving mesh of Lagrangian cells which track the liquid sodium in the coolant slugs and sodiumfission gas flow in the interaction zone. Each cell containing fuel particles is treated as a single interaction zone which gives an axial resolution to the FCI and allows the fuel-coolant heat-transfer to be space-dependent.

\section{Limitations}

PLUTO-1 :

1. No backflow of materials into the pin is allowed when an FCI leads to a pressure in the coolant channel which is greater than the pin pressure.

2. Available only as a stand-alone version. Since it has not been coupled to SAS, there are no heat-transfer calculations for fuel and clad temperatures and the pressures at the inlet and exit plenums must be assumed constant.

3. Since calculations are only for a single fuel pin and coolant channel, radial incoherence of pin failures and of fuel and sodium flow in a subassembly are neglected.

4. Clad ruptures longer than one pin node spacing cannot be treated.

5. Does not account for fuel freezing and plugging in the coolant channel.

6. Sodium film on the clad cannot be treated; sodium vapor condensate does not stick to the clad but is assumed to instantaneously mix with sodium in the coolant channel at that axial location.

7. Lagrangian formulation in coolant channel requires complicated rezoning. 


\section{Future Efforts}

PLUTO-2 will have the following improvements over PLUTO-1:

1. A semi-implicit Eulerian treatment for nonuniform cross-section flow of the sodium-fission gas mixture in the coolant channel will have the following advantages over the Lagrangian treatment in PLUTO-1:

a. It will simplify the implementation of fuel freezing.

b. The complicated rezoning of the PLUTO-1 Lagrangian treatment can be avoided.

c. It will simplify incorporation in SAS (e.g., heat transfer between clad and coolant or frozen fuel, reactivity calculation, initialization).

d. Cladding rupture enlargement and multiple ruptures can be included more easily.

e. A static sodium film on the cladding can be treated. This allows a better modeling of sodium boiling.

2. Treatment of fuel freezing and plugging in the coolant channels.

3. Option for incompressible treatment of liquid sodium.

4. Improved incompressible treatment of densely packed fuel (improves computer running time).

5. Direct interfacing capability with SAS 3D.

\section{Interface/Overlap}

SAS/HOTPIM

\section{References}

1. H. V. Wider, An Improved Analysis of Fue1 Motion During an Overpower Excursion, Ph. D. Thesis, Northwestern University (November 1973).

2. H. V. Wider, et al., An Improved Analysis of Fuel Motion During an Overpower Excursion, Proceedings of the Fast Reactor Safety Meeting, Beverly Hills, California (April 1974). 
Probabilistic analysis of clad loading and response up to, and including, failure under TOP conditions.

\section{Status}

A. Development: Under development at GE-BRD. Code specification is in progress.

B. Availability: A non-probabilistic model will be developed during 1975 and a probabilistic model will be developed during 1976.

C. Utilization: Code utilization will be in two areas, corresponding to the probabilistic and non-probabilistic versions of the code. The non-probabilistic version will be economical and fastrunning. This will allow more extensive application to sensitivity-parametric studies than is possible with larger codes such as BEHAVE-3. In addition, the reactor core (or individual fuel assemblies) can be modeled using an increased number of distinct fuel rods. This provides the capability to investigate the influence of spatial distributions of transient operating conditions on cladding failure, voiding and reactivity feedback and to relate these effects to whole-core response to accident conditions. The non-probabilistic version will also provide capability to run the multiple cases necessary for effective code validation.

The ultimate POPS code will provide probability distributions describing the time of cladding failure for each rod, the total number of rods failing in specified core zones before some time, and the amount of fission gas released in the core before some time. Other quantities of interest remain to be identified during specification of the code. Probabilistic output will be used as a quantitative measure of the uncertainty associated with current transient overpower cladding failure predictions, and will quantify the improvement in predictive capability that will result from data acquisition. One of the most important immediate applications of the probabilistic results will be to avoid the assumption that all rods in an identical group fail, and that they fail simultaneously.

Mean values for the number of rods failing in specified time intervals will be used instead in existing nonprobabilistic accident analysis codes. This should provide a more realistic model for whole-core accident analysis. In addition, probabilistic results will provide meaningful definitions for "maximum" and "minimum" rod failure times, etc. 


\section{Problems Solved}

POPS will describe initiating phase of TOP accident sequence probabilistically in order to avoid pessimistic and unrealistic assumptions regarding coherent multiple-rod failure and consequent massive voiding of coolant. Thermalstructural analysis of individual fuel rods under transient overpower conditions will be performed. Probabilistic failure predictions will be made. Models will be simple to achieve economical computing time. Results will be used to investigate coherence effects in whole-core accident analysis.

\section{Models}

Models will employ correlations derived from transient overpower experiments. Specific models to be included are to be described in code specification in progress.

\section{Limitations}

Not applicable

Future Efforts

Complete program specification.

Interface/Overlap

PECS-II is the interfacing steady-state cladding failure analysis code. Information from POPS and the non-probabilistic POPS model will interface with codes such as SAS and MELT.

No overlap. Non-probabilistic model may be used in place of BEHAVE-3 or DEFORM-II to provide fast-running alternative to these models.

\section{$\underline{\text { References }}$}

None 
PORPLUG

\section{Purpose}

Prediction of temperature distributions in porous heat-generating blockages in the fuel region of a LMFBR subassembly.

\section{Status}

A. Development: Developed at ANL/RAS.

B. Availability: Documentation only available through ANL intra-lab memos.

C. Utilization: Used by ANL for fuel failure propagation analysis.

\section{Problems Solved}

For a specified size, flat, porous-bed, heat generating blockage in the fuel region of a LMFBR pin bundle, the coolant temperature profile is calculated.

\section{Models}

The blockage has the following properties:

1. Planar, with user specified thickness.

2. Porous-bed configuration (random-packed spheres).

3. Energy generated at arbitrary uniform volumetric rate and is transferred to coolant by convection.

4. Flow passing through porous-bed is based on the assumptions that the pressure gradient across the bed is the only driving force and the pressure drop across the porous bed is the same as that of an equal length normal flow channel.

\section{Limitations}

Major assumptions are:

1. Heat flow is $1-D$ (in flow direction only).

2. A11 physical and thermodynamic properties of both the porous-bed and coolant are constant.

3. Volumetric heat transfer coefficient and volumetric heat generation rate are constant.

4. Porous-bed is isotropic.

5. Heat transfer by radiation is negligible. 
6. Heat generation starts at time when the porous-bed has already been established.

\section{Future Efforts}

None planned.

Interface/Overlap

$-1-$

\section{References}

1. W. W. Marr and M. M. E1-Wakil, "Hybrid Computer Solution of Therma1 Energy Equations in Porous Fuels," Nucl. Sci. Eng., 41, 271-80 (1970).

2. W. U. Choudhury and M. M. El-Wakil, "Heat Transfer and Flow Characteristics in Conductive Porous Media with Energy Generation," Proceedings of the Fourth International Heat Transfer Conference, Versailles, France, August 1970 .

3. R. Byron Bird, et a1., "Transport Phenomena," John Wiley and Son, Inc., pp. 196-200, 1965 .

4. M. M. E1-Walkil, "Nuclear Heat Transport," International Textbook Co., p. 268, 1971.

5. W. W. Marr, "Hybrid Computer Solution of Energy Equations in Conductive Porous Media," Ph.D. Thesis, The University of Wisconsin, 1969. 


\section{Purpose}

Analysis of single core subassembly hydrodynamic-structural response to internal FCI accidents.

\section{$\underline{\text { Status }}$}

A. Development: Under development at ANL/RAS.

B. Availability: REXCAT consists of REXCO-HT and SADCAT coupled in a single package. It is operational and under testing at ANL on the IBM 370 .

C. Utilization: The code is being tested.

\section{$\underline{\text { Problems Solved }}$}

REXCAT consists of REXCO-HT and SADCAT coupled into a single package. The internals of the subassembly are treated by REXCO-HT, which models the internals as a homogeneous, compressible, inviscid fluid in 2-D, axisymmetric, cylindrical geometry. An FCI zone is included along the center axis of the subassembly to generate axisymmetric driving pressures. SADCAT models the structural response of the duct wall. This coupled analysis provides an extension of REXCO-HT since the cylindrical vessel of REXCO-HT is replaced by a hexagonal duct, thus providing a more realistic subassembly boundary condition.

\section{$\underline{\text { Models }}$}

1. Geometry

2-D axisymmetric hydrodynamics with a hexagonal vessel boundary.

2. Subassemb1y Internals

Same as REXCO-HT (see REXCO summary).

3. Duct Wal1

Same as SADCAT (see SADCAT summary).

Limitations

Same as for SADCAT and REXCO-HT.

\section{Future Efforts}

Improve coupling procedure. 
Interface/Overlap

$-1-$

$\underline{\text { References }}$

See references in SADCAT and REXCO summaries. 


\section{Purpose}

Analysis of reactor primary containment hydrodynamic-structural response to pressure loadings resulting from HCDA's.

\section{Status}

A. Development: All versions of REXCO were developed at ANL/RAS. Current development version is REXCO-HEP.

B. Availability: The REXCO series was designed for the IBM 360 , but CDC 7600 versions are available.

- REXCO-H was released in 1973.

- REXCO-HT is operational at ANL and W-ARD.

- REXCO-HEP is operational at ANL, LBL, W-ARD and at several European sites.

- REXCO-HEP-HT is operational at ANL.

C. Utilization: The REXCO series has been used extensively in support of the FFTF FSAR and the CRBR PSAR for evaluation of the primary containment structural damage consequences resulting from HCDA-generated pressure loadings.

\section{Problems Solved}

Al1 versions of REXCO use a 2-D (axisymmetric) compressible hydrodynamics formulation coupled with mechanical response models of various primary containment structures to calculate the propagation of shock waves, loads imposed on different parts of the reactor components and the resulting structural damage. The pressure sources which drive the REXCO codes are input or calculated internally, as by REXCO-HT and REXCO-HEP-HT for the case of an FCI-generated pressure source. For each problem the codes compute the accelerations, velocities, displacements, changes of volumes, densities, strains, pressures, and specific energies at every spatial point for a specific time internal. For elastic-plastic materials, the codes also calculate deviatoric stresses and distortion energies. These computations are repeated for every time interval until (a) the maximum time specified is reached, (b) the reactor vessel ruptures, or (c) the vessel head holddown system fails. Outputs of displacements and pressures can be given pictorially, showing the movements and deformations or magnitudes of pressures at all spatial points at any instant of time. A REXCO code will evaluate:

1. Core barrel deformation

2. Reactor vessel deformation 
3. Pressure at the inlet and outlet nozzles

4. Loads on core support structures

5. Sodium slug impact force history on head

6. Ho1ddown bo1t system deformation

7. Energy partition history of upward and downward axial fluid slug kinetic energies, radial fluid slug kinetic energies, core barrel strain energies, vessel strain energy, internal energy and head motion energy.

REXCO has also been used for analysis of experiments in which the elasticplastic response of fluid-filled pipes to high-pressure pulse loads was studied.

Models

Al1 versions of REXCO have the following features in common:

1. Geometry

Al1 formulations are for 2-D, cylindrical, axisymmetric geometry.

2. Hydrodynamics

The governing equations for the fluids are the compressible, inviscid, non-heat conducting conservation equations of mass, momentum and energy. The numerical problem of calculating shock discontinuities is eliminated, without jeopardizing the conservation laws, by the artificial viscosity method of von Neumann and Richtmyer, which spreads the shock discontinuity over several spatial grids by replacing the discontinuous pressure jump across a shock by a rapid but continuous pressure change. Various mathematical forms of the artificial viscosity are available depending on the type of problem under consideration.

3. Vessel and Core Barrel Models

Due to the relatively small thickness of the core barrel and reactor vessel relative to the radial dimensions of the reactor, an option in the codes allow these structures to be treated as thin shells. The governing equations are the equations of equilibrium for a shell of revolution undergoing large deflections. The thickness of the shell is idealized by layers of subshells that can carry only normal stresses in the planes parallel to the tangential plane of the shell structure. These subshells are connected by material which carries only shears. The vessel material is considered to be elastic-plastic, strain-hardening and strain-rate sensitive. The strain-hardening shell is represented by a model in which the thickness of the subshell is further decomposed into subregions of elastic-perfectly-plastic materials having different yield stresses, but common strains. The von Mises yield condition and the incremental strain theory of plasticity is used. 
4. EOS

To describe the behavior of the reactor materials, particularly in the reactor core and under high-temperature conditions, various optional EOS's are built into the codes.

5. Method of Solution

In the numerical analysis, all equations are expressed in Lagrangian coordinate form and then set into numerical form by finite-difference equations which use an explicit time differencing scheme. The reactor system is represented by a network of quadrilateral meshes (i.e., Lagrangian zones). For media inside the reactor containment, the White stability criteria is used for time-step selection to ensure stability of the finite-difference equations. For the shell equations, the stability criteria of shell structures must also be satisfied.

Unique features of the various versions of the REXCO series codes are as follows:

REXCO-H :

This early version assumes all solid materials in the reactor, except for the core barrel which may be treated as a thin shell, to behave like compressible, inviscid non-heat conducting fluids. This assumption is made due to the behavior of solids subjected to high pressure (kilobars) shock compression which allows their mechanical properties to be approximated by a compressible fluid model. This approximation breaks down, however, as the solid material recovers from the compressive shock loading or is under tension, where the tensile strength of the solid becomes important.

REXCO-HEP :

This version is an improvement over REXCO-H in that solids within the reactor can be treated as elastic-plastic materials. In addition, REXCO-HEP has the following features:

1. Options for artificial viscosity

a. Quadratic artificial viscosity

b. Linear artificial viscosity

c. Navier-Stokes artificial viscosity, which is a special linear viscosity formulation used when shearing action is introduced into a material, as in an elastic-plastic material.

d. Membrane artificial viscosity, which is a special linear viscosity formulation for shell structure

2. Mesh regularization

The major disadvantage of codes like the REXCO series which solve the governing differential equations in a Lagrangian coordinate 
system is the limitation imposed on the degree of distortion of the quadrilateral Lagrangian zones as computation proceeds through a problem calculation and extended material motions occur. Severe distortions may not always be physically real, but may be caused by the method of solution rather than the physics of the problem. Such is the case for the commonly occurring "hour-glass" distortions which may grow until the numerical computation becomes unstable. It is thus necessary to have some means to eliminate or minimize zone distortions and control or regulate non-physical distortion effects so that reliable calculations can be made when computation time is to be extended. The two methods used in REXCO-HEP for these purposes are:

a. Mesh regularization: a scheme which is built into the code to control, regulate or suppress hour-glass and other non-physically real distortions

b. Rezoning: the REZONE code (see REZONE summary) may be used to transform the distorted Lagrangian grids in the fluid (hydrodynamic) regions into new, undistorted grids. In cases where distortions are large, but physically real, rezoning may be required since the use of mesh regularization can introduce errors into the true solution

3. EOS

The following EOS's have been built into REXCO-HEP to describe behavior of reactor materials in the core and at high temperatures:

a. Equation for vaporizing core

b. Tabulated pressure as a function of volume

c. Tabulated pressure as a function of time

d. Ideal gas

e. Mie-Gruneisen

f. Murnaghen

g. TNT explosives

4. Reactor head model

Two options are available to model head motion:

a. Non-deformable: the head is modeled as a rigid solid circular plate, which can move uniformly in the axial direction by stretching of the head bolts.

b. Deformable: in a special version, the head is treated as an elastic-plastic material by a $2-D$, axisymmetric finite-element program DYNASMY.

5. Crushable material

Crush tubes under the head are modeled as a structure which has deformation resistance up to some critical axial compression. 
REXCO-HT

This version consists of an FCI model incorporated directly into REXCO-H. This coupling of an FCI model with 2-D reactor structural response allows a more accurate calculation of the actual constraints on the FCI expansion than a 1-D calculation, which must assume acoustic on inertial constraints. REXCO-HT has the following features:

1. Interaction region mode1

The region in which the FCI takes place is divided into several rectangular zones, each zone initially specified with a unique fuel temperature, sodium temperature, fuel solid fraction and volumetric fraction of sodium vapor.

\section{Heat transfer model}

Two basic options are available for description of heat transfer in the FCI zones:

a. ANL parametric model: allows fuel fragmentation and mixing with sodium to occur at a finite rate.

b. Quasi-steady-state model: assumes that all fuel is instantaneously fragmented into small spheres of the same radius and is dispersed uniformly inside the sodium mass of the zone.

In both of the above models, the only resistance to the heat transfer from the fuel to the sodium is due to the thermal conductivity of the fuel, which is a good assumption when sodium is in the liquid phase. When sodium vaporizes, however, the vapor layer around the fuel will create additional resistance to heat transfer, which can be taken into account using a vapor blanketing option. This model assumes a percentage of the fuel particles equal to the volumetric fraction of sodium vapor present in an FCI zone will not participate in the heat transfer process.

REXCO-HEP-HT

This, the most advanced version of REXCO, consists of an FCI model directly incorporated into REXCO-HEP. The interaction region and heat transfer models are the same as for REXCO-HT.

\section{Limitations}

Al1 versions of REXCO have the following 1imitations:

1. Due to Lagrangian formulation, cannot treat accurately large material displacement problems

2. Axisymmetric geometry does not allow treatment of 3-D effects 
3. A11 materials are considered isotropic

4. Core region is assumed to be a homogenized material

5. Detail of core support structure cannot be modeled precisely

6. Complex interacting head holddown bolt systems, as in CRBR, cannot be modeled precisely

Specific 1imitations of REXCO-HT and REXCO-HEP-HT are:

1. Heat transfer between FCI zones is not allowed

2. Fuel-coolant slip within zones is not modeled

\section{Future Efforts}

The following are planned for REXCO-HEP:

1. Improve sliding interface modeling

2. Include anisotropic materials

3. Studies on 3-D phenomena

4. Model flow through openings in core support structure

The following are planned for REXCO-HT and REXCO-HEP-HT:

1. Introduce neutronics in the fuel during FCI

2. Introduce delay time for each FCI zone

3. Improve sodium EOS

Interface/Overlap

VENUS/ICECO

\section{$\underline{\text { References }}$}

REXCO-H and -HEP:

1. Y. W. Chang and J. Gvildys, "REXCO-HEP: A Two-Dimensional Computer Code for Calculating the Primary System Response in Fast Reactors," ANL/RAS 75-11, March 1975.

2. J. GVildys and Y. W. Chang, REXCO-HEP Users Manual, ANL/RAS 75-1, January 1975.

3. Y. Chang, J. Gvildys and S. Fistedis, "Two-Dimensional Hydrodynamics Analysis for Primary Containment," ANL-7498, November 1969. 
4. G. Cinel1i and J. Gvildys, S. Fistedis, "Inelastic Response of Primary Reactor Containment to High-Energy Excursion," ANL-7499, November 1969.

5. J. Gvildys and S. Fistedis, "Inelastic Response of Primary Reactor Containment to High-Energy Excursions," ANL-7499, Supplement, June 1971.

REXCO-HT :

6. T. J. Marciniak, "Heat Transfer Problems in LMFBR Containment Analysis," ANL-8037, July 1973 .

7. J. Bratis, T. J. Marciniak and J. Gvildys, "REXCO-HT: A Hydrodynamic Containment Code Including Molten Fue1-Coolant Interaction," ANL/RAS 75-13, March 1975.

8. J. C. Bratis, T. J. Marciniak, "Reactor Structural Response to Moltenfuel-coolant Interactions," invited paper E1/4, 2nd Int1. Conf. on Structural Mechanics in Reactor Technology, Berlin, 1973.

FCI Models:

9. D. H. Cho, R. O. Ivins, and R. W. Wright, "A Rate-limited Model of Molten-fuel/Coolant Interactions: Model Development and Preliminary Calculations, ANL-7919, March 1972. 
REZONE

\section{Purpose}

To rezone distorted Lagrangian fluid mesh grids which occur in REXCO-HEP computations during long time duration and/or extended material motion calculations.

\section{Status}
A. Development: Developed at ANL/RAS.
B. Availability: Operational at ANL on IBM 370 and at LBL on CDC 7600 ; a program description has been documented (Ref. 1).
C. Utilization: Used by ANL and GE-BRD to extend REXCO-HEP calculation capabilities in support of FFTF and CRBR safety analysis.

\section{Problems Solved}

REZONE provides a means to eliminate or minimize computational problems which arise in REXCO-HEP (see REXCO summary) due to severe Lagrangian nodal mesh or grid distortions in the fluid (hydrodynamic) regions. Such distortions occur because of the inherent nature of solving finite-differenced mathematical equations in a Lagrangian or moving coordinate system whereby the computational nodal points are embedded in and thus move with the system materials. Large material motions therefore lead to distortions of the quadrilateral zones or grids which connect the mesh nodal points. These distortions may be physically real, as in the case of an interface between two different media where material properties discontinuities occur. However, it is also possible for these distortions to be non-physical, being caused by the method of solution rather than the physics of the problem. An example is the frequently occurring "hour-glass" distortion of a quadrilateral mesh. The mesh regularization scheme built into REXCO-HEP is effective in controlling, regulating or suppressing these nonphysical distortions. However, since mesh regularization can introduce errors in the true numerical solution, rezoning of the distorted meshes is often the only true solution to such problems. Rezoning allows REXCO-HEP calculations to be extended for calculations of low-energy HCDA's, where large material motions occur over the time scale of interest, or for calculation of high-energy excursions where the system response is of interest for the full time scale up to dynamic equilibrium.

\section{Mode1s}

The rezoning process involves establishing a new set of undistorted Lagrangian meshes in accordance with rezoning instructions, and then determining the new mesh properties from those of the old, distorted mesh. New properties are determined by an averaging method which is user dependent. The user must decide himself when to rezone and how to rezone, with the code merely executing the user's instructions by performing the necessary computations. The procedure for deciding when to rezone must be based both upon experience gained by comparing alternative computational procedures and by the laborious method of 
examining key variables at each time-step to see that numerical values are physically reasonable and consistent with conservation laws. The averaging method is required since a zone variable can have only a single value for all material inside the zone. Averaging will always involve approximations and thus a trade-off of errors is required to achieve maximum overall computational accuracy.

REZONE has the following features:

1. Distorted meshes: distorted meshes to be rezoned must be either a normal quadrilateral mesh (all interior angles are less than $180^{\circ}$ ) or a re-entrant mesh (only one interior angle exceeds $180^{\circ}$ ).

2. New meshes: the boundary of the new meshes must coincide with that of the old meshes to be rezoned.

3. Averaging method: the values of the zone velocities, pressures, densities, initial masses, initial positions and internal energies of the new meshes are calculated by several optional methods including user input and an averaging procedure. Averaging is based on an area averaging method with the old zone divided into $32 \times 32$ subquadrilaterals and then superimposing the old meshes on the new ones.

\section{Limitations}

1. Meshes to be rezoned are limited to either the normal mesh (all interior angles are less than $180^{\circ}$ ) or the re-entrant mesh (only one interior angle exceeds $180^{\circ}$ ).

2. Only fluid (hydrodynamic) materials can be rezoned.

3. If the new mesh contains two or more different materials, the type of material and EOS of that mixed zone must be specified.

4. If meshes to be rezoned contain shell structures, the locations of the mesh points on the shell wall must be unchanged, or else the shell must be removed.

5. The accuracy of the rezoning process is largely dependent upon the experience and judgment of the user.

Future Efforts

None specified

Interface/Overlap

REXCO-HEP/ -

\section{$\underline{\text { References }}$}

1. J. Gvildys and Y. W. Chang, "REZONE: A Computer Code for Rezoning the Distorted Lagrangian Meshes," ANL/RAS 75-14 (March 1975). 
RIBD

\section{$\underline{\text { Purpose }}$}

Analysis of fission product inventories in reactor fuel as a function of irradiation history.

\section{Status}

A. Development: Developed and under improvement at HEDL.

B. Availability: RIBD-1 was documented in 1969 (Ref. 1). RIBD-2 is operational at GE-BRD and at HEDL on the UNIVAC 1108 and is available through the Radiation Shielding Information Center.

C. Utilization: Used for FFTF FSAR and CRBR PSAR analysis to provide input to dose calculations.

Problems Solved

The RIBD codes calculate fission product isotopic concentrations in fuel resulting from two fission sources (e.g., $\mathrm{U}^{238}$ and $\mathrm{Pu}^{239}$ ) with down-chain decay by beta emission and isomeric transfers and interchain coupling resulting from neutron-induced transmutation reactions. The calculations follow a flexible irradiation history through an unlimited number of step changes of unrestricted duration and variability including shutdown periods, restarts at different power levels and/or any other level changes. The code output consists of fission product isotopic concentrations, activities, beta and gamma powers, and energy releases for the specified decay times.

Models

RIBD-2 has the following capabilities:

1. Isotope Library and Data

A 770 isotope master library is available. The user has a choice of fission product yields from various data (Ref. 2-4) for a thermal neutron spectrum, a fission neutron spectrum or $14 \mathrm{Mev}$ neutrons. Thermal or FTR core-spectrum weighted cross sections are available. For the FTR, data libraries are based on ENDF/B-IV, with neutron capture cross sections based on one energy group values averaged over the FTR spectrum.

\section{Isotopic Concentration Calculation}

Isotopic concentrations are calculated by standard down-chain decay from beta emission and isomeric transfer. Interchain coupling due to neutron capture reactions is accounted for. The chain sources are due to the direct yields of two fissioning nuclides. The code follows the irradiation history through an unlimited number and variety of power changes including outages. The isotope buildup portion of the code does not use the standard 
Bateman equation for its solution form and is therefore not limited to simple, nonbranching chains. The concentration of each nuclide is calculated from a choice of three alternative series solutions depending on the magnitude of the parameters involved. During shutdown decay calculations, when neutron capture is not possible, equations with characteristics similar to the Bateman equation are used. The fission product calculations are based on the fission rate within the entire mass or volume of fuel of interest. Therefore, the inventory can be calculated for a unit volume of fuel, a unit mass of fuel, a unit length of fuel, or any other assembly of interest. In each case, it is assumed in the calculation that all fuel is in exactly the same envi ronment.

\section{Limitations}

1. Does not include inter-chain coupling by neutron decay.

2. Only includes inter-chain coupling by the ( $n$, gamma) process and not by $(n, a 1 p h a)$ or $(n, p)$ reactions.

3. Does not include production of transplutonium isotopes nor decay heat or activity associated with such isotopes; however, it does calculate the desay heat of U-239 and $\mathrm{Np}-239$.

4. Isotopic ground states are allowed to have no more than seven source paths, with up to five source paths allowed for isomeric states.

5. No beta decay is allowed from one isomeric state to another isomeric state.

\section{Future Efforts}

None defined.

Interface/Overlap

COMRADEX, ISOSHLD/CINDER

\section{References}

RIBD-1

1. R. 0, Gumprecht, "Mathematical Basis of Computer Code RIBD," Dun-4136, June $17,1968$.

\section{Yield Data}

2. Y. A. Zysin, et al, "Fission Product Yields and Their Mass Distribution," Consultants Bureau, New York, N.Y., 1964.

3. D. A. Anderson, Jr., "Fission Product Yields from Fast Neutron Fission of Pu239," LA-3383, Los Alamos, N.M., December 1965.

4. L. W. Weaver, et al, "Estimated Total Chain and Independent Yields for Several Neutron Induced Fission Processes," USNRDL-TR-633, March 1963. 


\section{SADCAT}

\section{Purpose}

3-D analysis of a single core subassembly duct transient structural response to local pressurization accidents.

\section{$\underline{\text { Status }}$}

A. Development: Developed and under improvement at ANL/RAS.

B. Availability: Operational at ANL on IBM 360. Documentation is available (Ref. 1).

C. Utilization: SADCAT is developmental. It has been applied by ANL to experiment analysis.

\section{Problems Solved}

3-D analysis of subassembly duct transient structural response to rapid pressurization. The structural damage to the accident subassembly duct is determined, as well as the potential for subassembly-to-subassembly damage propagation. SADCAT is essentially a 3-D version of STRAW (see STRAW summary) and has been applied to beams, plates, shells and hexagonal ducts. It employs a finite-element method which is valid for large-displacement problems with material non-linearities and strain-rate effects. An arbitrary stress-strain law can be specified.

SADCAT includes a thermal stress analysis capability (similar to STRAW) which can analyze an entire hexcan subjected to arbitrary thermal loadings. It can al so be coupled with a hydrodynamic code, such as REXCO-HT (see REXCAT summary) to provide an integrated hydrodynamic-structural response analysis of a subassembly.

$\underline{\text { Models }}$

1. Geometry

3-D, but has been tested with 1 - and 2-D problems.

2. Governing Equations

SADCAT analysis is based on the finite-element method which uses a convected coordinate formulation enabling simple strain-nodal displacement and force-stress relations. Based on a flat triangular finite-element possessing both membrane (nodal displacement) and bending (nodal rotation) capabilities, continuity of displacements and rotations is provided at the element nodes, implying six degrees of freedom. Lumped masses are employed at the nodes and discretized equations of motion are solved with an explicit temporal integration scheme. Local coordinates which move (but do not deform) with the element facilitate the use of small deformation theory (large displacements, small strains). Large rotations at the 
nodes are made possible by the use of Euler angles. A membrane artificial viscosity is used to eliminate spurious numerical oscillations.

3. Duct Simulation

The discrete model of the duct structure consists of an assemblage of flat triangular plate elements interconnected by nodes. The relative displacements of these nodes provide the strain and thus the membrane effect inside the elements. Relative rotations of the elements at the nodes account for the bending contribution inside the elements.

\section{Limitations}

Does not include a 3-D continuum element for calculation of asymmetric fluid dynamics, nor does it model in detail the subassembly internal fuel pin structures. It is thus limited to the analysis of a single isolated duct wall response to a pressure load applied arbitrarily on the wall.

\section{Future Efforts}

1. Include option for implicit temporal integration.

2. Generalization of mass matrix (internal generation of mass moment of inertia at each node).

3. Include a 3-D continuum element to account for asymmetric fluid dynamics.

4. Model internal fuel pin structures and interaction with adjacent subassemblies.

Interface/Overlap

REXCO-HT / STRAW

\section{Reference}

1. A. H. Marchertas and T. B. Belytschko, Nonlinear Finite-Element Formulation for Transient Analysis of Three-Dimensional Thin Structures, ANL-8104 (June 1974). 


\section{Purpose}

Analysis of core neutronic-thermal-hydraulic behavior during the initial phases of a postulated whole-core accident.

\section{Status}

A. Development: All versions were developed at ANL/RAS. Current development version is SAS 3D.

B. Availability: The versions of SAS which have been or are in the process of being made operational are:

SAS 1A: Released in 1969 (Ref. 1).

SAS 2A: Operational at UCLA, LBL, W-ARD and ANL. Has been documented ( $\operatorname{Ref} .2$ ), but will not be released in lieu of SAS 3D release.

SAS 2D: Operationa 1 at LBI and ANL. Will not be released in lieu of SAS 3D release.

SAS 3A: Operation at LASL, LBL, BNL and ANL. The various modules of SAS $3 \mathrm{~A}$ have been documented independently in ANL/RAS reports. SAS 3A will not be released in lieu of SAS 3D release.

SAS 3D: Developmental at ANL on IBM 370. Will be made operational at LBL by November 1975 and will be released by February 1976.

C. Utilization: The SAS codes have provided the primary tools for initiating phase analysis of LOF and TOP HCDA's in support of the FFTF and CRBR SAR's.

\section{Problems Solved}

Each version of SAS predicts transient core behavior from an unfaulted, normal operating condition through the early phases of a whole-core involvement accident initiated by a hypothesized faulted condition which leads to a severe power-to-flow mismatch. Each version of SAS consists of overlayed modules which compute the neutronic-thermal-hydraulic behavior of the core up to the point of (a) permanent neutronic shutdown with no loss of subassembly duct integrity, (b) loss of subassembly duct integrity due to melting attack or internal pressurization or (c) a prompt-critical neutronic burst.

SAS calculations start from a steady-state initialization of core conditions based on the user's specifications which define the pretransient operating state of the reactor system. A steady-state thermal-hydraulics calculation initializes fuel temperatures, fuel and clad thermal expansion, and the coolant 
temperatures, pressures and flow rates. Calculations then proceed through the transient history of the reactor response to a power-to-flow perturbation resulting from either a specified reactivity insertion (or power increase) and/or a specified reduction in coolant flow. Throughout the history of SAS calculations is the basic assumption that the overall core subassembly geometry remains intact; that is, subassembly ducts do not lose their integrity, although any individual subassembly may have an internally disrupted condition, as fuel dispersal following clad disruption. This limitation of SAS is derived from 1-D nature of the code which performs calculations of axial material motion within the confines of a strong duct barrier but neglects radial motion as would occur between subassemblies following duct failure.

\section{$\underline{\text { Mode1s }}$}

All versions of SAS are based on a modular structure in which the models for describing the various interrelated accident phenomena are programmed into specific modules (each module may contain one or more subroutines) which are then coupled to provide an integrated, comprehensive accident analysis. This modular form allows ready incorporation of improvements in specific models without affecting overall code structure. A11 SAS codes contain at least the following basic modules: fuel heat transfer, coolant dynamics, fuel deformation, fuel dynamics, and neutronics.

\section{SAS 1A:}

\section{Geometry}

The entire core is modeled by a single "channel" which consists of a single full length fuel pin surrounded by its associated coolant and structure (i.e., lumped wire wrap and associated subassembly duct) in cylindrical axisymmetric geometry. The channel is assumed to represent the average behavior of a core fuel pin. Since all fuel pins within a given subassembly are assumed to behave identically (i.e., no intrasubassembly incoherence), a channel may also be assumed to represent the coherent behavior of an entire subassembly.

2. Fue1 heat transfer

Since axial and angular conduction of heat are relatively unimportant compared to radial heat flow, a $1-D$ (radial) heat-flow model is used. The channel is divided into axial segments and temperature calculations are made for each section in a marching procedure following coolant flow. The Storrer effect of heat transfer from downstream coolant to the fuel in the axial blanket is automatically included. The 1-D transient heat conduction equations are finite differenced in an explicit scheme using the Crank-Nicholson method and take into account:

a. Dimensional changes due to thermal expansion and phase change

b. Latent heat absorption due to phase change

c. Variable fuel-clad gap size and thermal conductance

d. Temperature dependence of fuel thermal conductivity and heat capacity 
3. Coolant dynamics

The main function of the coolant dynamics calculation is to provide an axial profile of transient sodium voiding due to coolant expulsion by fission gas release into the coolant channel or by sodium boiling. Two different models are used for different parts of the sodium boiling process. A slip-flow, two-phase model is used for the initial portion and up to a short time after flow reversal (i.e., ejection of coolant from the channel inlet) when a reasonably large void fraction (larger than .9) exists. Since the slip-flow model is less meaningful from a physical standpoint when the vapor-void fraction is approaching 1.0 , a switch is then made to a simple slug model to continue the boiling calculation. The basic assumption in developing this "slug-ejection" model is that there is a differential pressure across the liquid slugs which tend to move them out of the channel, the driving pressure being generated by the coolant vapor pressure.

4. Fuel deformation

Provided by DEFORM I (see DEFORM summary).

5. Fuel dynamics

Axial fuel motion and displacement are calculated following gross fuel melting in the central region of the pin. The model assumes molten fuel to be in the form of a partially molten "slurry" within an intact clad. Axial pressure gradients are assumed to arise from the radial restraining force of the clad which is imposed on the solid-liquid fuel material.

6. Neutronics

A one-energy group, space-independent (point) kinetics model is used to describe the reactor neutron kinetics. The net reactivity is the sum of the five following contributions:

a. Programmed input (initial ramp or scram)

b. Doppler feedback, based on the volume-averaged temperature over a given fuel pin axial segment

c. Coolant density/voiding feedback, based on sodium worth per axial segment

d. Axial fuel expansion feedback, based on fuel worth per axial segment

e. Structural expansion feedback due to core radial expansion

SAS 2A:

This version is a multiple-channel outgrowth of SAS 1A with new sodium voiding models. 
1. Geometry

The entire core is modeled by up to ten separate channels, each having a geometry as in the SAS $1 \mathrm{~A}$ channel. The core subassemblies are divided in up to ten groups, with each channel representing the average behavior of a particular group. The basis for grouping is to match subassembly operating characteristics, such as power-to-flow ratio or burnup conditions. The precise method for selecting the grouping requirements is user-specified. The multiple-channel treatment of SAS $2 \mathrm{~A}$ allows for variations in pin power, coolant flow rate and fuel irradiation history across the core.

2. Fuel heat transfer

Same as SAS 1A.

3. Coolant dynamics

A multiple-bubble slug ejection model is used to calculate voiding due to boiling and/or fission gas release from failed fuel pins. Voiding is assumed to result from the formation of bubbles that fill the entire crosssection of the coolant channel, with up to nine bubbles, separated by liquid slugs, allowed in a channel at any time. Each bubble may contain sodium vapor and or fission gas. The liquid film left on the clad and structure following bubble formation is assumed to be a static film whose thickness varies only due to vaporization and condensation. Film dry-out is predicted on this basis.

4. Fuel deformation

Same as SAS 1A.

5. Fue1 dynamics

Same as SAS 1A, with additional allowance for effect of fuel slumping at a user-specified slumping criterion, a reactivity feedback is allowed through the neutronics calculation.

6. Neutronics

Same as SAS 1A, with additional reactivity feedback for fuel slumping treated by a user-supplied worth table.

SAS 2D :

A variable-channel version of SAS $2 A$ (Ref. 4). Has same physical models as SAS $2 \mathrm{~A}$, but with improvements in data-storage methods, computer memory requirements and the number of channels which can be specified.

1. Geometry

The maximum number of channels is 1 imited only by the amount of computer memory available. 
2. Fuel heat transfer

Same as SAS $2 \mathrm{~A}$.

3. Coolant dynamics

Same as SAS $2 A$.

4. Fuel deformation

Same as SAS $2 A$.

5. Fuel dynamics

Same as SAS $2 \mathrm{~A}$.

6. Neutronics

Same as SAS $2 \mathrm{~A}$.

SAS 3A:

An advanced version of SAS $2 \mathrm{~A}$ with much improved models.

1. Geometry

Same as SAS $2 \mathrm{~A}$.

2. Fuel heat transfer

Same as SAS $2 \mathrm{~A}$.

3. Coolant dynamics

Same as SAS 2A, with new film dryout model (Ref. 9) which calculates a moving film under the influence of vapor stripping (drag) by streaming vapor, wall friction, gravity and axial pressure gradients. Droplet entrainment is not included.

4. Fuel deformation

Same as SAS $2 \mathrm{~A}$.

5. Fuel dynamics

The motion of fuel in a voided channel following clad disruption is calculated by SLUMPY (see SLUMPY summary).

6. Neutronics

Same as SAS $2 \mathrm{~A}$ 
7. Clad dynamics

The motion of molten clad in a voided channel is calculated by CLAZAS (see CLAZAS summary).

8. Steady-state fuel characterization

Direct fuel restructuring calculations are made with correlations for fuel swelling, clad swelling and fission gas release and retention. Fue 1 restructuring is based on restructuring temperatures at each axial node for equiaxed - and columnar - grain fuel.

9. Primary loop hydraulics

PRIMAR (Ref. 10) provides hydraulic coupling between coolant channels, with allowance for compression of cover gas volume and primary-loop hydraulics for a single loop containing a pump, IHX and piping.

10. FCI

A model (Ref. 11) treats molten fuel ejection into the coolant channel and the resulting FCI phenomena.

SAS 3D:

This variable-channel version is currently under development. When released, it will have the following improved capabilities over SAS 3A:

a. Geometry will be same as SAS 2D

b. Direct data transfer capability to VENUS II will be available

c. PLUTO 2 (see PLUTO summary) will do FCI calculations

d. Improved CLAZAS and SLUMPY will be incorporated

e. Improved coolant dynamics models to include consistent treatment of fission gas release into a voided channel and sodium entrainment in sodium film motion model

f. Will have capability for interfacing with a space-time neutron kinetics code (2-D diffusion and perturbation theory).

\section{Limitations}

Current limitations of SAS $3 \mathrm{~A}$ are:

1. No treatment of intrasubassembly incoherence or pin-to-pin effects on voiding and on clad and fuel motion (i.e., only axial material motions are calculated and radial or 2-D motions are ignored within a subassembly).

2. Neutronics is limited to point kinetics (i.e., no allowance for flux spatial variations). 
3. Same 1imitations as CLAZAS, SLUMPY, DEFORM and other models.

\section{Future Efforts}

Short term efforts are directed toward release of SAS 3D. Long term efforts include:

1. Treatment of intrasubassembly incoherence or pin-to-pin effects.

2. Incorporation of advanced fuel mechanics model (e.g., DEFORM III).

\section{Interface/Overlap}

VENUS/MELT, FREADM, HOPE

\section{References}

\section{SAS 1A:}

1. J. C. Carter, G. J. Fischer, T. J. Heames, D. R. MacFarlane, N. A. McNea1, W. T. Sha, C. K. Sanathanan, and C. R. Youngdah1, SAS 1A, A Computer Code for the Analysis of Fast Reactor Power and Flow Transients, ANL-7607 (1970).

SAS 2A:

2. F. E. Dunn, G. J. Fischer, T. J. Heames, P. Pizzica, N. A. McNeal, W. R. Bohl, and S. M. Prastein, The SAS 2A LMFBR Accident Analysis Computer Code, ANL/RAS 73-39 (1973).

3. F. E. Dunn, T. J. Heames, P. A. Pizzica, and G. Fischer, "The SAS 2A LMFBR Accident Analysis Code," Proc. of Conf. on New Developments in Reactor Mathematics and Applications, CONF-710302, p. 120 (1971).

SAS 2D:

4. F. E. Dunn, "SAS Code Development," ANL-RDP-24, p. 7.1 (January 1974).

\section{SAS 3A:}

5. M. G. Stevenson, W. R. Boh1, F. E. Dunn, T. J. Heames, G. Hoppner, L. L. Smith, "Current Status and Experimental Basis of the SAS LMFBR Accident Analysis Code System," Proc. of the Conf. on Fast Reactor Safety, Beverly Hills, California (April 1974).

6. W. R. Bohl, F. E. Dunn, G. J. Fischer, T. J. Heames, J. F. Jackson, R. B. Nicholson, L. L. Smith, M. G. Stevenson, J. K. Travis, and A. Watanabe, "Progress in Analysis of Severe Accidents," Proc. Int. Conf. on Engineering of Fast Reactors for Safe and Reliable Operation, Karlsruhe, Germany (October 1972).

Multiple-Bubble Slug Ejection Coolant Voiding Model:

7. F. E. Dunn, G. J. Fischer, T. J. Heames, and P. A. Pizzica, A Multiple Bubble Slug Ejection Model for Coolant Voiding, Trans. Am. Nuc1. Soc., 14 (1) 241 (1971). 
Film Motion Voiding Mode1:

8. G. Hoppner and F. E. Dunn, Sodium Film Model in SAS 2A Voiding, Trans. Am. Nuc1. Soc., 16 (2) (Nov. 1973).

9. G. Hoppner, Sodium Film Motion Model of SAS 3A, ANL/RAS 74-22 (September 1974).

Primary Loop Hydraulics

10. F. E. Dunn, "Initiating Accident Code Development," ANL-RDP-2, p. 8.1 (February 1972).

Fuel-Coolant Interaction

11. L. L. Smith, J. R. Travis, M. G. Stevenson, F. E. Dunn, and G. J. Fischer, "SAS/FCI, A Fuel-Coolant Interaction Model for LMFBR Whole-Core Accident Analysis," Proc. Topical Meeting on Mathematical Models and Computational Techniques for Analysis of Nuclear Systems, CONF-730414-P1, Ann Arbor, Michigan (April 9-11, 1973). 


\section{Purpose}

Analysis of the steady-state thermal performance characteristics of mixed oxide fuel pins in a fast neutron environment.

\section{Status}

A. Development: Developed and under improvement at HEDL. SIEX II is current development version.

B. Availability: SIEX II is operational at HEDL on UNIVAC 1108. Documentation is available (Ref. 1).

C. Utilization: SIEX II has been used by HEDL as a data analysis and design tool for systematic analysis and prediction of EBR-II tested fuel pins, performance predictions for FTR driver fuel pins under normal operating conditions, design of fuel element experiments in FTR and for initialization of the MELT code.

\section{Problems Solved}

SIEX II is a steady-state heat transfer code for thermal performance and dimension change (swelling and thermal expansion) calculations of mixed oxide fuel elements in a fast neutron environment. Fuel restructuring, fuel and clad displacements due to swelling and thermal expansion, fuel-clad gap heat transfer and fission gas release are included to provide an assessment of fuel, clad and coolant temperatures throughout the history of a fuel element. Modeling emphasis is placed on correlations to measurable quantities from EBR-II irradiation tests and the inclusion of these correlations in a physically based computation scheme. The code is completely modular in construction, allowing the user options for material properties and correlated models. Required input is limited to geometric and environmental parameters.

SIEX II provides estimates of thermal performance characteristics with the requirement of only a small amount of computer core storage and running time. The resulting thermal analysis of SIEX II provides groundwork for:

1. Subsequent steady-state or transient stress analysis

2. Prediction of steady-state or transient failure modes and times

3. Safety related accident analysis, as with MELT (see MELT summary)

The following are calculated by SIEX II:

1. Coolant temperature

2. Cladding temperature 
3. Fue1-cladding heat transfer coefficient (gap conductance)

4. Fuel temperature profile

5. Fuel restructuring radii

6. Fuel and cladding displacements due to swelling and thermal expansion

7. Fission gas generated and released

\section{Models}

SIEX II models consist of a combination of mathematical and physically-based correlated models. The mathematical models are for heat transfer, gas plenum pressure and, to a certain extent, dimensional changes of the fuel and clad. The correlated models are for gas release, restructuring, and fuel-clad gap dimensions and conductance.

\section{Geometry}

The fuel pin is axisymmetric, with the fuel portion divided axially into segments of equal height. Each segment (node) may contain a central void, columnar grain fuel, equiaxed grain fuel, unrestructured fuel, a fuel-clad gap and clad. The axial segments are coupled only through their boundary conditions. There is one axial segment for the gas plenum.

2. Mathematical Models

\section{a. Heat transfer}

1-D radial heat transfer is assumed at the axial center of each axial segment. The fuel steady-state radial temperature distribution is calculated using the integral of the thermal conductivity, which allows for temperature-dependent thermal conductivity and fuel geometry changes. The increase in coolant temperature is found by adding the heat deposited in the coolant at each axial segment.

b. Fuel and clad dimension changes

The fuel and clad change dimensions by thermal expansion and swelling.

c. Gas plenum pressure

Gas pressure comes from fill gas, water vapor in fuel, absorbed gases in fuel and released fission gases.

3. Correlated Models

a. Fuel-clad residual gap and gap conductance

b. Fuel microstructure (restructuring)

c. Fission gas release 


\section{Limitations}

1. Axisymmetric geometry with 1-D radial heat transfer only.

2. Coolant inlet temperature and flow rate for a specific fuel pin are input, with no coolant cross-channel mixing calculated.

3. Fuel-clad mechanical interaction and the "gas bottle" effect are ignored.

Future Efforts

Continue correlation with data.

Interface/Overlap

MELT/LIFE

\section{References}

\section{SIEX II :}

1. D. S. Dutt and R. B. Baker, "SIEX, A Correlated Code for the Prediction of Liquid Metal Fast Breeder Reactor Fuel Thermal Performance," HEDL-TME 74-55, Dec. 13, 1974. 
SIMMER

\section{Purpose}

Analysis of core thermal, neutronic and material motion behavior during the core-disruptive events of an HCDA over the full-time domain up to permanent neutronic shutdown.

\section{$\underline{\text { Status }}$}
A. Development: Under development at IASL.
B. Availability: Is developmental on CDC-7600; various modules of the code are operational at LASL. Progress in code development has been reported (Ref. 1 and 2).
C. Utilization: When completed, SIMMER will provide one of the most advanced tools for analysis of core disruptive events. It will be utilized by NRC for an independent con- firmatory assessment of the FFTF and CRBR SAR's.

\section{$\underline{\text { Problems Solved }}$}

SIMMER is being designed to predict the extended material motion behavior and associated thermal and neutronic phenomena in an HCDA-disrupted LMFBR core through the full range of disruptive events up to the point of a stable, permanently subcritical and coolable core geometry. Code capabilities will allow the study of potential recriticality events.

\section{Mode1s}

The following describes the ultimate goal of SIMMER models and the current level of sophistication:

\section{Fluid dynamics}

The fluid dynamics algorithms of SIMMER will ultimately describe the motion of a multi-component vapor (fuel, sodium and steel) moving through globules of molten or solid fuel and globules representing molten steel or steel in the form of superstructure or confining walls. Current capabilities are provided by the KACHINA (Ref. 3) and SHALAKO codes, which are 2-D multifield hydrodynamics codes based on the ICE numerical technique (see ICECO summary for ICE references).

\section{Neutronics}

The neutronic capability will ultimately include 2-D, time-dependent transport theory. The current capabilities are the 1-D TIMEX (Ref. 4) and TWOTIME codes. 
3. Heat transfer

U1timately, the following heat transfer problems will be incorporated:
a. Freezing of steel and fuel
b. $\mathrm{UO}_{2} / \mathrm{PuO}_{2}$ vaporization condensation
c. Melting and ablation of steel
d. $\mathrm{UO}_{2}-\mathrm{PuO}_{2}-$ sodium heat transfer

4. EOS

U1timately, theoretical techniques will be developed for EOS data in the high-temperature and high-pressure regimes of mixed-phases and imperfect gases.

Future Efforts

Develop ultimate capabilities outlined in Models.

Interface/Overlap

REXCO/VENUS

\section{References}

Progress Reports:

1. K. D. Lathrop, "Quarterly Report: Transport Theory, Reactory Theory, and Reactor Safety, October thru December 31, 1974," LA-5858-PR.

2. Ibid, January 1 thru March 31, 1975, LA-5964-PR.

3. Anthony A. Amsden and Francis H. Harlow, "KACHINA: An Eulerian Computer Program for Multiphase Flow," LASL Report LA-5680 (December 1974).

4. W. H. Reed, "TIMEX: A Time-Explicit Discrete Ordinates Program for Solution of the Multi-Group Transport Equations," LASL Report LA-4800 (1972). 
SIMPLE

\section{Purpose}

A steady-state thermal-hydraulic analysis code for calculating first order thermal and flow effects on a wire-wrapped pin bundle

\section{Status}
A. Development: Developed at ANL/RAS; INTB, the transient version of SIMPLE, is under development.
B. Availability: Operational at ANL on IBM 360; model description has been published.
C. Utilization: Used by ANL in small bundle experimental design for OPERA facility and first order approximations for large bundles.

\section{$\underline{\text { Problems Solved }}$}

1. Calculates, with very little computer time (30 seconds for a 217 pin bundle), flow and temperature distributions within a wire-wrapped pin bund 1 e.

2. A design tool for understanding first order thermal effects in fu11sized wire-wrapped subassembly.

3. Aids in designing small test bundles such that they are prototypic of reactor conditions.

Mode1s

SIMPLE postulates that the wire-induced sweep flows in an LMFBR bundle are negligible in the central channels in comparison with the forced diversion cross-flows for inducing interchannel mixing. Forced diversion cross-flows are computed by assuming that the presence of the wire in one subchannel causes a decrease of flow in it by an amount determined by the decrease in flow area and equivalent diameter. In inner channels, the resulting excess fluid is assumed to be shared equally by all three adjacent channels. In corner channels, the cross-flow is taken to move in the direction of the spacer wire, resulting in a sweep flow effect. The wire-wrap is modeled as six straight segments along the fuel pin, with mixing occurring when fluid moves into or out of the subchannel specified a wire-wrap segment. Thermal conduction between subchannels is calculated.

Other assumptions in the models are:

1. All subchannels experience the same axial pressure gradient. 
2. Velocity and temperatures within a subchannel are uniform.

3. Single phase, incompressible, fully developed turbulent flow.

4. Fluid density and friction factor are constant for all.

\section{Limitations}

SIMPLE is designed to do fast, first-order effect calculations, free of empirical constants. The code capabilities do not include:

1. Two-phase flow.

2. Transient analysis.

3. Second order mixing effects, as turbulent diffusion.

Future Efforts

Develop transient version.

Interface/Overlap

- /THT, ORRIBLE, COBRA

\section{$\underline{\text { References }}$}

Henry, R. E. and R. M. Singer, ANL-RDP-4, p. 81, April, 1972. 
SLUMPY

\section{Purpose}

A module of SAS 3A utilized for analyzing axial, intra-assembly fuel motion resulting from a LOF HCDA.

\section{Status}

A. Development: Developed and under improvement at ANL/RAS.

B. Availability: Available as a module of SAS 3A; current documentation is informal (ANL/RAS report).

C. Utilization: Used in analysis of FFTF LOF HCDA consequences for FFTF FSAR support. Current application is for CRBR PSAR support. SLUMPY predictions have been compared with L-series experiments in TREAT and with out-of-pile experiments.

\section{Problems Solved}

SLUMPY, when integrated into the SAS 3A coolant dynamics, clad motion, heat transfer and neutron kinetics modules, provides an assessment of the consequences of axial fuel motion in a voided subassembly following clad melting. Its applicability is limited chiefly to slowly developing undercooling transients. Some features of SLUMPY are:

1. Flexible slumping initiation criteria.

2. Models fuel debris explicitly as a multi-phase mixture.

3. Estimates acceleration of the relocating fuel pins above the failure point of the fuel.

4. As long as the subassembly hexcan furnishes an initial barrier for fuel motion during a power burst, termination of the burst due to fuel dispersal can be determined as part of a consistent calculation.

\section{Models}

1. Geometry

Initial unperturbed geometry is same as multiple-channel concept of SAS 3A (see SAS summary). The basic calculational model is the "channel," which consists of a single fuel pin surrounded by its associated coolant and structure in cylindrical, axisymmetric geometry. SLUMPY calculates axial fuel motion within each channel, assuming radial motion is prohibited by the resistance of the structural wall, which represents the mechanical restraint of the subassembly duct. 


\section{Fuel Motion Models}

At fuel motion (slumping) initiation, pressures due to retained fision or fill gas in the fuel and any fission gas in a central void is assumed to cause radial expansion to fill the voided channel volume with the material in the axial node(s) (including fuel, fission gas and/or stainless steel) which first satisfy a slumping criteria. Subsequent fuel motion is determined by considering fuel in three distinct regions: (a) a middle "slumped" or compressible region, (b) an upper falling solid fuel segment and (c) a lower stationary solid fuel segment.

\section{(a) Middle Region Motion}

The middle slumped region moves according to a rea-dependent 1-D (axial) compressible hydrodynamics in Lagrangian formulation, which includes gravity, wall friction, intra-channel heat transport to SAS structure and channel-to-channel heat transport once the SAS 3A structure exceeds the melting temperature. Clad is assumed to be mixed with fuel if fuel melting has occurred at the same time or before clad melting; otherwise, fuel is pure oxide. As additional fuel nodes satisfy the slumping criteria, the slumped region is rezoned and grows. Limiting boundaries axially for the slumped region are dependent on user input, or if explicit clad motion is specified, the boundaries are determined by the time dependent positions of calculated clad blockages. The slumped region mathematical treatment is based on mass, momentum and energy conservation in a simplified three-component (fuel, steel and fission gas) formalism, with fuel and steel (if present) homogeneously mixed. Slip between fuel and fission gas assumes that fuel exists as either solid fuel particles or liquid fuel droplets of one characteristic diameter. Some of the simplifying as sumptions in the conservation equations are:

(1) in the energy equations, fission gas has negligible heat capacity, there is no heat transfer via conduction and the heat transfer terms are approximated by a heat transfer coefficient and temperature difference, with heat assumed to flow from restructured fuel to unrestructured fuel and from unrestructured fuel to steel,

(2) work terms in the energy equations are neglected except at the transition between the two-phase regions where small differences in energy result in large pressure differences,

(3) fuel and steel velocity in the energy equation is approximated by a mass-averaged velocity,

(4) viscous and friction terms are approximated by a wall friction term representing the viscous effects from an assumed velocity profile and an explicit axial viscosity dissipation component based on mass-averaged velocity, 
(5) due to negligible fission gas inertia, fission gas momentum conservation equation is treated as quasi-steady state, and

(6) fission gas release is assumed proportional to the retained gas in the fuel.

(b) Upper Region Motion

The upper segment moves by the forces of gravity, friction, pressure forces exerted by the slumped region and by any user-specified forces. Movement of the upper segment either into or out of the slumped region changes the area available for the slumped region. The upper segment is assumed to separate from the upper SAS axial blanket if clad motion occurs prior to fuel motion and no user specified forces act downward on the SAS blanket. Constraints placed on the motion of the upper segment are: (1) upward motion beyond a user specified distance is prohibited and (2) downward movement into a lower stationary segment is prohibited.

(c) Lower Region Motion

The lower segment is stationary and restricts the area available for the slumped region. The area occupied by the lower segment includes or excludes the clad area depending on whether the fuel pin was clad or, alternatively, clad motion had occurred before slumping initiation.

\section{Slumping Initiation Criteria}

(a) Base Case

The basic case initiates fuel motion within any channel following satisfaction of each of three basic conditions:

(1) channel sodium voiding has occurred,

(2) clad has melted and

(3) a fue1 thermal condition is satisfied.

The fuel thermal condition may be either:

(1) melting in the unrestructured fuel,

(2) user-specified fuel temperature to be exceeded at a specified radial node at any axial position, or

(3) a user-specified fraction of molten fuel to be reached at any axial node. 
(b) User Options

(1) a minimum necessary sodium vapor mass flow rate to simulate sodium vapor breakup of the fuel column or

(2) no requirement of clad melting; user must ensure that sodium voiding has occurred before slumping is initiated.

4. Heat Transfer

The SAS 3A transient heat-transfer module calculates temperatures in both the upper moving segment and the lower stationary segment. A simplified theory is used to treat intra-channel heat transport from fuel to the SAS 3A steel structure (hexcan plus wire wrap) and channe1to-channel heat transfer. Inter-channel heat transfer is based on an assumed equivalence to convective plus radiative heat transfer in a pipe, and is terminated after the structure exceeds melting. At this point, channel-to-channel (i.e., subassembly-to-subassembly) heat transfer occurs and can be treated by at least five various models available in SLUMPY.

\section{Fission Gas Treatment}

The fission gas retained in the fuel is determined at steady-state by the SAS 3A SSFUEL module. User specifies what fraction of this gas is available for dispersal of fuel and how gas is to be released, with available options including the fraction instantaneously available upon slumping initiation, and the specification of time constants for release of gas from solid and molten unrestructured fuel. Released fission gas pressurizes the available space via the perfect gas law contained in the EOS.

6. Neutronics

Fuel motion reactivity, Doppler feedback and changes in fuel power as a function of axial position are treated by perturbation theory. Channe1dependent axial distribution curves are defined for:

(a) the fuel worth per unit fuel mass,

(b) the local fuel Doppler coefficient per unit fuel mass and

(c) the fuel power per unit fuel mass.

The integral fuel reactivity and Doppler feedback are evaluated by multiplication with the time dependent fuel spatial distribution and each fuel segment and/or compressible node is assigned a power based on the reactor power level at the spatial location of the fuel in question. The reactor neutron flux shape is assumed to be unchanged by fuel melting and fuel motion.

7. EOS

The EOS is composed of five parts which include a background pressure (from sodium vapor or user specified), a fission gas pressure, a vapor 
pressure from fuel and/or steel (from ANL EOS), a single-phase pressure if a pure liquid and/or solid exists, and a pseudo-viscous pressure to provide a more stable numerical solution for large pressure gradients.

\section{Limitations}

SLUMPY applicability is limited to slowly developing undercooling accidents, as in the highest power subassemblies following a LOF in the FTR, where fuel motion occurs in a completely voided subassembly after clad melting. SLUMPY currently cannot handle accurately the following fuel motion regimes:

1. TOP-type fuel motion which involves fuel movement inside relatively strong clad, clad failure, and fuel movement into the coolant channel where it undergoes strong pressure gradients from interactions with sodium liquid and vapor.

2. Fuel motion in medium-power subassemblies undergoing a power burst during an LOF, where fuel pin breakup occurs without complete voiding and only a small degree of clad melting. The fundamental limitations which prohibit application in this regime are:

(a) integration of SLUMPY fuel motion with the SAS sodium voiding model is crude and possibly inadequate to properly assess the degree of slip between sodium vapor and fuel,

(b) fuel motion inside the pin (a strong clad boundary) is not allowed; SLUMPY presumes that clad mixes uniformly with fuel when fuel motion occurs,

(c) SLUMPY does not take into account the possibility of strong 2-D effects due to radial incoherence of fuel motion and

(d) SLUMPY does not explicitly calculate freezing and plugging of fuel, which may occur in the relatively cold sodium flow channels in the blanket and fission-gas plenum regions.

3. Energetic prompt-critical core disassembly fuel motion, as predicted by VENUS, where radial motion is important in terminating the excursion.

To summarize, the general limitations of SLUMPY are as follows:

1. 1-D model cannot calculate radial incoherency effects within a disrupted as sembly.

2. Reactivity treatment, based on perturbation theory, is not precise.

3. Slip of all possible vapor species in any possible mode is not treated.

4. Clad-fuel mixtures cannot vary in composition axially.

5. Freezing and plugging of fuel is not explicitly calculated. 
6. All fuel motion is compressible.

7. Geometry is limited to that of SAS $3 A$.

8. The SAS FCI module and SLUMPY cannot operate in the same channel simul taneously.

9. SLUMPY applicability is primarily for the highest power subassemblies in a FTR-type core under an LOF transient; considerable modification is required for applicability to the full range of subassemblies powers in larger cores.

\section{Future Efforts}

1. Short-term (FY '75) modifications

a. Improved fission-gas source term.

b. Improved treatment for slowly slumping, quasi-compressible fuel.

2. Longer-term (FY' 76 and beyond) modifications

a. Differential mixing of steel and fuel as a function of axial position.

b. Molten clad area restrictions leading to momentum and energy interchanges with fuel.

c. Steel blockage effects on fuel motion and heat transfer.

\section{Interface/Overlaps}

$\mathrm{SAS} /-$

\section{$\underline{\text { References }}$}

1. Documentation:

W. R. Boh1, SLUMPY: The SAS 3A Fuel Motion Model for Loss-of-Flow, ANL/RAS 74-18 (August 1974)

2. Conferences:

W. R. Bohl and M. G. Stevenson, "A Fuel Motion Model for LMFBR Unprotected Loss-of-Flow Accident Analysis," CONF-730414-P2, Ann Arbor, Michigan (Apri1 1973). 


\section{SODIPROP}

\section{$\underline{\text { Purpose }}$}

Provides a consistent set of high-temperature thermodynamic properties for sodium in the two-phase and subcooled-liquid regions.

\section{Status}

A. Development: Developed at ANL/RAS.

B. Availability: Operational at ANL on IBM 370; code description is available (Ref. 2).

c. Utilization: Used by ANL to provide consistent thermodynamic calculations in LMFBR safety analysis.

\section{Problems Solved}

High-temperature thermodynamic properties for sodium are predicted in the twophase and subcooled-liquid regions between $2500^{\circ} \mathrm{F}$ and the critical temperature. The saturation properties determined are: vapor pressure, liquid and vapor enthalpy, liquid and vapor entropy, liquid compressibility (adiabatic and isothermal), liquid thermal-expansion coefficient, and liquid specific heat (constant pressure and constant volume). The subcooled liquid properties determined are: pressure, enthalpy, entropy, compressibility (adiabatic and isotherma1), thermal expansion coefficient, and specific heat (constant pressure and constant volume).

Models

The high-temperature saturation properties are an extension of the low-temperature properties (up to $2500^{\circ} \mathrm{F}$ ) recommended by Golden and Tokar (Ref. 1 ).

The high-temperature properties (above $2500^{\circ} \mathrm{F}$ ) are based on a number of hightemperature correlations and basic thermodynamic relationships summarized in Reference 2 .

\section{Limitations}

High-temperature sodium property data is not available for verification of some of the correlations used. Other fluids, for which data is available, are therefore used as sodium analogs.

\section{Future Efforts}

As data for cesium becomes available, correlations for sodium will be re-examined. 


\section{Interface/Overlap}

Any code requiring sodium data/ -

\section{References}

1. G. H. Golden and J. V. Tokar, "Thermophysical Properties of Sodium," ANL-7323, ANL, A vg. 1967.

2. A. Padilla, "High-Temperature Thermodynamic Properties of Sodium," ANL/RAS 73-35, November 1973. 
SOFIRE

\section{Purpose}

Analysis of the pressure and temperature history in a cell containing a sodium pool fire as the result of a sodium spill accident.

\section{Status}

A. Development: Developed and under improvement at AI.

B. Availability: SOFIRE-1 was documented in 1968 (Ref. 1). SOFIRE-2 was released in 1973 with user's manual (Ref. 2). SOFIRE-2 is operational at AI on the IBM 360, at HEDL on the UNIVAC 1108 and at GE- BRD on the HONEYWELL 6000.

C. Utilization: SOFIRE-2 has been used for FFTF FSAR and CRBR PSAR sodium pool fire analysis. SOFIRE-1 is no longer in use.

\section{$\underline{\text { Problems Solved }}$}

SOFIRE- 2 calculates sodium pool burning dynamics in a cell and the accompanying temperature and pressure transients in the cell gas atmosphere. In the "one-cell" option, the code considers the cell to be closed, while the "twocell" option allows the pool-containing cell to be connected with a second cell through a restricted opening which allows gas flow between the cells.

SOFIRE-2 calculates the following:

1. Sodium pool burning rates as a function of oxygen diffusion to the pool surface.

2. Temperature and pressure history of the cell gas atmosphere.

3. Thermal transients in the cell structures.

4. Sodium aerosol production.

5. Time and temperature dependent mass transfer of oxygen to the pool surface.

6. Natural convection heat transfer from the pool to the cell walls.

7. Radiation from the pool to the cell gas atmosphere. 


\section{Mode1s}

SOFIRE-2

\section{Geometry}

The basic equations in the code are 1-D and are not restricted to any specific size of pool or cell. In the optional two-cell case, a cell is located above the cell containing the pool. The duct opening between cells has a specified cross section, diameter and length.

\section{Sodium Burning Dynamics}

The sodium burning rate is proportional to the oxygen concentration and is controlled by the mass diffusion of oxygen to the pool surface. Heat release by self-absorption in the sodium pool due to gamma-active $\mathrm{Na}^{24}$ is included as an option. Also, selective releases of fission product decay heat may be accounted for in the gas, sodium and structure.

3. Mass Transfer

The time and temperature dependent mass transfer (Ref. 3) of oxygen to the pool surface is calculated for the pool-containing cell. In the two-cell case, the pool burns in a lower cell with hot gas produced which induces mass transfer between it and the cold upper cell by the following two mechanisms:

a. Natural Convection: due to the difference in gas temperatures in the two cells, there is a net mass transfer to the lower cell due to buoyancy effects which is based on the empirical correlation of Brown (Ref. 4).

b. Pressure Differential: mass flow from the lower to the upper cell due to static pressure difference is determined by Bernoulli's equation. In all cases, the thermodynamic relations for the gases in the cells are assumed to obey the ideal gas 1 aw.

4. Heat Transfer

Heat transfer within a cell is by:

a. Natural convection heat transfer from the gas to the structure (Ref. 5).

b. Radiation heat transfer from the pool to the cell walls.

c. An empirically determined quasi-radiation term from the pool to gas (Ref. 6).

For the pool and structures, the 1-D Fourier transient conduction equation is solved. 


\section{Heat Structures}

In addition to the sodium pool and the heat-storing masses in each cell, there are three heat structures representing the pool-containing cell and two heat structures for the other cell, with any of these structures being omitted at the user's option. Each heat structure has nine temperature nodes in series.

6. Method of Solution

Heat and mass balance equations are finite-differenced and solved by a march-out type calculation.

\section{Limitations}

1. Solution becomes unstable for very small sodium spills, restricting the pool depth to at least $\frac{1}{2}$ inch if it is not zero (no sodium).

2. Being programmed for liquid sodium, the code does not allow calculation in sodium phase transitions.

3. Thermal characteristics of all materials are assumed constant.

4. Radiation source term interchange between heat source to cell wall and the sodium aerosol is not aerosol concentration dependent.

5. Combustion product mixture (monoxide or peroxide) is not time and temperature dependent.

6. Mass transfer of oxygen to the pool surface should be governed by more sophisticated gas circulation models as in SOMIX (see SOMIX summary).

\section{Future Efforts}

Minimize effects of limitations by incorporating experimental information and better theoretical models.

\section{Interface/Overlap}

SOMIX, HAA-3/

\section{$\underline{\text { References }}$}

SOFIRE-1

1. R. P. Johnson, et a1, "Characterization of Sodium Pool Fires," Conf. on Sodium Tech. of Large Fast Reactor Design, Nov. 7-9, 1968, Part I, ANL-7520, 1968.

\section{SOFIRE- 2}

2. P. Beiriger, et al, "SOFIRE-2 User Report," AI-AEC-13055, March 30, 1973. 
3. R. B. Bird, W. E. Stewart, and E. N. Lightfoot, Transport Phenomena, John Wiley and Sons, 1960.

4. W. F. Brown, "Natural Convection Through Rectangular Openings in Partitions," J. of Heat and Mass Transfer, Vo1. 5, 1962.

5. E. R. G. Eckert and R. M. Drake, Heat and Mass Transfer, McGraw-Hill Book Co., New York, 1959.

6. H. A. Morewitz, et al, "Annual Technical Progress Report, LMFBR Safety Problems GFY 1969," AI-AEC-12858 (Health and Safety), Atomics International, Canoga Park, California, October 15, 1969. 


\section{Purpose}

Analysis of the transient convection in a heat-transfer equipment cell atmosphere heated by a hot sodium droplet spray from a pipe rupture accident in the cell.

\section{$\underline{\text { Status }}$}

A. Development: Under development at AI.

B. Availability: A developmental version is operational at AI on the IBM 370. Documentation is in the form of a status report (Ref, 1).

C. Utilization: When fully developed, will be used for SAR supporting analysis.

\section{Problems Solved}

SOMIX analyzes transient free convection motion in the low-oxygen gas environment of a cylindrical enclosure, representing an LMFBR heat transfer cell, following a large sodium pipe rupture in the cell which releases a spray of hot sodium droplets. Calculated are the combustion and transfer of heat from the falling spray to the cell gas atmosphere (which may contain any initial concentration of oxygen), the temperature rise of the gas, the internal gas circulation resulting from thermal gradients and entrainment of the falling droplets, and the effects on the cell gas pressure of the resulting heat and mass transfer, droplet motion and droplet combustion.

\section{Models}

1. Geometry

A 2-D analysis in cylindrical geometry can handle large single or multiple cells on the order of 30-40 feet in height. An arbitrary pipe rupture level can be accommodated.

2. Fluid Flow and Droplet Motion

The cell gas atmosphere is treated with a 2-D compressible fluid flow analysis in cylindrical geometry. The large spectrum of falling droplet sizes is categorized into groups with one mean drop size per group. The droplet velocity at any cell level is determined by balancing gravitational force against buoyant and drag forces. Gas circulation by free convection in the cell atmosphere is limited to Grashoff numbers on the order of $10^{6}$, which is characteristic of gas circulation properties in small volumes. 
3. Heat Transfer and Droplet Combustion

Heat transfer is calculated from the cell gas to the ceilings and walls. The droplet burning model of Shires (Ref. 2) is used in which the droplet is divided into four zones: the liquid droplet itself, a gas film transport zone, a burning zone, and a boundary layer. Sodium is transported from the liquid droplet through the gas film zone and reacts with oxygen in the burning zone. The resulting oxide is transported from the burning zone through the boundary layer to the environment. Any initial cell gas oxygen concentration is allowed.

4. Method of Solution

All equations are finite differenced and solved numerically with an explicit time-differencing scheme.

The Boussinesq approximation used in the finite-difference numerical formulation of the convecting cell gas is valid only for relatively small gas temperature changes (on the order of $10 \%$ of the initial temperature) which limits the maximum allowable values for the cell gas temperature gradients.

\section{$\underline{\text { Limitations }}$}

1. Maximum cell gas temperature gradient is limited by the Boussinesq approximation made in the numerical solution technique of the finitedifference equations.

2. Cell gas natural circulation properties are limited to Grashoff numbers no larger than $10^{6}$, which are not sufficient to calculate full-sized LMFBR equipment cells.

\section{Future Efforts}

1. Extend code to calculate higher Grashoff numbers (up to $10^{12}$ ) which are characteristic of full-sized LMFBR cells.

2. Extend maximum allowable cell gas temperature gradient by replacing Boussinesq approximation of limitation $k_{1} 1$.

3. Incorporate pool burning model to describe oxygen transport to sodium pools formed due to agglomeration of sodium droplets.

\section{Interface/Overlap}

SOFIRE/

\section{References}

1. M. P. Heisler, "Status Report on SOMIX Development," TI-707-130-028, 1973.

2. P. R. Shire, M. S. Thesis, U. of Wash., 1972. 


\section{Purpose}

Analysis of sodium spray fire accidents in low-oxygen equipment and pipeway cells.

\section{Status}

A. Development: Developed at HEDL

B. Availability: No documentation is available. The code is operational at GE- BRD and at HEDL on the UNIVAC 1108.

C. Utilization: Used in FFTF FSAR and CRBR PSAR sodium spray fire analysis.

Problems Solved

Calculates, for cells containing initial gas atmospheres up to $2 \%$ oxygen, the temperature and pressure history of the cell gas and the cell structure transient thermal response resulting from a sodium spray fire accident.

Mode1s

1. Geometry

An option allows venting of the gas in the spray fire containing cell to an adjacent cell.

2. Sodium Burning Dynamics

The code performs the thermodynamic, heat transfer, mass transfer and sodium droplet combustion calculations for droplets falling through a conical volume in a gravitational field.

3. Venting

Venting to an adjacent cell is determined by compressible gas dynamics.

\section{Limitations}

1. Limited to cell atmospheres with up to $2 \%$ oxygen concentrations.

2. Does not contain effects of cell gas entrainment of sodium and cell gas recirculation effects.

Future Efforts

None 
Interface/Overlap

- /SOMIX, CACECO

Referencer

None 


\section{Purpose}

Analysis of a single core subassembly hydrodynamic-structural response to local pressurization accidents and the interaction of the accident subassembly with its surroundings.

\section{$\underline{\text { Status }}$}

A. Development: Developed and under improvement by ANL/RAS .

B. Availability: Operational at ANL on IBM 370. Documentation is available (Ref. 1-3).

C. Utilization: Has been used for FFTF and CRBR safety analysis. Experiment analysis has been performed for EBR-II ducts.

\section{Problems Solved}

2-D analysis of subassembly transient respouse to rapid pressurization and the transmittal of the pressure loading to adjacent subassemblies. The structural damage to the accident subassembly duct is determined as well as the potential for subassembly-to-subassembly damage propagation. It employs a finite-element method which is valid for large-displacement, small-strain problems with material non-1inearities.

Some capabilities of STRAW are:

1. Interaction of accident subassembly with surrounding: since the transient response of a duct to an internal pressure load is sensitive to the restraints surrounding it, STRAW analyzes the interaction of the accident duct with the surrounding subassembly structures and with the betweensubassembly fluid. Plane (i.e., within the duct cross section) and axial (i.e., perpendicular to the duct cross section) compressible fluid motion is calculated within and between ducts.

2. Pressure source: the driving internal pressure may be input or internally calculated with an FCI model.

3. Treatment of long-duration accidents with an implicit temporal integration formulation.

4. Thermal effects: can analyze a structure subjected to variable inside and outside temperature distributions (as a duct wall subjected to a high heat flux from molten fuel) and determine thermal stresses. 
Models

1. Geometry

The standard LMFBR geometry is a unit thickness cross-section of a hexagonal subassembly and its surroundings with no axial dependence.

2. Governing Equation

Analysis is based on the finite-element method which uses a convected coordinate technique (each element being associated with a coordinate system which rotates with that element) and a direct nodal force computation scheme for the internal nodal forces. Two types of elements are included: the flesural-beam element (for modeling of duct wa1ls) and the continuum element (for modeling of fluids). Both elements can handle arbitrarily large rotations and translations, a1though the continuum element is restricted to small deformations. The beam element includes a correction for the change in crosssectional area based on complete incompressibility of the material. The beam element material is considered elastic-plastic with linear, isotropic, strain-hardening properties. The continuum element material may be linear and hydrostatic or linear, isotropic and elastic.

The governing finite-element equations for the beam element are based on the derivations of Belytschko and Hsieh (Ref. 4) and those for the continuum element are based on the fluid flow formulation of Oden (Ref. 5).

3. Method of Solution

The governing equations may be solved using an implicit or an explicit temporal integration scheme. The implicit scheme allows the calculation of long-duration transients, static analysis and thermal stress analysis since a strict stability limitation is not imposed on the time-step size, as is required for the explicit case. In the explicit case, lumped masses are used to represent the inertial properties of the structure and continuum, while the implicit scheme uses a consistent mass mode of calculation.

4. Axial Fluid Flow

A superimposed model of axial flow (i.e., perpendicular to the duct cross section) calculates the axial compliance of the duct internals. The axial flow of fluid above the pressurization zone is resisted only by the viscous shear stresses exerted by the fuel pin walls and the inertia of the fluid. This axial flow is modeled by super elements which are coupled to the 2-D model of the subassembly cross section.

5. Heat Transfer

An FCI model, identical to REXCO-HT (see REXCO summary) is available as an option.

\section{Limitations}

1. Geometry is restricted to $2-D$. 
2. Subassembly internal structure is assumed to behave like a homogenized material.

3. The implicit integration mode cannot be used with the sliding interface or rotated coordinate option that is available in the explicit mode.

\section{Future Efforts}

1. Eliminate 1 imitation number 3 .

2. Develop mathematical mode1 for fuel pin bundle response to treat distinct regions of fuel and sodium.

3. Develop models for subassembly impact, fracture effects and fuel pin stress analysis.

Interface/Overlap

- /SADCAT

\section{References}

1. J. M. Kennedy and T. Belytschko, Energy Source and Fluid Representation in a Structural Response Code--STRAW, ANL-8140 (November 1974).

2. D. F. Schoeberle, et a1., Implicit Temporal Integration for Long-Duration Accidents in a Structural Response Code--STRAW, ANL-8136 (October 1974).

3. J. M. Kennedy, Nonlinear Dynamic Response of Reactor-Core Subassemblies, ANL-8065 (Janua ry 1974).

Beam Element:

4. T. Belytschko and B. J. Hsieh, "Nonlinear Transient Finite-Element Analysis with Convected Coordinates," Rep. 72-7, Dept. of Materials Engr., U. of I11. at Chicago Circle (1972).

Continuum Element:

5. J. J. Oden, "Finite Elements of Nonlinear Continua," McGraw-Hill, Inc., New York (1972). 


\section{Purpose}

A general 3-D heat transfer program for computation of steady-state and transient temperature distributions for problems including conduction, convection and thermal radiation.

\section{Status}

A. Development: The THT-series was developed at GE. The fifth, most advanced and current developmental version is THT-E.

B. Availability: THT-D was released in 1968 for use on the GE-325, and was subsequently made operational on the UNIVAC- 1108 and CDC-6400. THT-E is operational at GE on the GE-635. Hydraulic features recently added to THT-E require verification before full production status can be assigned.

C. Utilization: THT-D and -E have been used in analysis of TRFAT experiments. Both versions have been used for TREAT TOP experiment analysis, but only THT-E has been applied to LOF experiments because it provides the necessary flow and pressure drop computations. Coupled with the BEHAVE- 3 code, the THT codes provide a complete thermal-mechanical analysis of TREAT experiments.

\section{Problems Solved}

The THT codes provide a solution capability for large, complex, 3-D transient and steady-state heat transfer problems which can include conduction, convection, and radiation modes of heat transfer, with the option to compute fluid flow rates on a 1-D basis. Material thermal properties are temperature dependent. THT-E is specifically intended for use in thermal-hydraulics problems where flow and pressure drop relationships are required, calculating coolant (single phase gases and liquids) flow and pressure drop in independent flow channels containing compressible or incompressible fluid. THT-E is faster and potentially more accurate than THT-D.

\section{Models}

\section{Geometry}

THT-D and -E use the lumped parameter approach for describing thermal systems, the problem geometry being divided into nodal volumes (i.e., nodes). These are preferably small volumes to minimize spatial truncation errors in the solution. A single temperature, assumed to be at the centroid of the node, characterizes the entire node. The nodes can have up to six faces each. Thus, a node can have a maximum of six neighbors with respect to heat transfer by conduction and convection, while no such 
limitation exists with respect to thermal radiation. The number of nodes which can be specified depends on the available computer memory and amount of non-geometrical data, with 6000 nodes being the invariant maximum for THT-E. Nodes may uniformly contain solid, flowing gas or liquid, or stationary gas or liquid. Nodes may be of any shape. Nodes may change phase irreversibly. In THT-E, fluid mixing is allowed at flow channel junctions. Flow channels are independent otherwise and connected to common pressure sources (as an option, flow may be specified and pressure calculated assuming no common pressure source). Flow is treated in one dimension. Cylindrical geometry is generated by a subroutine using abbreviated input. THT-D allows nodes to contain a binary gas mixture which varies with time.

2. Radiative Heat Transfer

Grey-surface radiation is modeled by definition of a radiation heat transfer coefficient. Receiving and emitting nodes are defined by the user. Emissivities may be specified as functions of temperature.

3. Convective Heat Transfer

Convective heat transfer coefficients are determined from empirical correlations or may be tabulated. In THT-D flow rates for use in the correlations (and in heat transfer calculations) are provided by the user as tables of flow rate vs. time. The THT-E code calculates flow rate vs. time if the user selects that option. Fluid temperature mixing at flow channel junctions is modeled by an eddy diffusivity method.

4. Phase Changes

Solid-to-liquid and 1 iquid-to-vapor phase changes are allowed, but transition from stationary to moving fluid is not allowed.

\section{Heat Generation}

Heat generation rates are specified in tabular form as functions of time, location, and temperature. Temperature-dependent heat generation is operational but user experience is insufficient to verify stability of the solution. Surface heat flux may also be specified in tabular form as a function of time and position.

6. Thermal Material Properties

Properties of each material are specified by the user in tabular form as functions of temperature. Latent heats may a1so be specified.

7. Fluid Flow (THT-E only)

One-dimensional, single-phase compressible or incompressible flow without chemical reactions in independent flow channels. One option calculates flow rate and flow distribution for parallel channels connected to common plenums with the pressure conditions specified. The other option calculates the pressure drop for individual channels with the channel flow rate 
specified. Fluid flow is calculated on a pseudo-transient basis (steadystate flow in response to time-varying conditions). Compressible and/or incompressible flow may be present in a single problem. Arbitrarily connected flow channels cannot be analyzed at present.

\section{Current Limitations}

1. Cannot analyze two-phase compressible flow with boiling phenomena.

2. Phase changes are irreversible.

3. Cannot analyze flow distribution in arbitrarily connected flow channels.

4. Coolant mixing model cannot analyze forced diversion or flow sweeping.

5. Too large and costly to perform iterative analysis of redistribution of material after melting.

6. THT-D limited to 2000 nodes; THT-E limited to 6000 nodes.

7. Pressure-drop calculation not validated by experiment.

8. Temperature-dependent heat generation option may not be numerically stable.

9. Operationa1 only on GE-600 series ( $-D$ and $-E$ ) and Univac-1108 (-D only).

10. THT-E does not allow variable binary gas mixture nodes.

\section{Future Efforts}

No major activities planned. The following code improvements are under consideration:

1. Add reversible phase change and model boiling phenomena.

2. Model forced diversion flow and flow field near a blockage.

3. Consider fuel motion (by inexpensive approximate methods) in thermal solution.

4. Validate pressure drop calculation.

5. Convert THT-E to other computers.

6. Add variable binary gas mixture to THT-E.

Interface/Overlap

BEHAVE, TOFF/COBRA, SIMPLE, ORRIBLE 


\section{$\underline{\text { References }}$}

S. C. Skirvin, "User's Manual for the Standard THT-D Computer Program on GE-600 Series Computers," General Electric Research and Development Center, May $1969,69-\mathrm{C}-205$.

S. C. Skirvin, "A Brief Guide to the Use of Version E of the Transient Heat Transfer Computer Programs (NMP-857)," General Electric Missile and Space Division, June 1968 (GEMP-614). 


\section{Purpose}

Analysis of fuel motion, clad loading and clad failure for fuel pins under TOP conditions.

\section{$\underline{\text { Status }}$}

A. Development: Developed and under improvement at GE-BRD. TOFF-II is current development version.

B. Availability: Operational on Honeywe11-6000 at GE. The code is documented only in an internal GE memo (Ref. 1).

C. Utilization: TOFF-II was intended to be used as a fuel pin failure prediction subroutine to the whole-core accident analysis mode of FREADM-II. Utilization of TOFF-II has been confined to design and interpretation of transient overpower experiments. Analytical scoping studies intended to identify important clad loading mechanisms have also been performed. Recent development of BEHAVE- 3 has made that code the primary GE tool for design and interpretation of transient overpower experiments. TOFF-II is presently being evaluated as a possible basis for the probabilistic POPS code and to examine the relative importance of various proposed clad loading mechanisms.

\section{Problems Solved}

Simulates the physical processes occurring in a fuel pin subjected to a TOP energy input. Performs a simplified analysis of clad failure under the influence of internal pressure caused by fission gas, fuel swelling, fuel thermal expansion and fuel melting. An external heat transfer calculation is required to provide molten fuel volumes and clad and fuel temperatures. TOFF-II is intended for simultaneous analysis of multiple independent fuel pins to represent core-wide variations during TOP conditions. The following are user input parameters:

1. Assumed radial fission gas distribution.

2. An accounting of the thermal volumes of all constituents, fuel, clad and gas.

3. Clad strength and ductility as a function of temperature and irradiation history.

4. Rate of energy input during TOP.

5. Post clad failure analysis. 
Models

TOFF-II :

1. Geometry

Cladding treated as thin-walled cylinder with any number\% of axial sections. No clad wastage effects are modeled. Fuel is divided into solid and molten regions. Fuel has no structural integrity; pressure is transmitted directly through fuel to cladding. Any number: of radial fuel rings may be defined to account for movement of molten fuel. Fission gas plenum modeled as a volume used to calculate gas pressure. Axial fuel restraint by hardware in plenum region modeled as a boundary condition. Three region radial model used to describe porosity distribution in fuel.

* Note: A tota1 of 1000 nodes may be specified in any manner.

2. Cladding Stress and Strain

One-dimensional creep and plasticity analysis is used to describe cladding behavior. Minimum-yield-stress axial position is assumed to deform during transient conditions. Cladding properties are provided by the user in tabular form or as correlations. The predicted mechanism leading to failure is primarily based on the fuel volume change during melting (about $10 \%$ ) and the resulting compression effect on fission gas entrained in the fuel as a result of prior steady state irradiation.

3. Thermal Model

Temperature distributions within the clad and fuel are supplied by THT-D or THT-E (see THT summary). As a result, temperature distributions are not consistent with fuel structure or fuel motion.

4. Fuel Motion

Molten fuel is modeled as a compressible material which can move axially or produce short-term plastic clad strain. Molten fuel is allowed to move axially when pressure in the central fuel region exceeds the forces exerted by nonmolten fuel and blanket material, fuel-clad shear forces, and the force exerted by fission gas plenum pressure. Nonmolten fuel above the molten fuel is assumed to move as a piston which compresses gas in the fission gas plenum.

5. Fuel Stress, Strain, and Cracking

These calculations are not performed in TOFF-II. Fuel is present in TOFF-II as an incompressible, nonmolten region which simply transmits pressure and as compressible molten fuel.

\section{Limitations}

The code is intended to treat fuel rod behavior in a simplified manner, so it neglects many phenomena that have been observed in fuel. Some of the areas in which increased modeling is being considered are: 
1. Providing an internal thermal model and establishing consistency between fuel motion and thermal conditions.

2. General upgrading of clad stress and strain analysis to consider interaction of axial clad sections.

3. Review of material property correlations to establish correspondence with basic property data.

4. Incorporation of additional features in fuel motion analysis in light of scenarios indicated by more sophisticated codes and correlations of TREAT data.

5. A maximum of 1000 fuel nodes may exist in any problem (which may include multiple rods).

\section{Future Efforts}

1. Incorporation of additional features as indicated by the 1 ist of limitations.

2. Clad loading mechanisms suggested by experimental data will be programmed and compared with data to assess their ability to describe all data.

3. TOFF-II may be the basic framework upon which the POPS code will be based. This determination depends upon the results of calculations now in progress.

\section{Interface/Overlap}

Interfaces with THTD and THTE codes, which provide thermal calculations for TOFF-II. TOFF-II is a greatly simplified model of processes analyzed by BEHAVE-3, DEFORM-II, and PECT.

\section{References}

1. "TOFF Program Description," R. G. Stuart, Draft Version Only, December 31 , 1972 .

2. PA-10 34th and 35th Quarterly Reports (GEAP 10028-34 and -35).

3. R. G. Stuart and G. R. Thomas, "Effects of Fission Gas on Transient OverPower Fuel Rod Failure," Trans. of Am. Nuc. Soc., 13, 654, 1970. 
TRANSWRAP

\section{$\underline{\text { Purpose }}$}

Analysis of 1-D flow transients in a sodium piping network subjected to a sodium-water reaction from a large-leak accident in a steam generator.

\section{Status}

A. Development: Developed and under improvement at AI. TRANSWRAP II is latest version.

B. Availability: TRANSWRAP $I$ is operational at AI and has been documented (Ref. 1-2). TRANSWRAP II is operational at AI and has been documented (Ref. 3-4).

C. Utilization: Has been used for LLTR design and analysis, and for CRBR PSAR safety analysis.

\section{Problems Solved}

Calculates time-dependent fluid velocities and pressures within the piping and various components comprising a secondary sodium loop following a large leak sodium-water interaction in a steam generator module. Calculated results include maximum pressures and velocities at all system locations, temporal locations of rupture disk failures, and a time history of the pressure, temperature, and volume of the expanding hydrogen gas bubble.

$\underline{\text { Models }}$

TRANSWRAP I :

1. Sodium-water reaction dynamics

A 1-D reaction zone model located at the junction of two or three pipes. Instantaneous reaction is assumed and wave motion in the reaction zone is neglected. The initial conditions require the specification of a bubble volume and reaction temperature. For single phase liquid water, the water in-flow and system transients are obtained by the method of characteristics and are coupled to the reaction zone response. Steam or two-phase flow is 1 imited to a specified ramp-rate in-flow, with fictitious values of velocities, sonic speed, pipe length and friction factors predetermined to match the water system to the specified mass flow. No compressible flow phenomena, as choking and subsonic or supersonic transient flows are taken into account.

2. Fluid flow and numerical method

Uses the method of characteristics to solve the 1-D non-1inear fluidhammer (slightly compressiblelequations in a fixed time-space grid for each pipe of the flow network. 


\section{Pipe dilation}

The elastic response of the pipe is handled by modifying the wave speed to account for pipe expansion due to fluid pressure.

4. Piping system

Forms pipe networks from numbered branches and junctions. Pipe junctions accommodate the joining of two or three pipes. Components and pipe end junctions include constant velocity boundaries, accumulators, rupture disks, and pressure boundaries. Pressure drops at two and three pipe junctions can be calculated by specifying constant loss coefficients. Pumps can be approximated by an equivalent pipe representation. The relief system piping downstream of a rupture disk can be included in the calculation.

\section{TRANSWRAP II :}

This version represents an improvement over TRANSWRAP I in the areas of bubble kinetic behavior and monitoring of the venting process in the relief system. Treatment of the sodium piping system is essentially the same as TRANSWRAP I.

\section{Sodium-water reaction dynamics}

The water injection treatment includes both single and two-phase water injection rate calculations. The sodium-water reaction allows for twophase water, non-instantaneous reaction time, partial water reaction, treatment of unreacted water, and various reaction equations with different proportions of solid reaction products resulting. The expansion of the bubble is tracked throughout the secondary system, leading to greater accuracy in the calculation of the change in bubble volume. A spherical bubble model calculates bubble behavior during the early part of the transient.

\section{Relief System}

Computation of filling and venting of the relief system includes noninstantaneous rupture disk failure and blowdown of bubble mixture out of the relief system.

\section{Limitations}

TRANSWRAP I has the following limitations, which are eliminated by TRANSWRAP II:

1. Sodium voiding of components and piping due to hydrogen gas displacement is not accounted for.

2. Transient (constantly changing properties) two-phase water flow cannot be treated within the framework of the constant property pipe assumption.

3. The calculation of the initial expansion phase ( $<1 \mathrm{msec}$ ) of the bubble growth is bypassed to accommodate the one dimensional plane wave calculational model. 
4. The calculation of the gas bubble behavior assumes instantaneous reaction, assumes only one chemical reaction $\left(\mathrm{Na}_{2} \mathrm{O}\right)$, and neglects any heat loss mechanisms.

5. Rupture relief disks are assumed to react instantaneously.

TRANSWRAP I and II both have the following limitations:

6. The 1-D nature of the code does not allow multidimensional treatments, such as for components.

7. Plastic wall deformation is not accounted for.

8. Piping system limitations are as follows:

a. Number of pipes and junctions: 169

b. Maximum nodes per pipe: 40

c. Pipe junction: up to 3 pipes

\section{Future Efforts}

1. Elastic-plastic pipe and component deformation.

2. Bubble instability.

Interface/Overlap

/NAHAMMER, NATRANSIENT

\section{References}

TRANSWRAP I

1. C. Bell and M. Heisler, "TRANSWRAP - A Compressible Hydrodynamic Code for Large Leak Sodium/Water Reaction Analysis," TI-001-130-025, February 5, 1975

2. C. Bell and M. Heisler, "Capabilities and Limitations of TRANSWRAP," TI-001-130-027, March 21, 1973

\section{TRANSWRAP II}

3. C. Be11, "TRANSWRAP II, Final Summary Report," TI-033-120-003, April 25, 1974.

4. TRANSWRAP II User's Manual, TI-033-120-002, to be published. 


\section{Purpose}

Analysis of 1-D pressure pulse propagation in fluid-filled pipes.

\section{Status}
A. Development: Developed at W-ARD from the BLOWDOWN-2 code.
B. Availability: Operational at W-ARD on $\mathrm{CDC}-7600$; a description of BLOWDOWN- 2 has been documented (Ref. 1).
C. Utilization: Used by HEDL to perform analysis of primary loop piping response to HCDA pressure pulses in support of the FFTF FSAR.

\section{Problems Solved}

TRAPP is a modified sodium version of the two-phase water code BLOWDOWN- 2 . TRAPP performs an analysis of the transient pressure field in the primary piping loops when HCDA pressure pulses are simultaneously imposed at the inlet and outlet nozzles of the reactor vesse1. Elastic behavior of the pipe walls and the effect on pulse propagation is accounted for. Sodium cavitation is calculated by a two-phase voiding model.

\section{Mode1s}

\section{Geometry}

The pipe system is modeled as a 1-D network of flow channels connected at junctions.

\section{Fluid dynamics}

The 1-D, non-linear, transient partial differential equations for conservation of mass, momentum and energy of a compressible fluid flow and the EOS for the fluid are transformed by the method of characteristics into a set of ordinary differential equations which describe the fluid motion and properties along three characteristic paths: one representing the wave travelling in the positive direction with speed equal to the local speed of sound plus the local flow speed, the second representing a wave travelling in the negative direction with speed equal to the local speed of sound minus the local flow speed and the third representing the path of the fluid particle with local flow speed. The equations of characteristics are solved for a fixed spatial grid and a variable time step determined by the minimum time required for the fastest moving wave to traverse the smallest mesh spacing. The local values of flow rate, pressure, enthalpy, temperature, density, quality and speed of sound are determined for the fixed spatial grid as a function of time, accounting for the effects of compressibility in two-phase flow such as flow choking. The code may be used with either one or two input pulses. 
3. Pipe dilation

The effect of elastic deformation of the pipe wall is taken into account by modifying the local speed of sound.

\section{Limitations}

1. The 1-D nature of the code does not allow for radial fluid motion effects.

2. No pipe wall plastic deformation is considered.

Future Efforts

HEDL will couple TRAPP with TUBE (see TUBE summary) to form SUPWAN for a complete elastic-plastic piping analysis.

\section{Interface/Overlap}

TUBE/ -

\section{References}

1. S. Fabic, "Description of the BLOWDOWN-2 Computer Code," WCAP-7593, Rev. 1, October 1970 . 
TUBE

\section{Purpose}

Analysis of 1-D pressure pulse propagation and attenuation in fluid-filled pipes which are undergoing plastic strain in the pipe wall.

\section{Status}

A. Development: Developed at HEDL. TUBE 30 is latest version.

B. Availability: Operationa1 at HEDL on UNIVAC-1108. No documentation is available.

C. Utilization: Has been used by HEDL to perform analysis of primary loop piping response to HCDA pressure loads in support of the FFTF FSAR.

\section{Problems Solved}

Calculates the transmission of pressure waves through a fluid-filled pipe which is undergoing plastic yielding of the pipe wall due to the fluid pressurization. The attenuation of the pressure pulses due to plastic yielding and the plastic strain in the pipe wall is determined.

Mode1s

1. Geometry

The pipe is modeled as a semi-infinite, horizontal tube, with a usersupplied wall thickness and diameter.

2. Fluid dynamics

Either sodium or water properties can be used for the pipe fluid. The 1-D non-linear conservation equations of mass and momentum for fluidhammer (slightly compressible) flow are solved by the method of characteristics. An arbitrary pressure history serves as a forcing function at the start of the pipe.

3. Pipe dilation

The plastic deformation of the pipe wall is calculated from the fluid pressure and an arbitrary true stress - true strain relationship for the pipe wa11 materia1.

\section{Limitations}

1. Pipe limited to 322 nodes along its length.

2. Heglects radial inertial effects of pipe wall, radial fluid motion, fluid cavitation and gravitational forces. 
3. No consideration of pipe wall elastic response.

Future Efforts

No refinements are planned. Will be coupled with TRAPP (see TRAPP summary) which considers pipe wall elastic response, to form the SUPWAN code for complete elastic-plastic piping analysis.

Interface/Overlap

TRAPP / NATRANSIENT, HAMOC, NAHAMMER

\section{References}

"HCDA Requirement and Loading for FFTF Design Evaluation," HEDL-FS-257 (to be published). 


\section{VENUS}

\section{Purpose}

Neutronic-hydrodynamic analysis of core disassembly resulting from a hypothesized prompt-critical excursion.

\section{Status}

A. Development: Developed and under improvement at ANL/RAS.

B. Availability: VENUS I (Ref. 1) was released in 1971 for use on IBM 360. VENUS II is operational at ANL and has been documented (Ref. 2).

C. Utilization: Has been the primary analytical tool used for disassembly analysis in support of the FFTF FSAR and the CRBR PSAR.

\section{$\underline{\text { Problems Solved }}$}

Computes in 2-D cylindrical, axisymmetric geometry the power, energy release and space-time history of the temperature, pressure, density and material motion of an LMFBR core during an energetic disassembly excursion resulting from a prompt-critical reactivity insertion. Reactivity feedbacks due to Doppler broadening and material motion are explicitly taken into account. A point-wise description of core material contents enables the assignment of the appropriate EOS corresponding to sodium-in and sodium-out conditions. A rigorous treatment is provided for implosion effects at any arbitrary boundary surface, such as a void region surrounded by a non-void region or at an interface of two regions of a zoned core.

A direct data transfer from SAS 3A to VENUS II can be performed.

\section{Models}

The following features are common to both VENUS I and II:

1. Geometry

2-D cylindrical, axisymmetric.

\section{Neutronics}

A one-energy group, space-independent model is used to describe the neutron kinetics. The formulation of Kaganove (Ref. 3), with up to six delayed neutron groups, is used for solution of the point kinetics equations. The time-dependent reactivity is the sum of the input driving reactivity and feedback effects from Doppler broadening and material motion. The reactivity change due to material motion is calculated by first-order perturbation theory, with the materialreactivity-worth distribution assumed independent of time. 
3. Material Motion

The reactor materials are assumed to behave like a homogeneous mixture, with the properties of an isotropic, non-viscous, compressible fluid. The motion of the reactor materials thus satisfies the equations of motion for a compressible, nonviscous fluid. The governing time-space dependent hydrodynamics equations of mass, momentum and energy conservation are formulated in Lagrangian coordinates. Shock discontinuities are eliminated by inclusion of an artificial pseudoviscosity expression as formulated in the numerical shock-smearing technique of von Neumann and Richtmyer. The equations are finite-differenced in an explicit time-difference scheme and solved with an automatic time-step-size selection scheme to provide numerical stability.

4. EOS

VENUS codes are structured such that the user can readily add as input any desired energy or energy-density dependent EOS's for reactor materials if the optional EOS's existing within the code are not suitable for the user requirements. The EOS's available as options within the codes are classified as EOS's for media with heat sources (i.e., fuel regions) and EOS's for media without heat sources (i.e., non-fueled regions, as in the blankets or reflectors):

a. Optional EOS's for media with heat sources

(1) Energy-dependent EOS's for mixed oxide fuel, which give an equilibrium vapor pressure as a function of temperature. These EOS's assume that the fuel density remains constant throughout the excursion.

(2) Energy-density dependent EOS's, which include sodium compressibility.

b. Optional EOS's for media with no heat sources: uses a simplified functional form for pressure-density dependence.

5. Heat Transfer

The basic codes consider heating of reactor materials to be restricted to the fuel (i.e., heat transfer from fuel to other core materials is neglected).

\section{Structural Effects}

For low-energy excursions where the structural strength of core internals (i.e., subassembly hexcans and non-disrupted fuel pin clad) cannot be ignored, two standard options are available to account for the effect of these structures on restraining radial motion of core materials:

a. Suppression of any pressures below a threshold value, which will prevent any unrealistic material motion due to low pressures. 
b. Radial motion of each Lagrangian mesh position is restrained until the pressure gradient across the position exceeds a threshold value, which is an estimate of the yield strength of the structure being simulated. Once the threshold is exceeded, the mesh position is free to move for the remainder of the calculation.

VENUS II has the following optional model capabilities:

1. Heat Transfer

An FCI model is available which includes heat transfer from fuel to sodium. An expression for heat transfer to sodium includes quasi-static and transient contributions. The parameters affecting the speed of the FCI are the fuel fragmentation and heat transfer delay time and the average fuel particle radius. The inclusion of the FCI model modifies the basic VENUS II as follows:

a. The vapor pressure of the sodium is added to the fuel vapor pressure.

b. Thermal expansion of sodium is calculated.

c. Cooling of the fuel caused by energy transfer to sodium (fuel chilling) is accounted for, which can decrease the fuel vapor pressure and Doppler feedback.

d. The temperature dependence of the sodium compressibility is more accurately accounted for, with the actual sodium temperatures used instead of the estimated average values.

2. Fission Gas Pressure

A simple fission gas model can account for the effect of fission gas pressure on the disassembly. The fission gas pressure in each Lagrangian mesh cell is calculated by treating the accumulated xenon and krypton as an ideal gas. A delay time accounts for the lag in fission-gas bubble formation.

3. Axial Expulsion of Sodium

A simple 1-D model calculates the axial expulsion of sodium following an FCI in intact coolant channels.

4. Treatment of Small Initial Void Spaces

A model introduces small amounts of initial void space in an attempt to simulate various physical situations, such as sodium voiding or fuel porosity.

\section{Limitations}

1. Material Motions

There are several 1 imitations associated with the hydrodynamics modeling for material motion. Reactor materials are assumed to behave like 
isotropic, homogeneous, non-viscous, compressible hydrodynamic fluids. This is a reasonable description of solid materials subjected to high pressure (kilobars) compression, but is not valid as the solid material recovers from the compressive loading or is under tension. Thus, the hydrodynamics model may be appropriate for every energetic excursion (i.e., a large reactivity insertion at prompt critical) but is not accurate for mild excursions where much of the core structure may still be intact and pressures are sufficiently low such that consideration of the mechanical resistance of these structures is important. Also, the Lagrangian formulation of the hydrodynamics has the inherent numerical limitation allowing only small material displacements. Thus, VENUS is applicable primarily to very energetic disassembly accidents where the neutronics burst ends before large material displacements have occurred.

2. Neutronics and Reactivity Feedbacks

VENUS uses point-kinetics neutronics (i.e., constant spatial power distribution), first-order perturbation theory for reactivity effects due to material motion, and a constant reactivity-worth distribution which distorts with the Lagrangian grid. These simplifying assumptions for the neutronics and reactivity feedbacks are valid for small material displacements. Reactor material distortion is usually sufficiently small at the termination of the neutronics burst so as not to violate the assumptions. Attempts to follow excursions much beyond termination of the burst will violate the validity of the assumptions.

\section{Structural Effects}

VENUS does not treat mechanistically the interaction of fluids with deformable structures. The restraint of the core structures (i.e., subassembly ducts and fuel pin clad) becomes important for low energy excursions where the structures absorb an appreciable portion of the available excursion energy.

\section{Future Efforts}

1. Improve the mixed-oxide EOS and add EOS's for advanced fuels.

2. VENUS III will be based on an Eulerian formulation.

3. Incorporation of space-time neutron kinetics formulations.

\section{Interface/Overlap}

SAS/PAD

\section{$\underline{\text { References }}$}

1. W. T. Sha and T. H. Hughes, VENUS: A Two-Dimensional Coupled NeutronicsHydrodynamics Computer Program for Fast-Reactor Power Excursions, ANL-7701, October 1970 .

2. J. F. Jackson and R. B. Nicholson, VENUS II: An LMFBR Disassembly Program, ANL-7951, September 1972. 
3. J. J. Kaganove, Numerical Solution of the One-Group, Space-Independent Reactor Kinetics Equations for Neutron Density Given the Excess Reactivity, ANL-6132, February 1960. 